\title{
REACTOR PHYSICS RESULTS FROM THE ATR POWER DEMONSTRATION PROGRAM
}

\author{
J. L. Durney \\ J. B. Willis \\ J. C. Tappendorf \\ C. H. Hogg
}

\section{Aerojet nuclear Company \\ NATIONAL REACTOR TESTING STATION Idaho Falls, Idaho -83401}

\section{MASTER}

DISTRIBUTION OF THIS DOCUMENT IS UNLIMITED

DATE PUBLISHED - OCTOBER 1972

PREPARED FOR THE

\section{U. S. ATOMIC ENERGY COMMISSION}




\section{DISCLAIMER}

This report was prepared as an account of work sponsored by an agency of the United States Government. Neither the United States Government nor any agency Thereof, nor any of their employees, makes any warranty, express or implied, or assumes any legal liability or responsibility for the accuracy, completeness, or usefulness of any information, apparatus, product, or process disclosed, or represents that its use would not infringe privately owned rights. Reference herein to any specific commercial product, process, or service by trade name, trademark, manufacturer, or otherwise does not necessarily constitute or imply its endorsement, recommendation, or favoring by the United States Government or any agency thereof. The views and opinions of authors expressed herein do not necessarily state or reflect those of the United States Government or any agency thereof. 


\section{DISCLAIMER}

Portions of this document may be illegible in electronic image products. Images are produced from the best available original document. 
Printed in the United States of America Available from

National Technical Information Service

U. S. Department of Commerce

5285 Porl Royal Road

Springfield, Virginia 22151

Price: Printed Copy

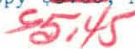

This report was prepared as an account of work sponsored by the United States Government. Ne ither the United States nor the United States Atomic Energy Commission, nor any of their employees, nor any of their contractors, subcontractors, or their employees, makes any warranty, express or implied, or assumes any legal liability or responsibility for the accuracy, completeness or usefulness of any information, apparatus, product or process disclosed, or represents that its use would not infringe privately owned rights. 
ANCR-1080

Reactor Technology

TID-4500

This report was prepared as an account of work sponsored by the United States Government. Neither the United States nor the United States Atomic Energy Commission, nor any of their employees, nor any of Commission, nor any of their employees, nor any of their contractors, subcontractors, or their employees, makes any warranty, express or implied, or assumes any legal liability or responsibility for the accuracy, completeness or usefulness of any information, apparatus, product or process disclosed, or represents that its use would not infringe privately owned rights.

\title{
REACTOR PHYSICS RESULTS FROM THE ATR POWER DEMONSTRATION PROGRAM
}

BY

\author{
J. L. Durney \\ J. B. Willis* \\ J. C. Tappendorf \\ C. H. Hogg
}

\section{AEROJET NUCLEAR COMPANY}

Date Published - October 1972

* Westinghouse Electric Corporation

P. O. Box 355,

Pittsburg, Pennsylvania

PREPARED FOR THE U. S. ATOMIC ENERGY COMMISSION

IDAHO OPERATIONS OFFICE

UNDER CONTRACT NO. AT(10-1)-1375 


\section{ACKNOWLEDGMENTS}

Successful completion of the measurements and analysis reported here resulted from the efforts of many people. In particular, J. W. Henscheid was instrumental in the program planning and execution. Acknowledgment and thanks are extended also to the following individuals: E. E. Burdick, R. L. Copyak, N. C. Kaufman, F. R. Phelps, and members of the ATRC staff. 


\begin{abstract}
The ATR successfully operated at design power (250 MW) for $8750 \mathrm{MWd}$ in a balanced power division and for $6658 \mathrm{MWd}$ in an unbalanced power division. The integrated powers obtained were well in excess of the design criteria of $4250 \mathrm{MWd}$ : Analysis of excess reactivity data during the power demonstrations indicates the maximum core lifetime obtainable is approximately $10,000 \mathrm{MWd}$.

During the approach to full-power operation, stability with respect to xenon oscillation was demonstrated. Reactor noise data were also obtained during the approach to power to establish reference data and to detect any anomalous power- dependent behavior.

The power coefficient was measured at the beginning and end of core life in an unbalanced power division. The value obtained was $-0.15 \notin$ per megawatt increase in reactor power and was independent of the operating time.

Neutron flux data were obtained in the flux traps and capsule experiment positions at the beginning and end of core life for comparison with calculations to be completed later.
\end{abstract}




\section{CONTENTS}

ACKNOWLEDGMENTS .................... . . . . . .

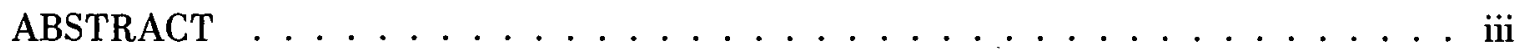

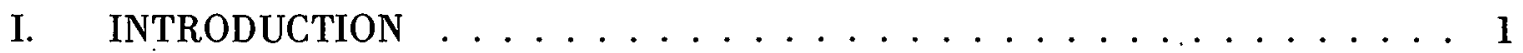

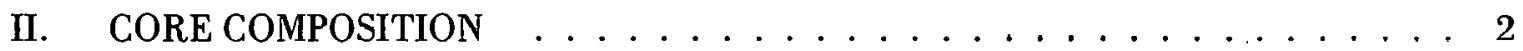

III. XENON AXIAL STABILITY MEASUREMENT $\ldots \ldots \ldots$

IV. REACTOR TRANSFER FUNCTLON MEASUREMENTS . . . . . . . . . . . 13

V. R.EACTOR NOISE MEASUREMENTS ................... 16

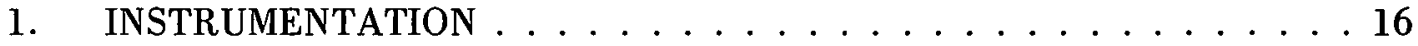

2. MEASUREMENTS AND PROCEDURE . . . . . . . . . . . 20

3. RESULTS AND COMMENTS . . . . . . . . . . . . . 22

4. ANALYSIS OF RESULTS . . . . . . . . . . . . . . 28

VI. EXCESS REACTIVITY DURING CORE LIFE . . . . . . . . . . . . . . 32

1. CORE 2 AND CORE 3 EXCESS REACTIVITY . . . . . . . . . . . 32

2. FUEL ELEMENT REACTIVITY COMPARISONS

AT THE END OF CORE $3 \ldots \ldots$. . . . . . . . . . . . . . . . . .

VII. POWER COEFFICIENT MEASUREMENTS $\ldots \ldots \ldots$

VIII. NEUTRON FLUX DISTRIBUTIONS . . . . . . . . . . . . . . . . 39

1. BEGINNING AND END-OF-LIFE NEUTRON

FLUX DISTRIBUTIONS . . . . . . . . . . . . . . . . 39

2. NEUTRON FLUENCE MEASUREMENTS ... . . . . . . . . . . . . 49

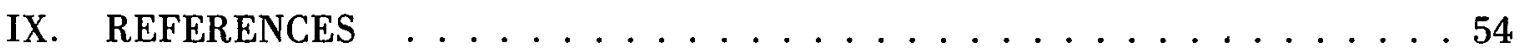

APPENDIX - THERMAL AND FAST NEUTRON FLUX

DENSITY MEASUREMENT . . . . . . . . . . . . . 55

\section{FIGURES}

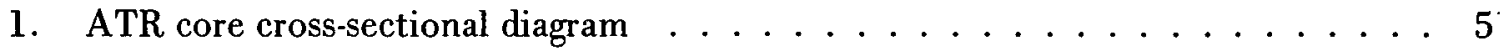

2. ATR core diagram showing fuel element serial numbers for Core 2 loading . . . . . . . . . . . . . 6

3. ATR core diagram showing fuel element serial numbers for Core 3 loading $\ldots \ldots \ldots \ldots$

4. Distribution of the neutron flux above and below core midplane at the beginning of the xenon axial stability test 
5. Distribution of the neutron flux above and

below core midplane 24 minutes after the beginning

of the control rod exchange during the xenon axial

stability test

6. Distribution of the neutron flux above

and below core midplane two hours and 24 minutes after

the beginning of the control rod exchange during the

xenon axial stability test ..................... 10

7. Distribution of the neutron flux above

and below core midplane approximately 28.5 hours

after the beginning of the control rod exchange

during the xenon axial stability test $\ldots \ldots \ldots \ldots$

8. Time-dependent amplitude for the first harmonic

in the sine series used to describe the axial neutron

flux distribution during the axial xenon stability test $\ldots \ldots \ldots$. . . . . . 11

9. Magnitude of the ATR core-reactivity

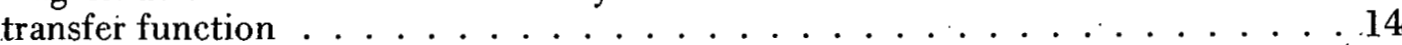

10. Phase angle of the ATR core-reactivity

transfer function . . . . . . . . . . . . . . . . . . 14

11. ATR auto-correlated power-spectral density

obtained at $27 \mathrm{MW}$ with a $3 \mathrm{He}$ chamber. The reactor

power level was controlled automatically

12. ATR auto-correlated power-spectral density

obtained at $27 \mathrm{MW}$ with a breeder fission chamber.

The reactor power level was controllcd automatically $\ldots \ldots \ldots \ldots$

13. ATR auto-correlated power-spectral density

obtained at $40 \mathrm{MW}$ with a $3 \mathrm{He}$ chamber. The reactor

power level was controlled manually . . . . . . . . . . . . . . 21

14. ATR auto-correlated power-spectral density obtained at $40 \mathrm{MW}$ with a breeder fission chamber. The reactor power

level was controlled manually . . . . . . . . . . . . . . . 22

15. ATR auto-correlated power-spectral density (corrected

for recording gain) obtained at $2.5 \mathrm{MW}$ with a

breeder fission chamber . . . . . . . . . . . . . . 23

16. ATR auto-correlated power-spectral density (corrected

for recording gain) obtained at $50 \mathrm{MW}$ with a breeder

fission chambe

17. ATR auto-correlated power-spectral density (corrected for recording gain) obtained at $80 \mathrm{MW}$ with a breeder fission chamber 
18. ATR auto-correlated power-spectral density (corrected

for recording gain) obtained at $125 \mathrm{MW}$ with a breeder fission

chamber

19. ATR auto-correlated power-spectral density obtained at $2.5 \mathrm{MW}$ with a fission chamber . . . . . . . . . . . . . 25

20. ATR auto-correlated power-spectral density obtained at $50 \mathrm{MW}$ with a fission chamber

21. ATR auto-correlated power-spectral density obtained at $80 \mathrm{MW}$ with a fission chamber $\ldots \ldots \ldots . \ldots . \ldots 26$

22. ATR auto-correlated power-spectral density obtained at $125 \mathrm{MW}$ with a fission chamber . . . . . . . . . . . . . 26

23. ATR auto-correlated power-spectral density obtained at $150 \mathrm{MW}$ with a fission chamber . . . . . . . . . . . . . 27

24. ATR auto-correlated power-spectral density obtained at $188 \mathrm{MW}$ with a fission chamber . . . . . . . . . . . . 27

25. ATR auto-correlated power-spectral density obtained at $250 \mathrm{MW}$ with a fission chamber . . . . . . . . . . . . . . 28

26. Flow dependence of the ATR cross-correlated power-spectral density obtained at $500 \mathrm{~W}$ with a ${ }^{3} \mathrm{He}$ chamber . . . . . . . . . . . 29

27. ATRC cross-correlated power-spectral density obtained using an ion chamber in a dry tube outside of core at a power of about $650 \mathrm{~W} \ldots \ldots . \ldots . \ldots 30$

28. Excess reactivity in Core 2 as a function of power-time $\ldots \ldots$. . . . . . . 32

29. Excess reactivity in Core 3 as a function of power-time $\ldots \ldots \ldots 33$

30. Power and regulating rod position as a function of time for the power coefficient measurement $\ldots \ldots \ldots$

31. ATR core diagram showing azimuthal location of monitors in the flux trap annuli $\ldots \ldots \ldots \ldots . \ldots \ldots$

\section{TABLES}

I Experiment Loading For Part II C . . . . . . . . . . . . . 3

II Types Of Detectors, Instrumentation, And Detector Positions Used In Reactor Noise Measurements . . . . . . . . . . . . . . 17

III Summary Of Data For Fuel Element Exchange In Core $3 \ldots 35$

IV Core Midplane Neutron Flux Data Obtained At The Beginning

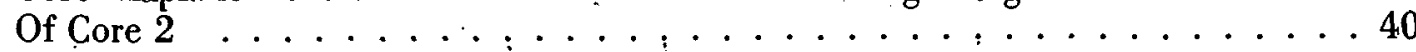


V Core Midplane Neutron Flux Data Obtained At The End Of

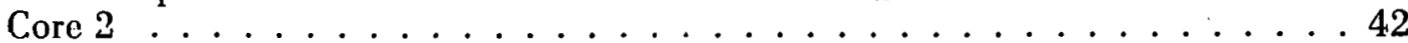

VI Core Midplane Neutron Flux Data Obtained At The Beginning

Of Core $3 \ldots \ldots \ldots \ldots . \ldots \ldots 4 . \ldots \ldots$

VII Core Midplane Neutron Flux Data Obtained At The

End Of Core $3 \ldots \ldots \ldots$. . . . . . . . . . . . . . . . . . . . .

VIII Summary Of Conditions During Irradiations $\ldots \ldots \ldots$

IX Core Midplane Neutron Flux Data At 250 MW Obtained From

Core 2 Fluence Measurements . . . . . . . . . . . . . . . 50

X Core Midplane Neutron Flux Data At 250 MW Obtained

From Core 3 Fluence Measurements . . . . . . . . . . . . . . . 52 


\section{INTRODUCTION}

The startup program for the Advanced Test Reactor (ATR) is an organized series of experiments which, in conjunction with the experiment program in the ATR Critical Facility (ATRC), demonstrated that the reactor is completely capable of operating according to the design specifications set forth in the safety analysis report[1]. The post-neutron testing program is divided into three parts: Part II A, Initial Fuel Loading and Zero-Power Experiments; Part II B, Approach-to-Power Program; and Part II C, High Power Demonstration. Part II A of the startup program was completed in July 1967 and indicated good agreement between ATR and its nuclear duplicate, the ATRC[2]. The low-power reactor physics measurements of Part II B[3] were completed in February 1968 and substantiated and extended the results of Part II A[4]. This report describes the noise measurements of Part $\Pi \mathrm{B}$ and the reactor physics results of Part $\Pi \mathrm{C}$. The lobe power monitoring system calibration and thermal hydraulic tests conducted in Part II B will be reported in other documents.

The general objectives of the reactor physics tests in Part II C were:

(1) To operate the reactor at $250 \mathrm{MW}$ for at least 17 days in a nominally 50-50-50 power division [a] (Core 2), and then after refueling, to operate at $250 \mathrm{MW}$ for at least 17 days in a nominally 40-50-60 power division $[\mathrm{b}]$ (Core 3 )

(2) To observe reactivity changes during operation in order to obtain data for core life calculations

(3) To obtain neutron flux data during core life in a number of in-core positions for comparison with calculations

(4) To obtain experimental verification of axial xenon stability.

[a] Each of the five lobes is generating $50 \mathrm{MW}$ in this power division. A lobe is defined as the eight fuel elements surrounding an inner flux trap.

[b] Two corner lobes are generating $40 \mathrm{MW}$ each, two corner lobes are generating $60 \mathrm{MW}$ each, and the center lobe is generating $50 \mathrm{MW}$ in this power division. 


\section{CORE COMPOSITION}

The core composition for Part II C of the ATR startup program is listed in Table I, and a core diagram showing the location of each position is shown in Figure l. The primary changes from the experiment loading in Part $\mathrm{Il} \mathbf{B}$ are:

(1) Flux trap fillers were added in the NW and SE flux traps

(2) Experiment trains were added in the NW, N, SW, S, and SE flux traps. (Experiment trains were added to the SW, S, and SE flux traps near the end of Part II B.)

The flux trap fillers were added to reduce the amount of fission-rate peaking in the adjacent fuel elements. Additionally, special zone-loaded fuel elements[5] (7F) were used in high power positions to reduce the fission-rate peaking and hence the heat generation at the core hot spot. The fuel element loadings for Cores 2 and 3 are shown in Figures 2 and 3 (7F elements have the prefix XA). Note that fuel element XAl0G in position 33 of Core 2 was damaged during startup measurements and was replaced with XA23G prior to reaching 250 MW core power. 


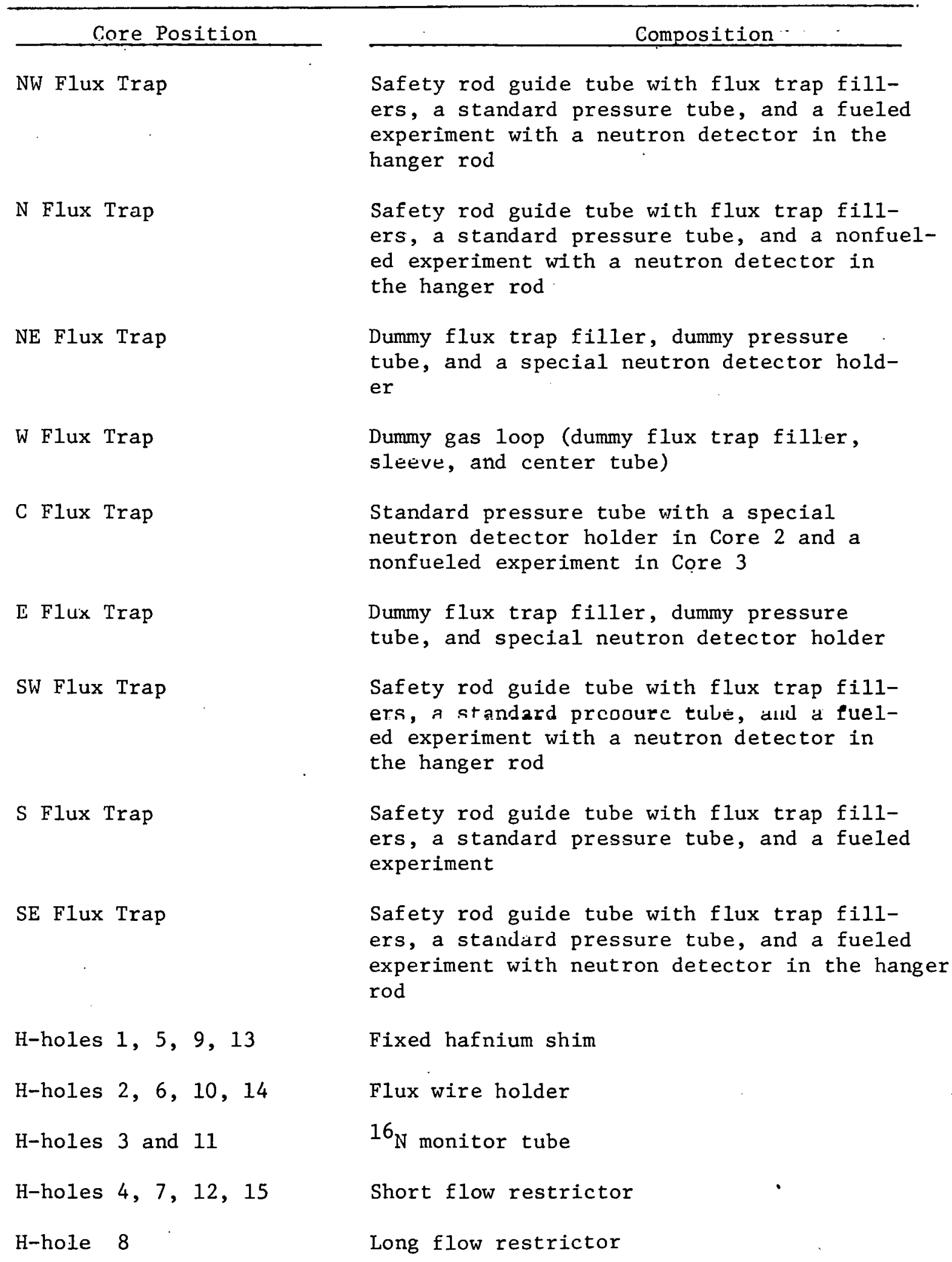


TABLE I (Contd.)

\begin{tabular}{|c|c|}
\hline Core Position & Composition \\
\hline H-hole 16 & Special neutron detector assembly \\
\hline A-holes 1 through 8 & Standard flow restrictor \\
\hline A-holes 9 through 12 & Flux wire holder \\
\hline B-holes $1,3,4,5,6,7$, & $\begin{array}{l}\text { Standard aluminum filler with flux wire } \\
\text { holder }\end{array}$ \\
\hline B-holes 2 and 8 & Special neutron detector \\
\hline I-holes 1, 11, 13 & Beryllium filler with flux wire holder \\
\hline I-holes 14 and 16 & Special neutron detector assembly \\
\hline $\begin{array}{l}\text { I-holes } 2 \text { through } 10 \text {, } \\
\quad 12,15 \text { and } 17 \text { through } 20\end{array}$ & Beryllium filler \\
\hline
\end{tabular}




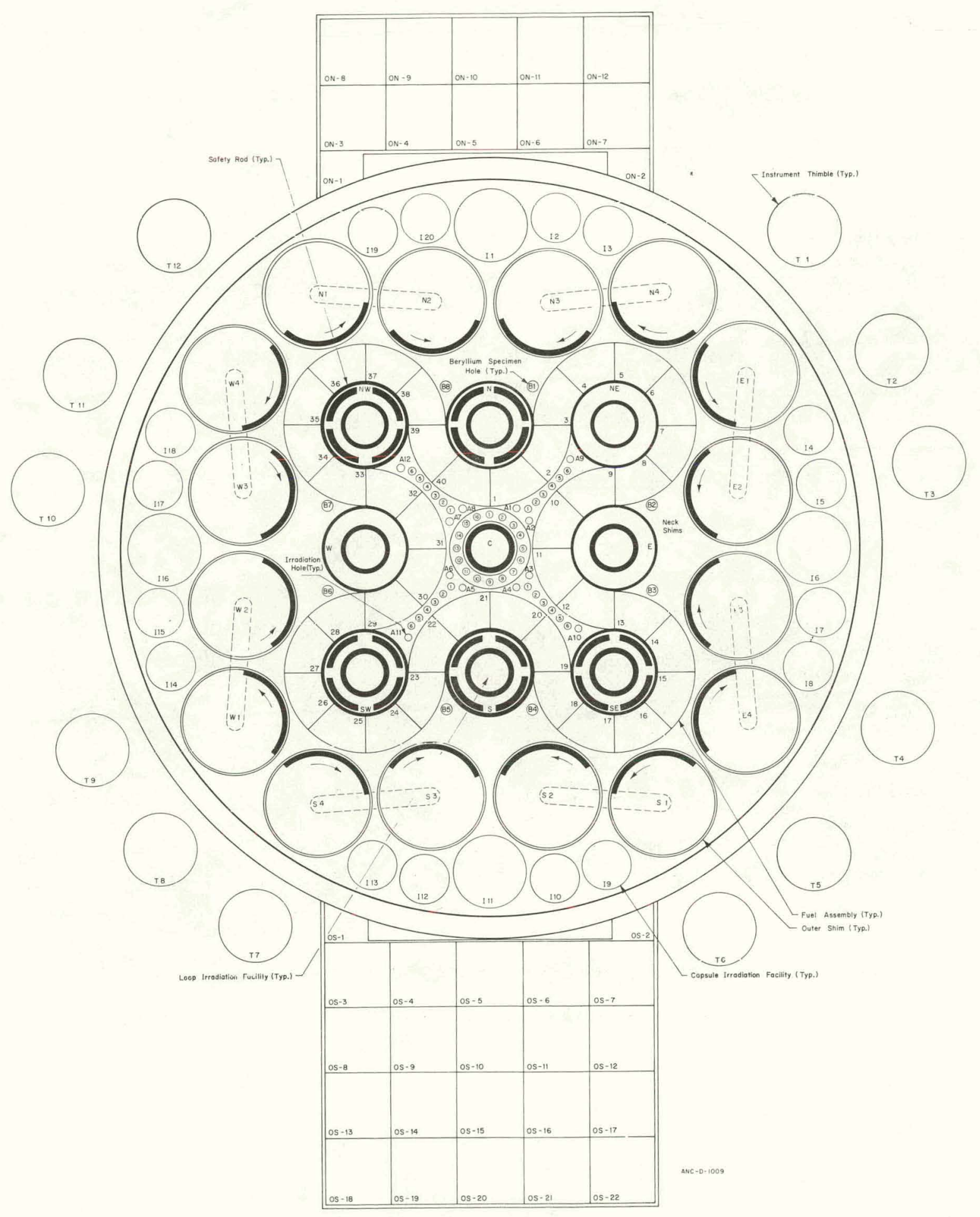

Fig. 1 ATR core cross-sectional diagram. 


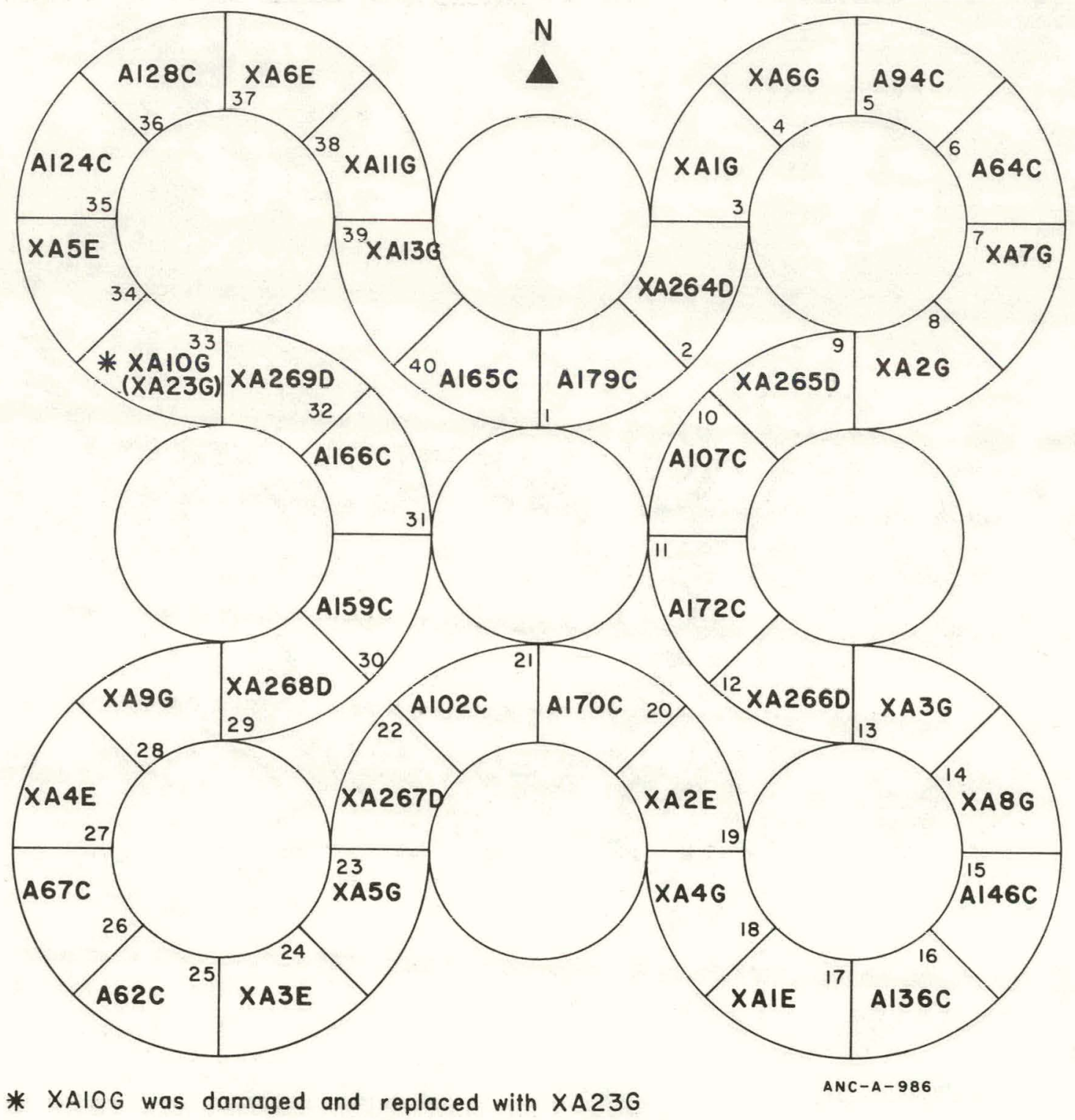

Fig. 2 ATR core diagram showing fuel element serial numbers for Core 2 loading. 


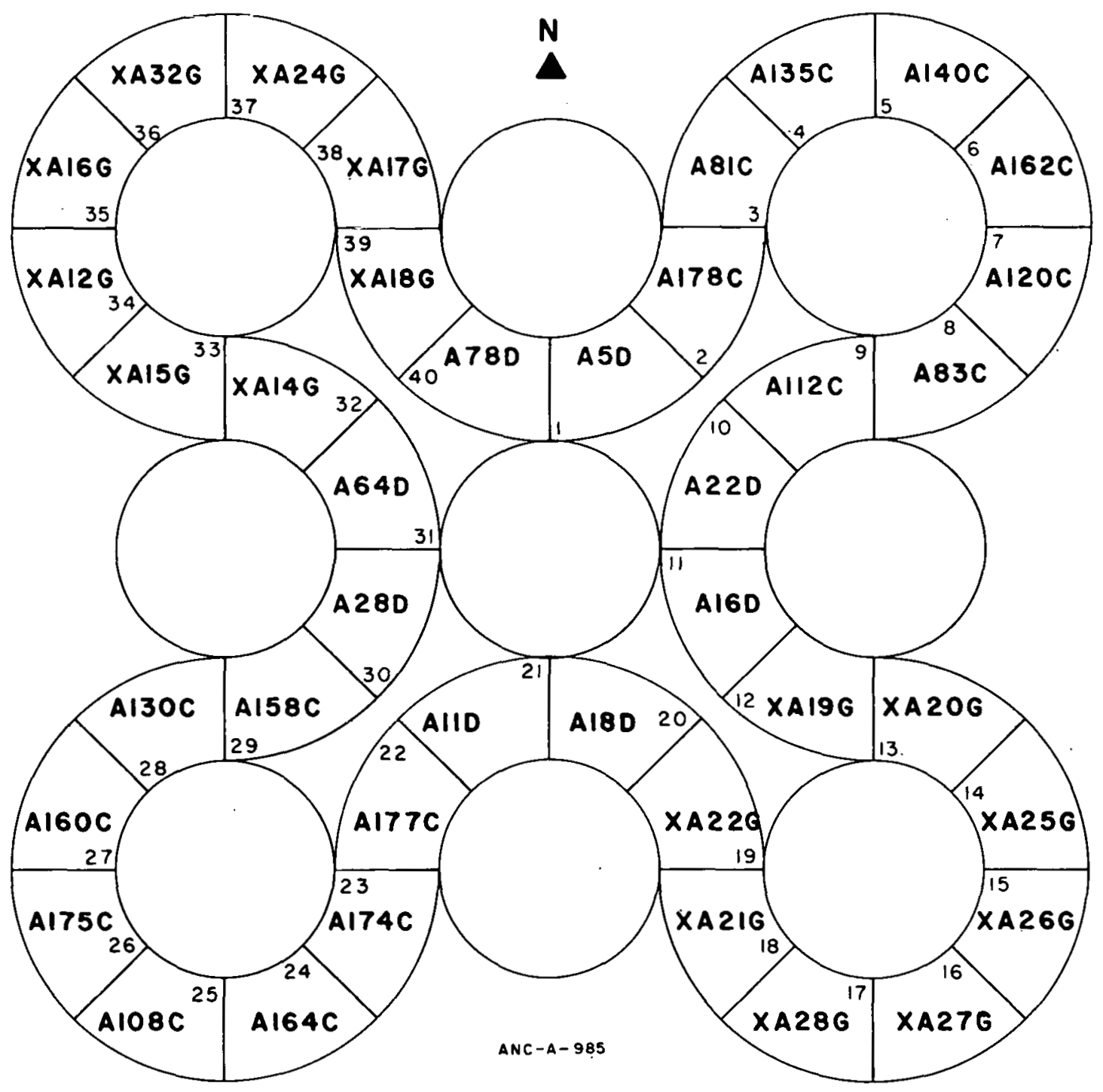

Fig. 3 ATR core diagram showing fuel element serial numbers for Core 3 loading. 


\section{XENON AXIAL STABILITY MEASUREMENT}

The ATR xenon axial stability test was designed to show that the ATR is stable to power oscillations in the axial direction caused by xenon oscillations in the same direction when a constant total reactor power is maintained. Xenon oscillations are likely to occur along the axis of the largest dimension of high-power-density reactors. The ATR is a high-power-density, reactor and was designed with no intention of power density control in the axial direction (the largest dimension of the ATR core). Hence, it was particularly important to show that the reactor is stable to xenon oscillations in order to prevent exceeding local heat transfer limitations.

The test consisted of (a) establishing xenon equilibrium at $125 \mathrm{MW}$ with all neck shims withdrawn about halfway, (b) inserting all neck shims to their lower limits while withdrawing the outer shims to maintain a constant reactor power, and (c) monitoring the neutron flux in the axial direction before and after the exchange of neck and outer shims until the axial neutron flux distribution reached an equilibrium state indicating stability. The shim exchange was accomplished in approximately thirteen minutes which was considered instantaneous relative to periods of xenon oscillation (10 to 20 hours) observed in other reactors. The neutron flux in the axial direction was monitored with a train of self-powered neutron detectors (SPND's) located in core position H-16.

Neutron flux distributions obtained in the axial direction near the beginning of the test are shown in Figures 4 and 5. The peak of the distribution, as cxpected, is initially located below the core midplane (see Figure 4) because the neck shims are withdrawn 24.5 inches. Shortly after the neck shims were inserted, the neutron flux distribution reached the maximum skew toward the top of the core as shown in Figure 6. The distribution then gradually approached the expected sine distribution shown in Figure 7. This normal distribution was reached about 28.5 hours after the shim exchange.

A sine series,

Neutron Flux $\left(\mathrm{z}, \mathrm{t}_{\mathrm{i}}\right)=\mathrm{B}_{1}\left(\mathrm{t}_{\mathrm{i}}\right) \sin \omega \mathrm{z}+\mathrm{B}_{2}\left(\mathrm{t}_{\mathrm{i}}\right) \sin 2 \omega \mathrm{z}+\mathrm{B}_{3}\left(\mathrm{t}_{\mathrm{i}}\right) \sin 3 \omega \mathrm{z}+\ldots$

was fit in the least-squares sense to the neutron flux distribution in the axial direction at each time point. A value of 0.059 radians per inch was chosen as the series frequency, $\omega$, based on previous measurements in ATRC, which also have shown that the flux distribution in the axial direction is described by a sine function over approximately $90 \%$ of the interval. Further, a sine series was used to represent the flux distribution in the test because a series representation converges with the least number of terms to a given distribution when the terms are natural eigenfunctions of the problem.

Generally, if the first harmonic of a power distribution is shown to be stable to xenon oscillations, all harmonics are assumed to be stable[6].Consequently, only the coefficient $\mathrm{B}_{2}(\mathrm{t})$ is shown in Figure 8 as determined by a least-squares fit of the sine series to the data. 


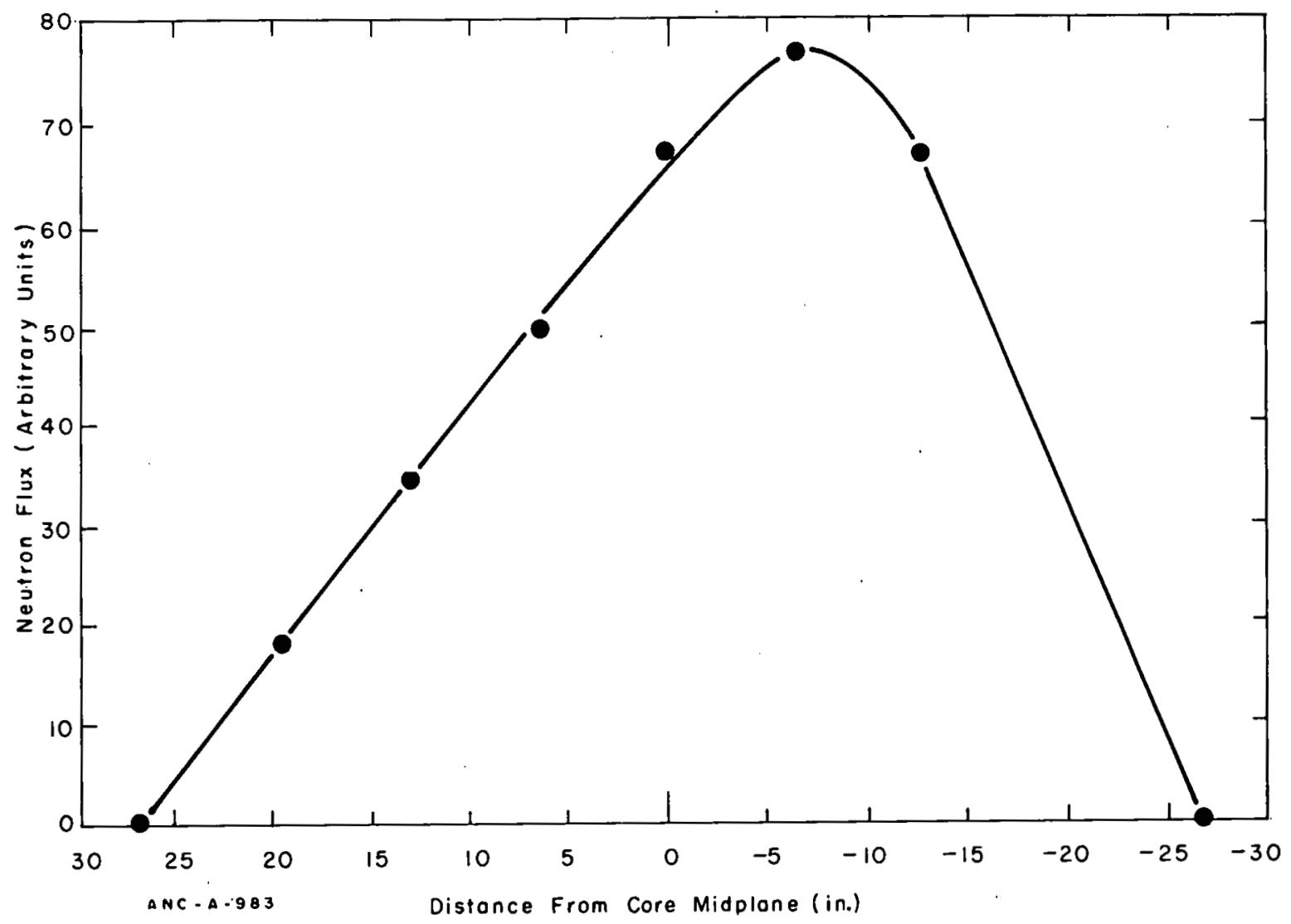

Fig. 4 Distribution of the neutron flux above and below core midplane at the beginning of the xenon axial stability test.

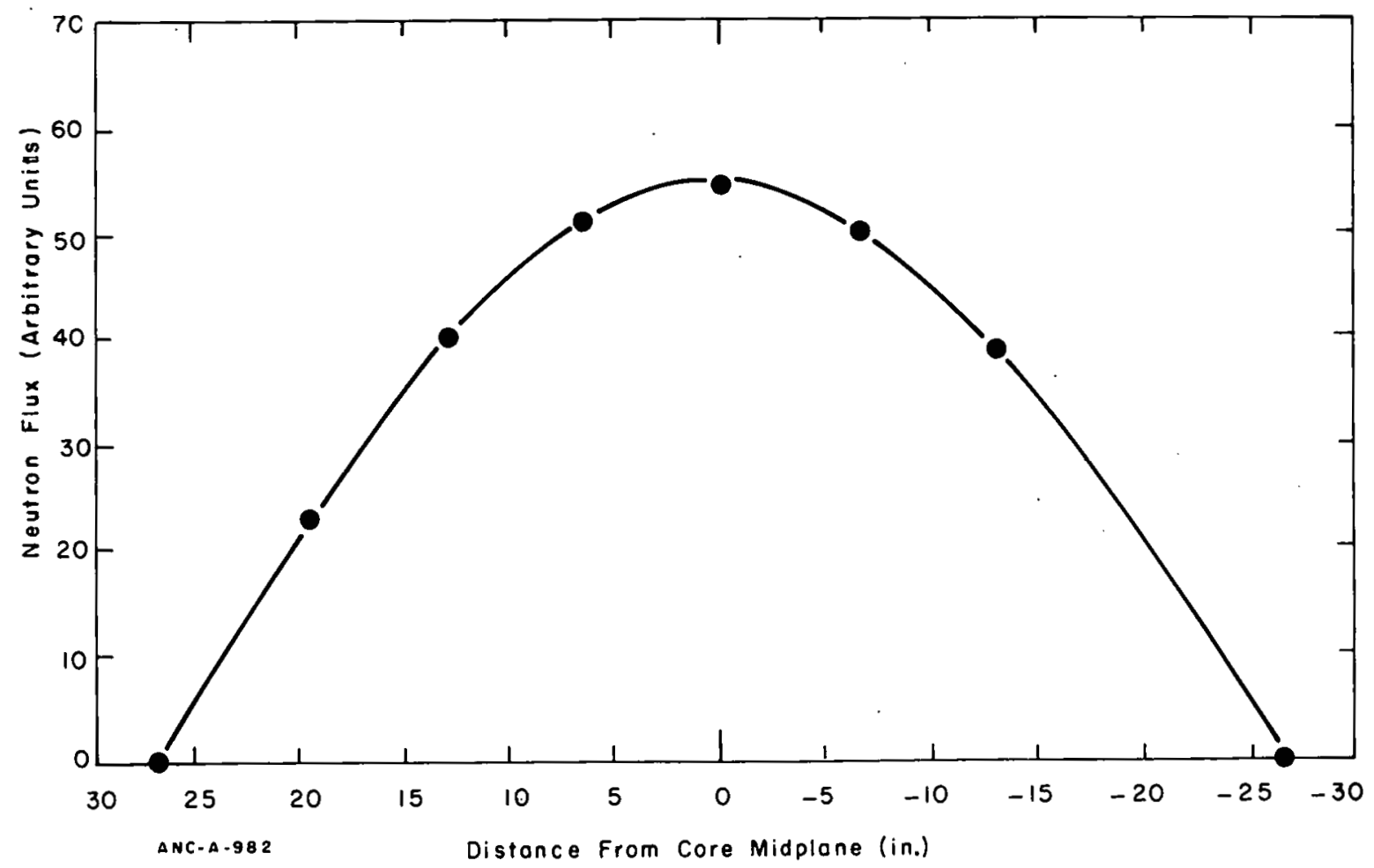

Fig. 5 Distribution of the neutron flux above and below core midplane 24 minutes after the beginning of the control rod exchange during the xenon axial stability test. 


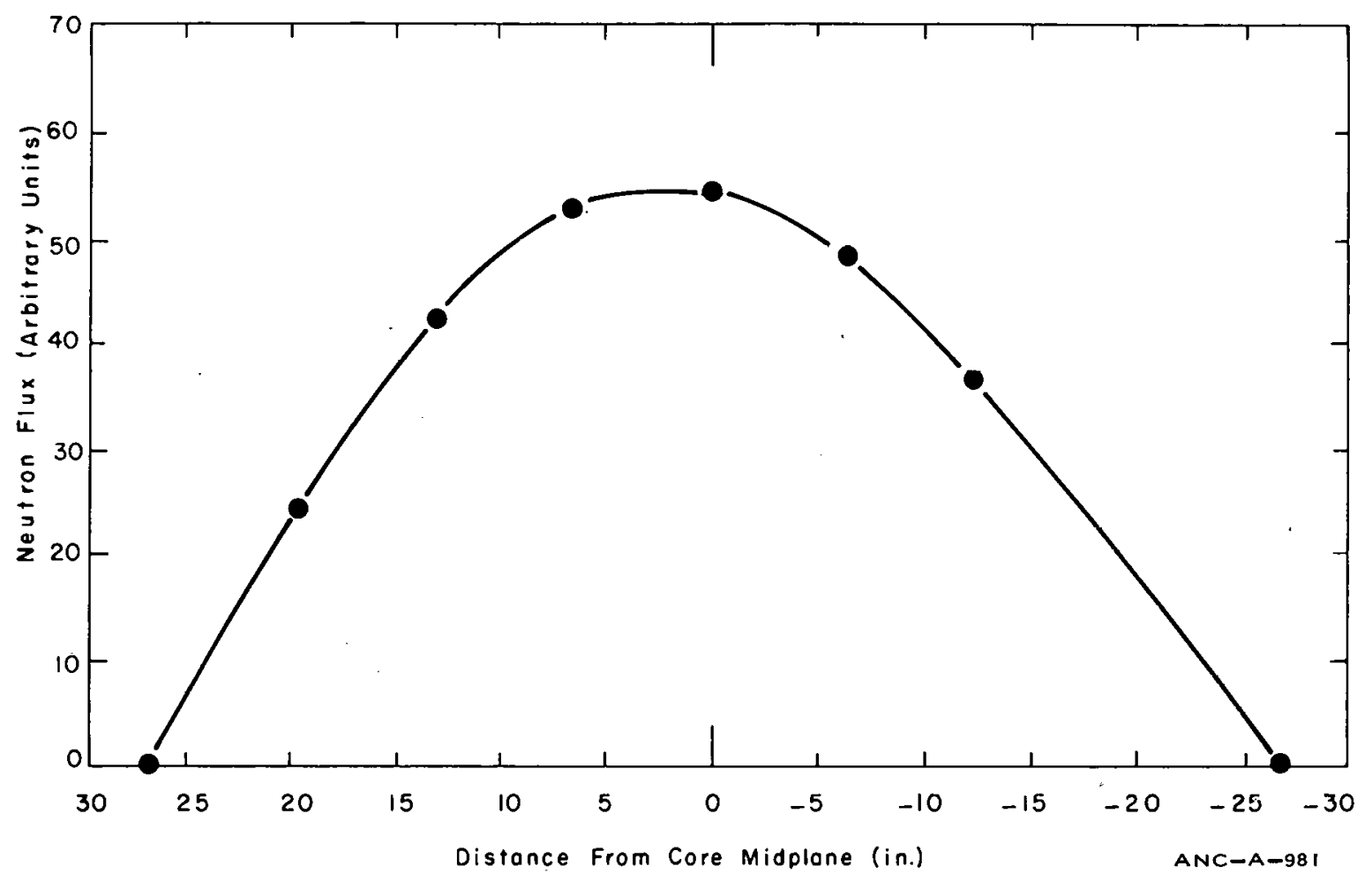

Fig. 6 Distribution of the neutron flux above and below core midplane two hours and 24 minutes after the beginning of the control rod exchange during the xenon axial stability test.

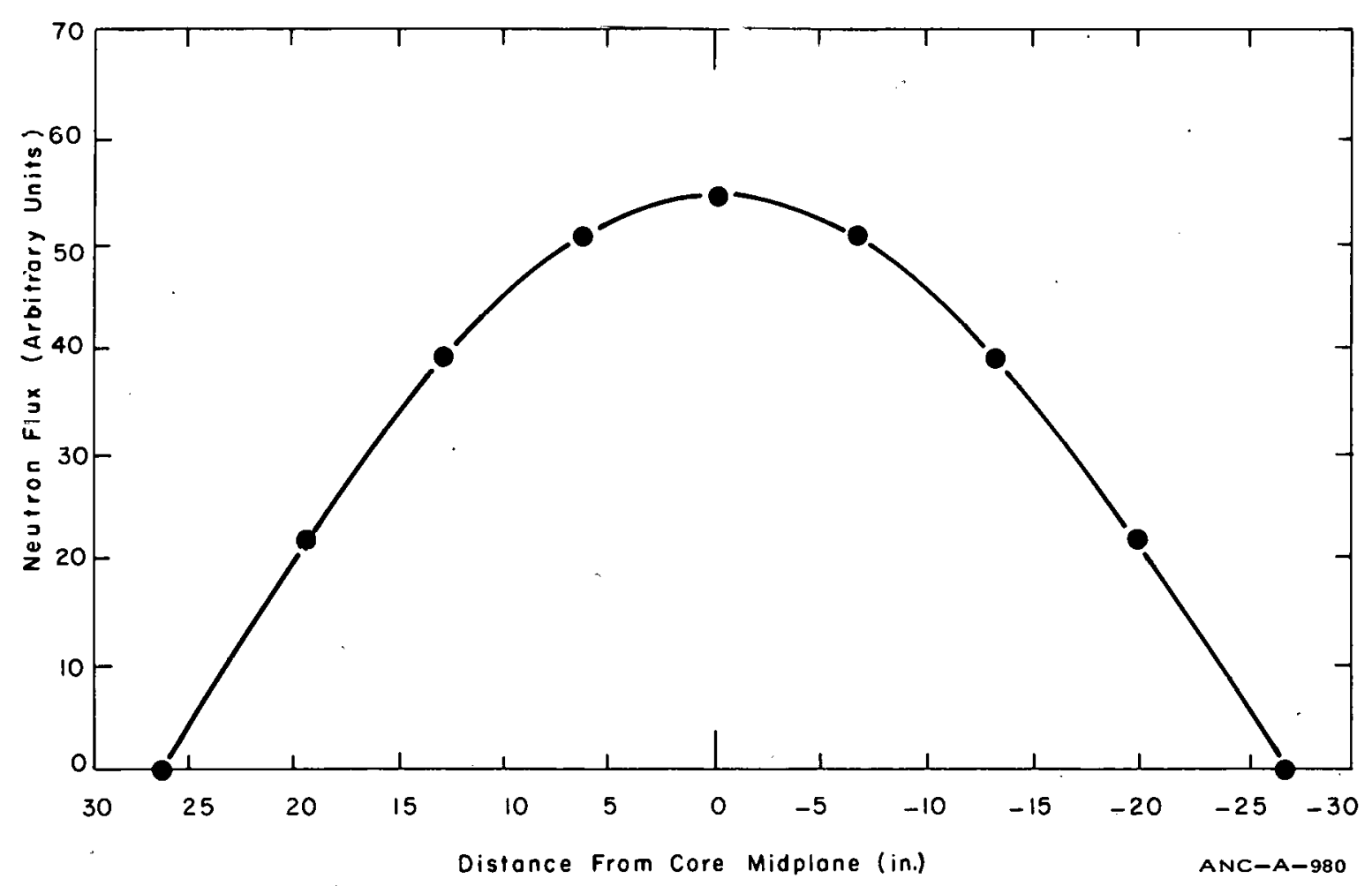

Fig. 7 Distribution of the neutron flux above and below core midplane approximately 28.5 hours after the beginning of the control rod exchange during the xenon axial stability test. 


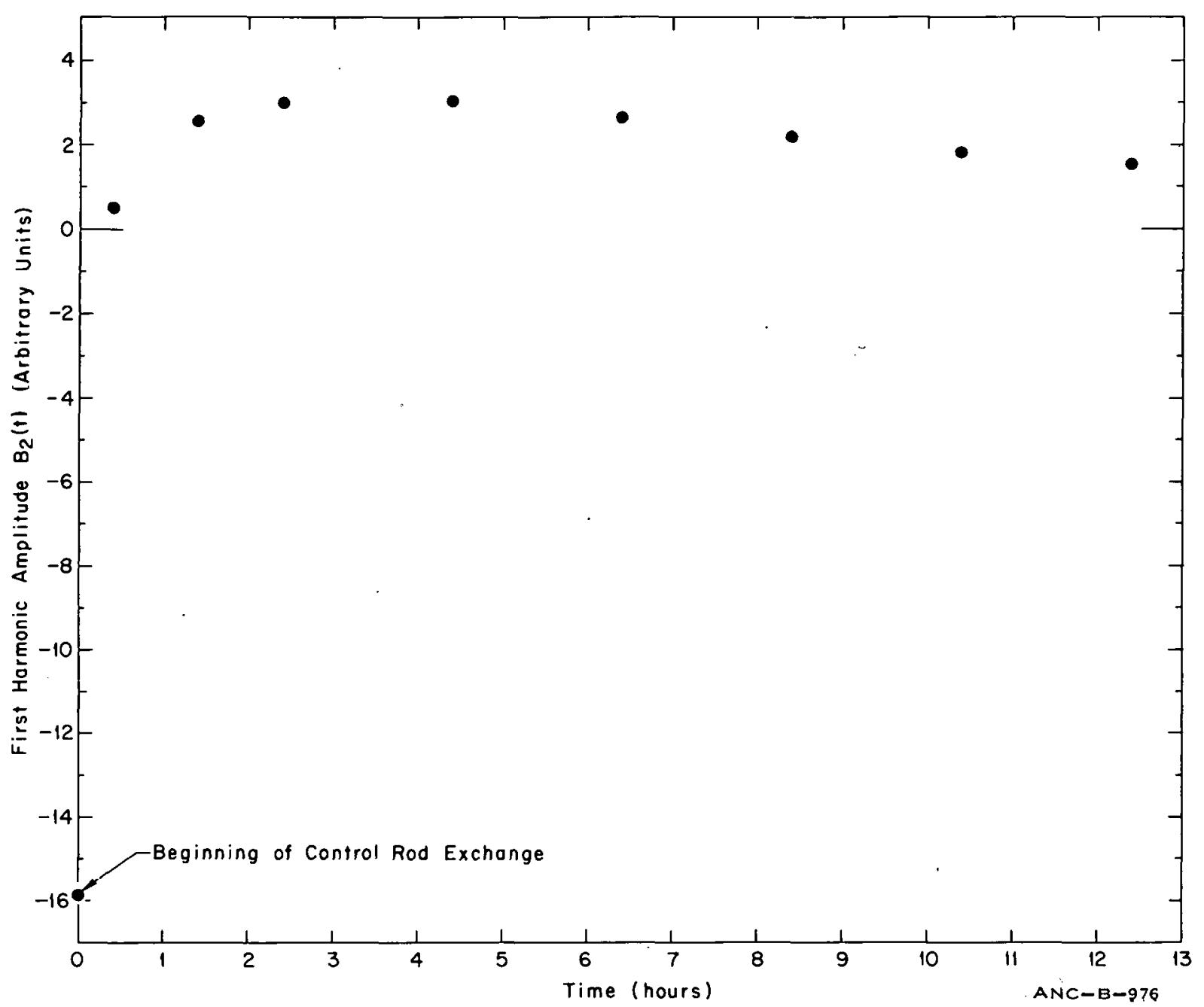

Fig. 8 Time-dependent amplitude for the first harmonic in the sine series used to describe the axial neutron flux distribution during the axial xenon stability test.

Examination of the time dependence of $\mathrm{B}_{2}$ shows the following:

(1) $\mathrm{B}_{2}$ was negative and large at the beginning of the test indicating that the neutron-flux peak was below core midplane.

(2) After the shim exchange, the neutron-flux peak rapidly shifted above core midplane because of the large xenon density in the lower half of the core.

(3) The neutron flux continued to increase in the top half of the core for approximately 3.5 hours after the shim exchange because of the increased net rate of formation of xenon in the lower half of the core caused by iodine decay and a decrease in the rate of xenon burnup. 
(4) Approximately 3.5 hours after the shim exchange, the net rate of formation of xenon in the top half of the core begins to increase relative to the net rate of formation of xenon in the lower half of the core. As a consequence, the neutron flux distribution began to return to a sine distribution.

(5) The net rate of formation of xenon in the top half of the core did not exceed the equilibrium value for $125 \mathrm{MW}$ after the net rate began to increase, and the neutron flux distribution returned asymptotically to a sine distribution showing that the reactor is stable to axial xenon oscillations. 


\section{REACTOR TRANSFER FUNCTION MEASUREMENTS}

Reactor transfer function measurements were made at $25 \mathrm{~kW}, 2.5,50,80$, and 125 MW as a part of the general surveillance during the reactor startup program. The measurements provided a method of diagnosing any incipient reactor instability perhaps due to the complex structure of the temperature coefficient of reactivity.

The ATR may be regarded as being multiregional for the purpose of stability considerations. The reactor core is composed of a region containing. 40 fuel elements, a region containing 9 flux traps, and a region containing the remaining core components (beryllium reflector, neck shim housing, etc.). The temperature coefficient of reactivity of the fuel-element region (which is the fastest acting coefficient) is strongly negative $\left(\sim \$-0.03 /{ }^{\circ} \mathrm{F}\right)$; however, the reactor isothermal temperature coefficient of reactivity is slightly positive $\left(+\$ 0.004 /{ }^{\circ} \mathrm{F}\right)$, with the flux trap region causing most of the difference in the two coefficients. The question of ATR stability is further complicated by the fact that, at present, six in-pile tubes are located in six of the flux traps, and each in-pile tube has independent temperature and pressure control. After examining temperature profiles throughout the core, no difficulty was expected with the temporal behavior of the reactor. Nevertheless, it was decided to perform transfer function measurements as an experimental verification of reactor stability.

Transfer function measurements were made in automatic control utilizing the reactor regulating rod as the reactivity oscillator, and the responding neutron flux signal was recorded on magnetic tape. The regulating rod has a maximum speed of approximately 50 in./sec with a full-stroke reactivity of approximately $\$ 0.23$. This fast response and low reactivity worth permitted its use as a reactivity oscillator and eliminated the usual design problems (core penetration and integrity) involved in developing a special oscillator system. The experiment was performed with the reactor in automatic control to eliminate power drifts during the measurements. The reactor transfer function was obtained by measuring and analyzing the regulating rod position together with the variation in neutron flux. The stress placed on the regulating rod at the higher frequencies of oscillation was limited by restricting the zero-to-peak amplitude of oscillation to $0.20 \mathrm{inch}$, which corresponds to a reactivity oscillation of approximately $\$ 0.002$ at a maximum frequency of $7.5 \mathrm{~Hz}$. This restriction reduced the signal-to-noise ratio of the neutron flux to the extent that the record of the neutron flux signal was necessarily analyzed with noise techniques. T'o obtain additional information about the servo system, the signals proportional to the regulatingrod demand error, the regulating-rod speed, and the servo channel isolation amplifier also were recorded during the measurements.

The magnitude and phase angle of the ATR transfer function as determined from the measurements are shown in Figures 9 and 10, respectively. The calculated magnitude and phase angle for the ATR zero-power transfer function (no reactivity feedback effects included) are also shown for comparison. The calculation used the measured value, $25.2 \pm$ 


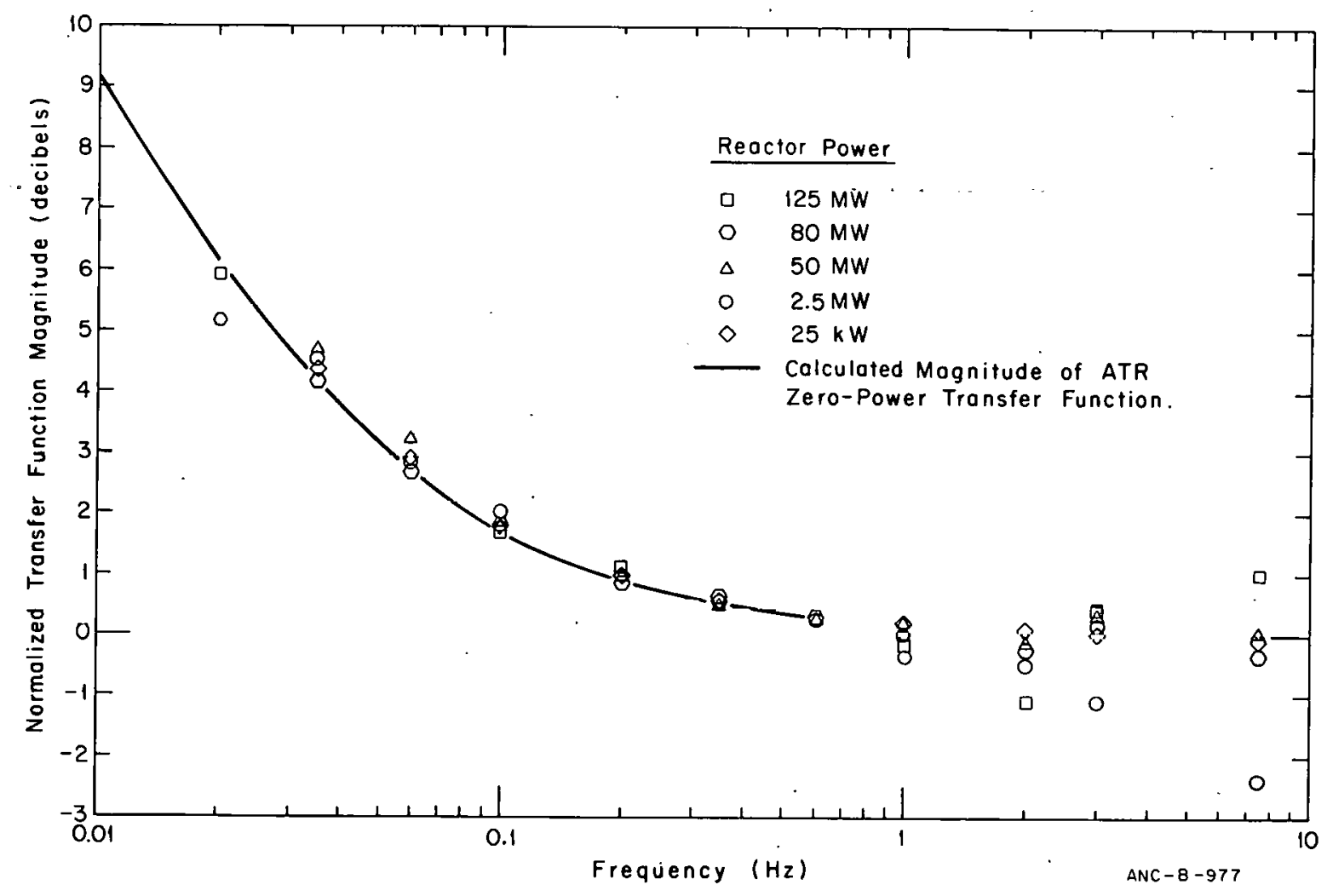

Fig. 9 Magnitude of the ATR core-reactivity transfer function.

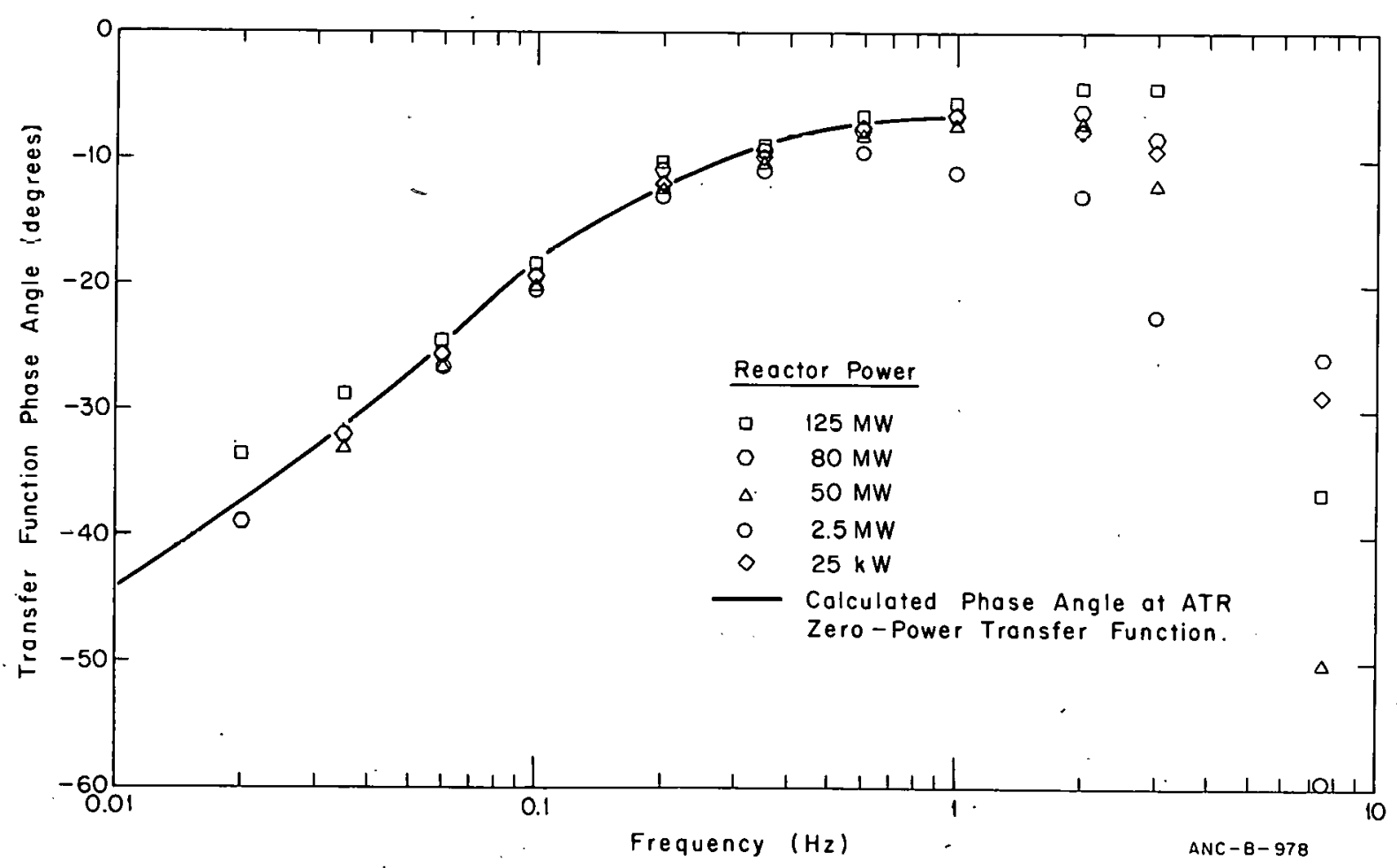

Fig. 10 Phase angle of the ATR core-reactivity transfer function. 
$0.3 \mathrm{~Hz}[3]$, for the break frequency, $\beta / \Lambda$. The scatter of the data at frequencies higher than $0.6 \mathrm{~Hz}$ was due to a noisy potentiometer in the servo position feedback loop and to the difficulty in obtaining reproducible results after analysis using a Boonshaft-Fuchs $711 \mathrm{Cl}$ spectrum analyzer.

Reactivity feedback effects generally are most important to stability considerations at frequencies lower than the break frequency, $\beta / \Lambda$, since the magnitude of the transfer function decreases at frequencies higher than $\beta / \Lambda$. A theoretical stability criterion which includes the effects of reactivity feedback [7] was used to analyze the transfer function data. The criterion states that a reactor is stable at any power where the power-normalized transfer function magnitude is less than the magnitude of the transfer function at zero power. The transfer function data obtained at $25 \mathrm{~kW}$ were used as the reference zero-power transfer function data in the analysis. The magnitude data shown in Figure 9 meet this criterion at $0.02 \mathrm{~Hz}$ indicating the beginning of negative-reactivity feedback effects. Any compensating positive-reactivity feedback effects at still lower frequencies would easily be controlled by the servo system. The reduction of the phase angle at $125 \mathrm{MW}$ (shown in Figure 10) relative to the phase angle at lower reactor powers also is a characteristic of a negative-reactivity feedback effect.

In summary, the ATR is stable to reactivity fluctuations and has a kinetic response similar to a compact homogeneous reactor with a single temperature coefficient of negative reactivity. 


\section{REACTOR NOISE MEASUREMENTS}

Neutron noise measurements were made throughout the ATR startup program (ie, in Cores 1,2 , and 3 ) to satisfy the following experiment objectives: ......

(1) To determine the feasibility of detecting the onset of nucleate boiling either with existent reactor instrumentation or with special instrumentation

(2) To determine changes if any in the characteristic frequencies of vibration of in-pile tubes and associated safety-rod guide-tubes with increasing reactor power and changing reactor power division

(3) To detect any anomalous power-dependent behavior of core components and/or the reactor system.

\section{INSTRUMENTATION}

Several different types of instrumentation (particularly neutron detectors) were used because of the diversity of the experiment objectives, the necessity of obtaining data in one-of-a-kind experiments with no opportunity for developing experimental technique, and because of the high radiation fields and temperatures encountered. The different types of detectors that were used are (a) a fission chamber, (b) a fission-breeder chamber, (c) a self-powered neutron detector (SPND), (d) a ${ }^{3} \mathrm{He}$ chamber, and (e) a gamma-compensated ion chamber. Several different detector positions relative to the reactor core also were used: The types of detectors, instrumentation, and detector positions used in accomplishing the experiment objectives are listed in Table II. All neutron detectors were used in the current mode of operation.

The ${ }^{3} \mathrm{He}$ chamber was used exclusively in ATR noise measurements at zero power and was used as a backup to other instrumentation in the nucleate boiling experiment because of its high neutron sensitivity. However, it was exchanged for a fission chamber for the at-power noise measurements because of its high gamma-ray sensitivity. Further, it was possible that the ${ }^{3} \mathrm{He}$ chamber would saturate at high reactor power.

Special breeder fission chambers were installed in the flux traps as a backup for the $16 \mathrm{~N}$ lnhe-power calibration. Because of the close proximity of the breeder fission chamber in the southeast flux trap to the site of possible nucleate boiling (fuel element position 12 in the southeast flux trap), a decision was made to use the breeder fission chamber as the primary means of detecting nucleate boiling. The ${ }^{3} \mathrm{He}$ chamber in instrument thimble No. 3 also was used to detect nucleate boiling because of its high neutron sensitivity but was regarded as backup instrumentation because of the increased distance to the site of possible boiling. Further, the small rate of change of sensitivity of the breeder fission chamber with exposure to large neutron fields and the fact that it was permanently positioned made it an attractive means of measuring the dependence of the vibration of the in-pile tubes with 
TYPES OF DETECTORS, INSTRUMENTATION, AND DETECTOR POSITIONS USED IN REACTOR NOISE MEASUREMENTS

\section{Neutron Detector}

Experiment Objective

(1) To determine the feasibility

of detecting the onset of nucleate boiling:

(a) with existent reactor instrumentation

Compensated ion chamber

Compensated ion chamber

(b) with auxiliary instrumentation
SPND

Breeder fission chamber

Auxiliary

$3_{\text {He }}$ chamber

Auxiliary

Auxiliary

Instrumentation

Detector Position

Output signal of isolation amplifier (TP4)

ATR servo amplifier No. 2

Output signal of preamplifier of ATR Level Channel No. 6
Instrument thimble No. 3

Instrument thimble No. 1

Southeast flux trap

Southeast flux trap

Instrument thimble No. 3 
TABLE II (Contd.)

\begin{tabular}{|c|c|c|c|c|}
\hline \multirow[b]{2}{*}{ (2) } & Experiment Objective & Neutron Detector & Instrumentation & Detector Position \\
\hline & $\begin{array}{l}\text { To determine the dependence } \\
\text { of in-pile tube vibration } \\
\text { on reactor power and } \\
\text { power division: }\end{array}$ & . & & - \\
\hline & $\begin{array}{l}\text { (a) up to } 188 \mathrm{MW} \text { in a } \\
50-50-50 \text { power division }\end{array}$ & Fission chamber & Auxiliary & $\begin{array}{l}\text { Instrument thim- } \\
\text { ble No. } 3\end{array}$ \\
\hline & $\begin{array}{l}\text { (b) up to } 125 \mathrm{MW} \text { in a } \\
50-50-50 \text { power division }\end{array}$ & $\begin{array}{l}\text { Breeder fission } \\
\text { chamber }\end{array}$ & Auxiliary & $\begin{array}{l}\text { Southeast flux } \\
\text { trap }\end{array}$ \\
\hline & $\begin{array}{l}\text { (c) at } 250 \mathrm{MW} \text { in a } \\
40-50-60 \text { power division }\end{array}$ & Fission chamber & Auxiliary & $\begin{array}{l}\text { Instrument thim- } \\
\text { ble No. } 7\end{array}$ \\
\hline
\end{tabular}


increasing reactor power. In contrast, the fission chambers in instrument thimble No. 3 were withdrawn after each noise measurement to prevent burnup, thereby increasing the uncertainty in the chamber efficiency. The breeder fission chambers were removed before the reactor attained very high powers because of temperature limitations.

Other detectors tried in noise measurements were the SPND in the center flux trap and the control system ion chambers. Although other experimenters [8] have successfully used an SPND in reactor noise measurements, the attempt to use one in ATR was unsuccessful. Although elaborate precautions were taken to shield the signal cable electrostatically and magnetically, the ratio of the neutron noise signal to $60 \cdot \mathrm{Hz}$ and harmonic noise pickup was 1 to 100 .

Noise recordings were made of the output signal of level channel No. 6 preamplifier and of the output signal (TP-4) of the isolation amplifier of servo amplifier No. 2 to determine the feasibility of making reactor noise measurements with existent reactor instrumentation. After analysis, the results from these recordings were compared with results obtained from a similar recording of the breeder fission chamber signal. The three-way comparison showed no significant differences and suggests that noise measurements may be made routinely with the existent reactor instrumentation.

All noise data were recorded using an FM tape recorder (Ampex FR-1300) at a recording speed of $3.750 \mathrm{in.} / \mathrm{sec}$ and were analyzed using a Boonshaft-Fuchs $711 \mathrm{Cl}$ Spectrum Analyzer and a Time Data 100 Spectrum Analyzer. The choice of recording speed was a compromise resulting from the desire to minimize the uncertainty of the data in the frequency interval from 0.10 to $40.0 \mathrm{~Hz}$ while maximizing the resolution. Low recording speeds are used to obtain better resolution at low frequencies and, for a given tape length, enable a longer recording time which reduces the uncertainty in the data. However, the operational specifications of the tape recorder suggested some tape flutter might occur if the lowest recording speed, $1.875 \mathrm{in.} / \mathrm{sec}$, were used. This particular frequency interval was chosen because (a) the characteristic frequencies of vibration of the in-pile tubes previously had been shown to occur at 4.2 and $7.0 \mathrm{~Hz}$, (b) the power spectral density of the reactor exhibited a resonant frequency at $11.0 \mathrm{~Hz}$ whose cause was unknown, and (c) the effects of nucleate boiling if it occurred were expected to be in this frequency interval. 


\section{MEASUREMENTS AND PROCEDURE}

During thermal-hydraulic tests to determine the convective heat transfer coefficient for ATR fuel elements and the phenomenon controlling the onset of flow instability in the fuel elements, reactor noise measurements were made to determine the feasibility of detecting the onset of nucleate boiling. Noise measurements were made with the primary coolant system flow rate at full emergency flow ( $\sim 5000 \mathrm{gpm})$, three-quarters of full emergency flow, and at approximately $23,000 \mathrm{gpm}$ which is $46 \%$ of full flow $(\sim 50,000$ $\mathrm{gpm})$. At each flow rate, noise measurements were made as reactor power was increased stepwise until a flow instability was initiated and the reactor was scrammed or until the test was terminated.

Reactor control during the thermal-hydraulic tests was maintained manually and with the servo system. Although the procedures for performing the noise measurements specified the use of manual control, it became obvious that constant reactor power, which was crucial to the thermal-hydraulic tests, could be maintained much more easily using the servo system. Consequently, noise measurements were made for the purpose of determining the effect of the mode of reactor control on the power spectral density. Partial results of the measurements are shown in Figures 11 through 14. No significant change was observed in the power spectral density due to the mode of control which was fortuitous since many measurements to detect nucleate boiling were necessarily performed using the servo system. The results of the comparison were fortuitous in another sense. Previous noise measurements at intermediate reactor powers had shown that more frequent control rod movement was required to maintain constant reactor power as the power level was increased, and noise measurements at increased power levels remained to be performed.

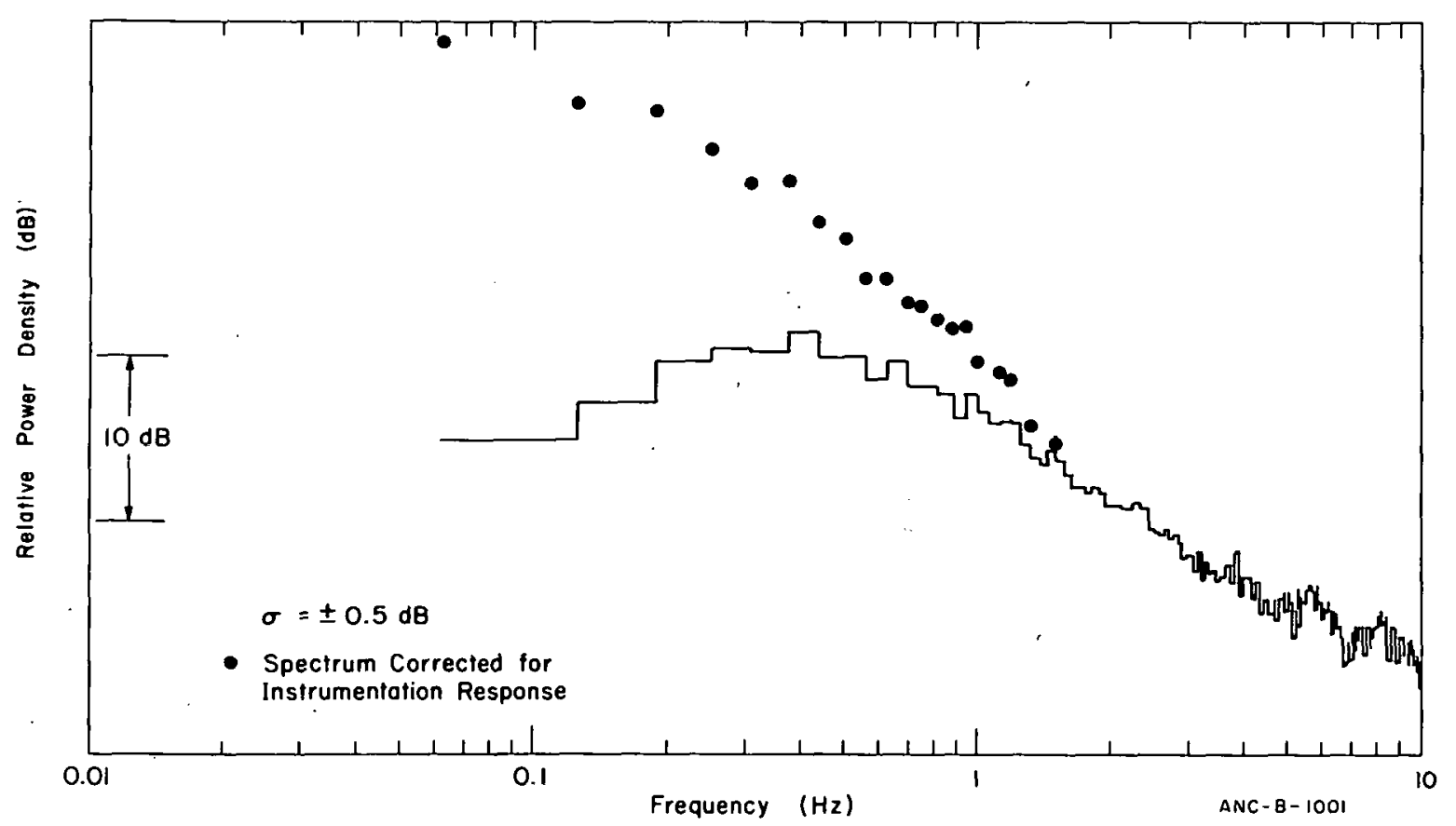

Fig. 11 ATR auto-correlated power-spectral density obtained at $27 \mathrm{MW}$ with a $3 \mathrm{He}$ chamber. The reactor power level was controlled automatically: 


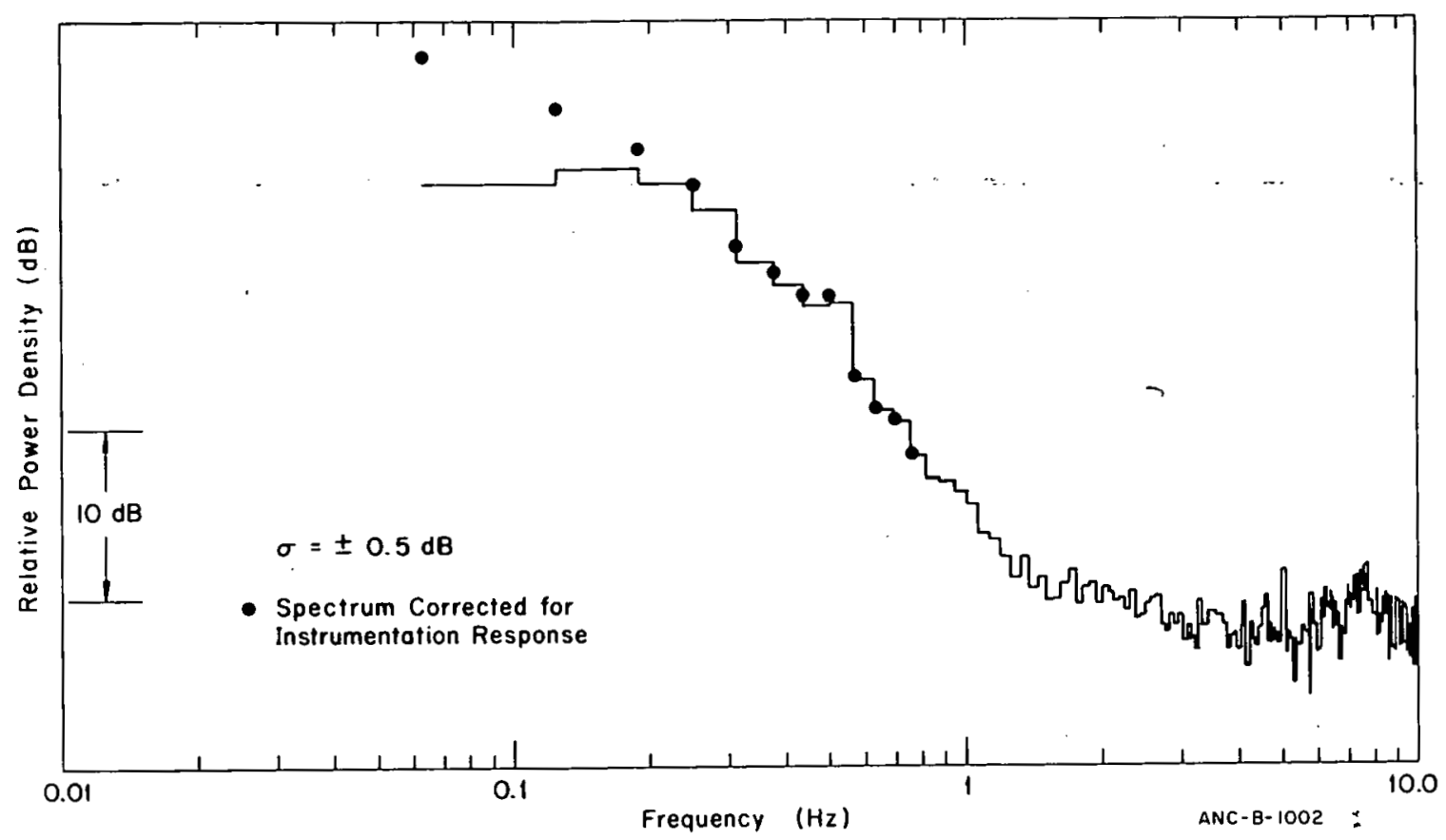

Fig. 12 ATR auto-correlated power-spectral density obtained at $27 \mathrm{MW}$ with a breeder fission chamber. The reactor power level was controlled automatically.

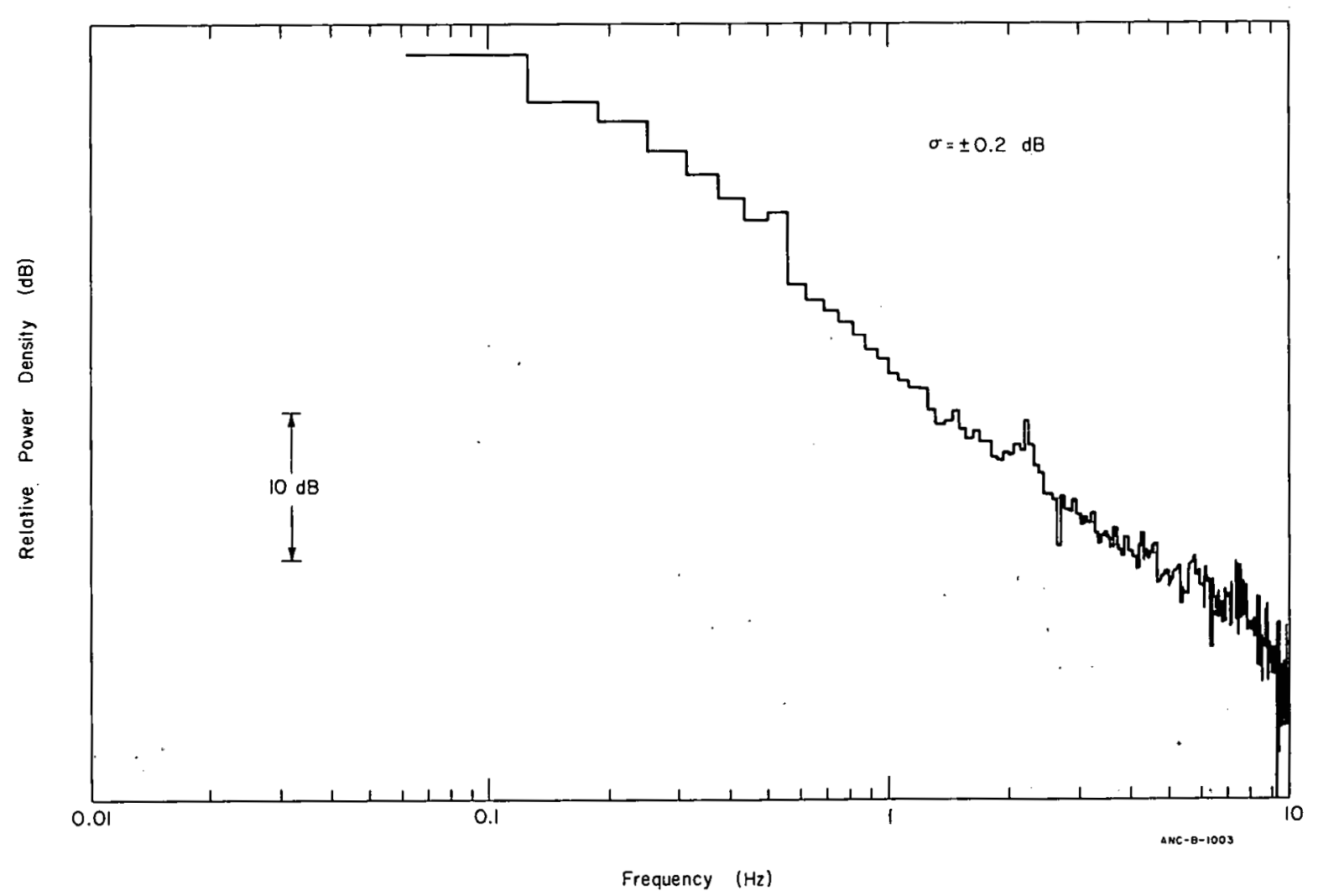

Fig. 13 ATR auto-correlated power-spectral density obtained at $40 \mathrm{MW}$ with a $3 \mathrm{He}$ chamber. The reactor power level was controlled manually. 


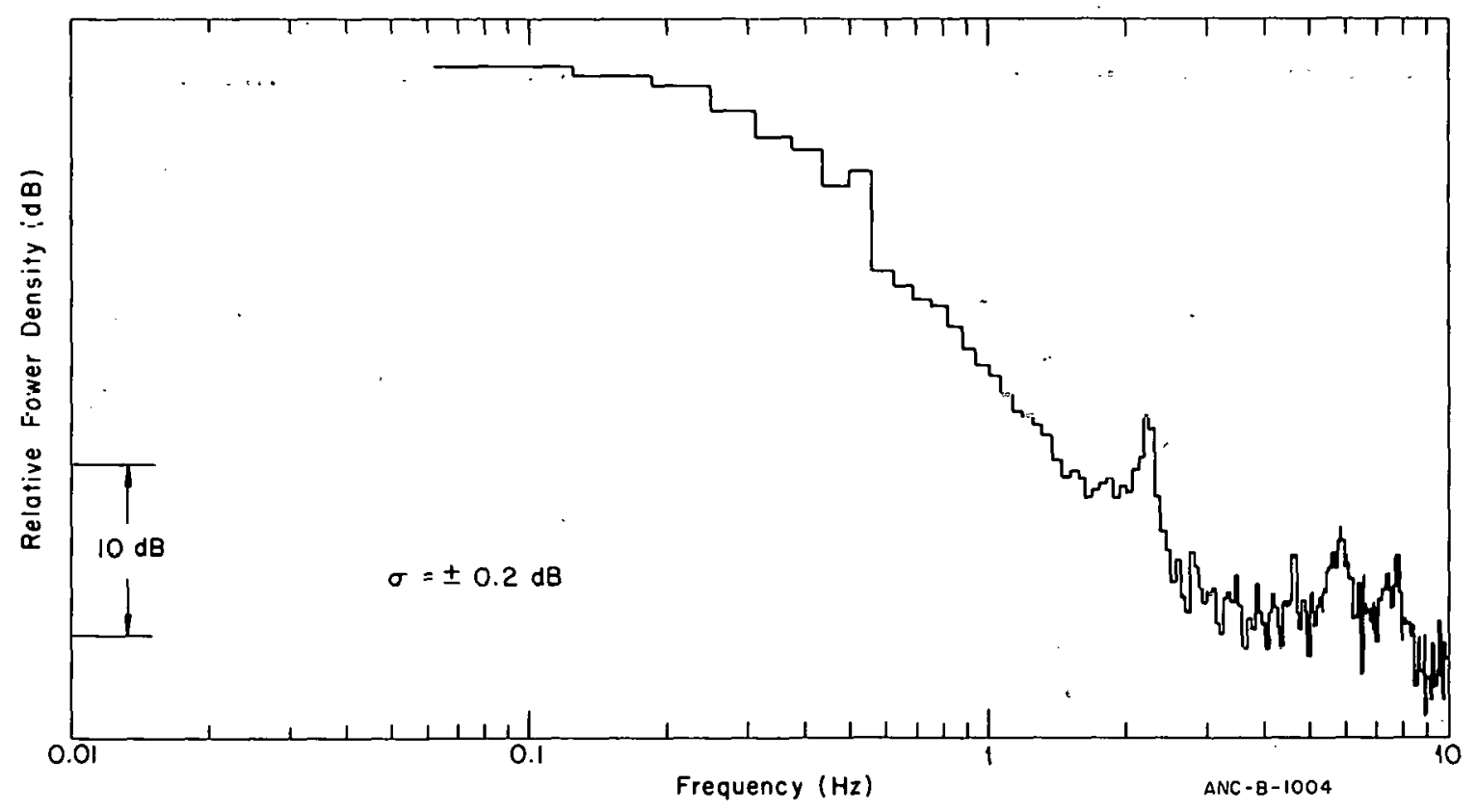

Fig. 14 ATR auto-correlated power-spectral density obtained at $40 \mathrm{MW}$ with a breeder fission chamber. The reactor power level was controlled manually.

Noise measurements that were considered a means of reactor surveillance were made in Core 1 with full flow at $2.5,50,80$, and $125 \mathrm{MW}$ with a nominally $50-50-50$ power division. The reactor power was controlled manually. More measurements were made in Core 2 with full flow at 150 and $188 \mathrm{MW}$ with a nominally 50-50-50 power division. In this case the reactor power was controlled using the servo system. The last measurement was made in Core 3 with full flow at $250 \mathrm{MW}$ with a nominally 40-50-60 power division and using servo control.

\section{RESULTS AND COMMENTS}

No indications of nucleate boiling were detected by any of the instrumentation during the thermal-hydraulic tests. When the primary coolant system was operated with emergency flow during the tests, the power spectral density remained essentially as shown in Figures 11 through 14 which were obtained during the servo-manual control comparison. The thermalhydraulic test with $46 \%$ of full flow was terminated before the special thermal and hydraulic instrumentation registered any anomalous behavior, and the associated power spectral density was characteristic of normal reactor operation with reduced flow. 
Results from the noise measurements that were a part of the reactor surveillance program are shown in Figures 15 through 25. The results shown in Figures 15 through 18 were obtained from the breeder fission chamber signal at reactor powers of $2.5,50,80$, and $125 \mathrm{MW}$ during the operation of Core 1 . Corresponding results obtained from the fission chamber signal are shown in Figures 19 through 22. Figures 23 and 24 show the results obtained from the fission chamber signal during the operation of Core 2 at reactor powers of 150 and $188 \mathrm{MW}$, respectively; and Figure 25 shows the results obtained from the fission chamber signal at $250 \mathrm{MW}$ reactor power during the operation of Core 3 .

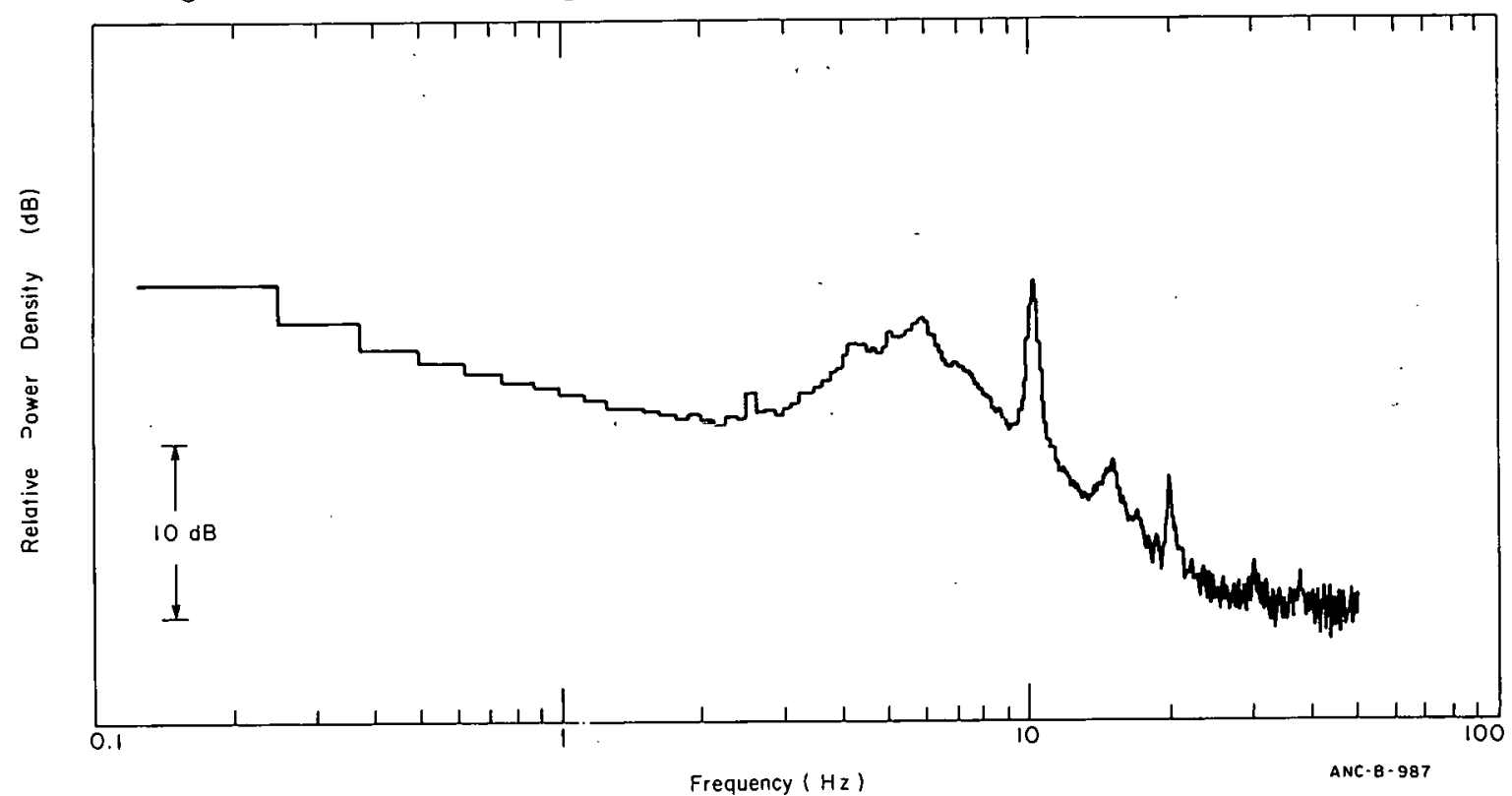

Fig. 15 ATR auto-correlated power-spectral density (corrected for recording gain) obtained at $2.5 \mathrm{MW}$ with a breeder fission chamber.

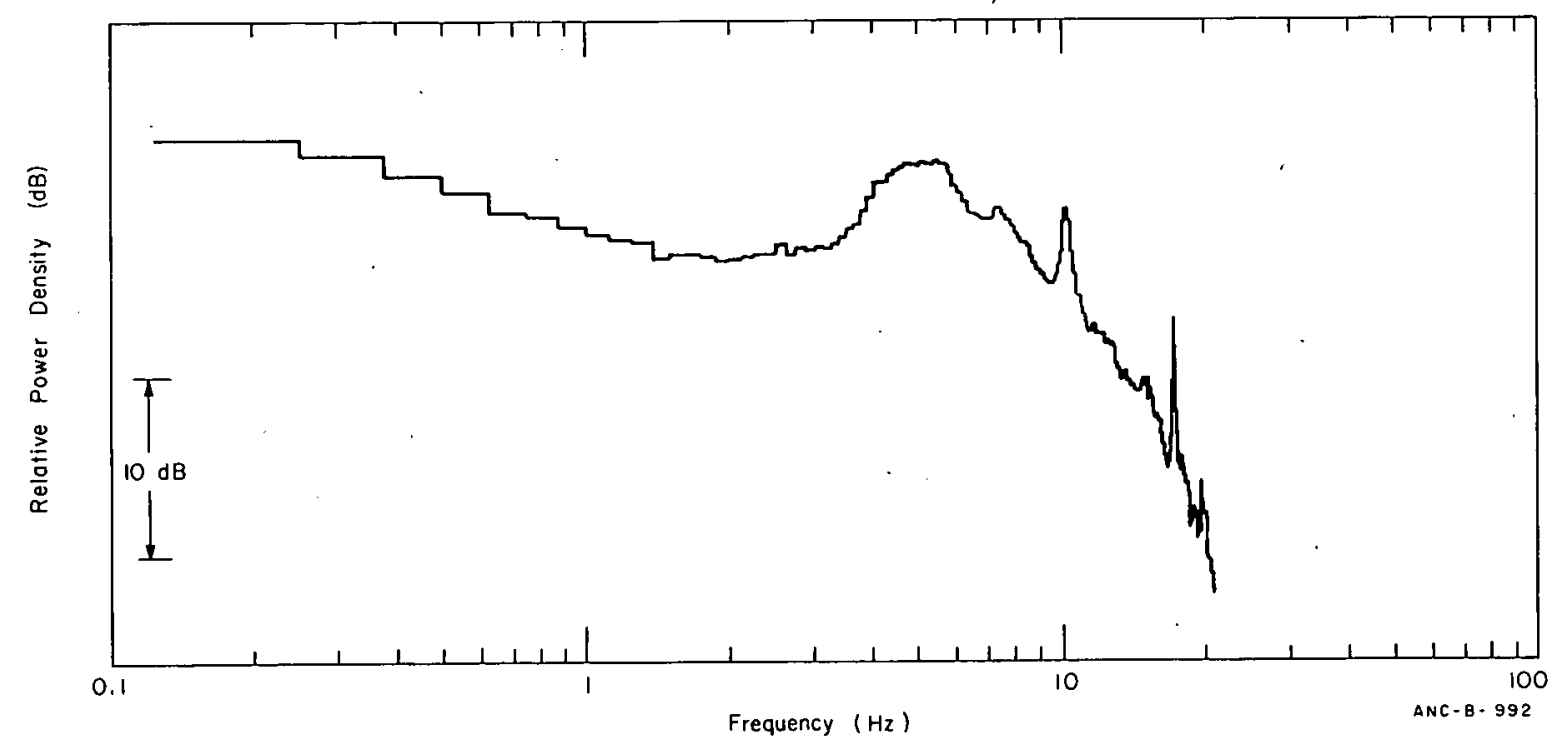

Fig. 16 ATR auto-correlated power-spectral density (corrected for recording gain) obtained at $50 \mathrm{MW}$ with a breeder fission chamber. 


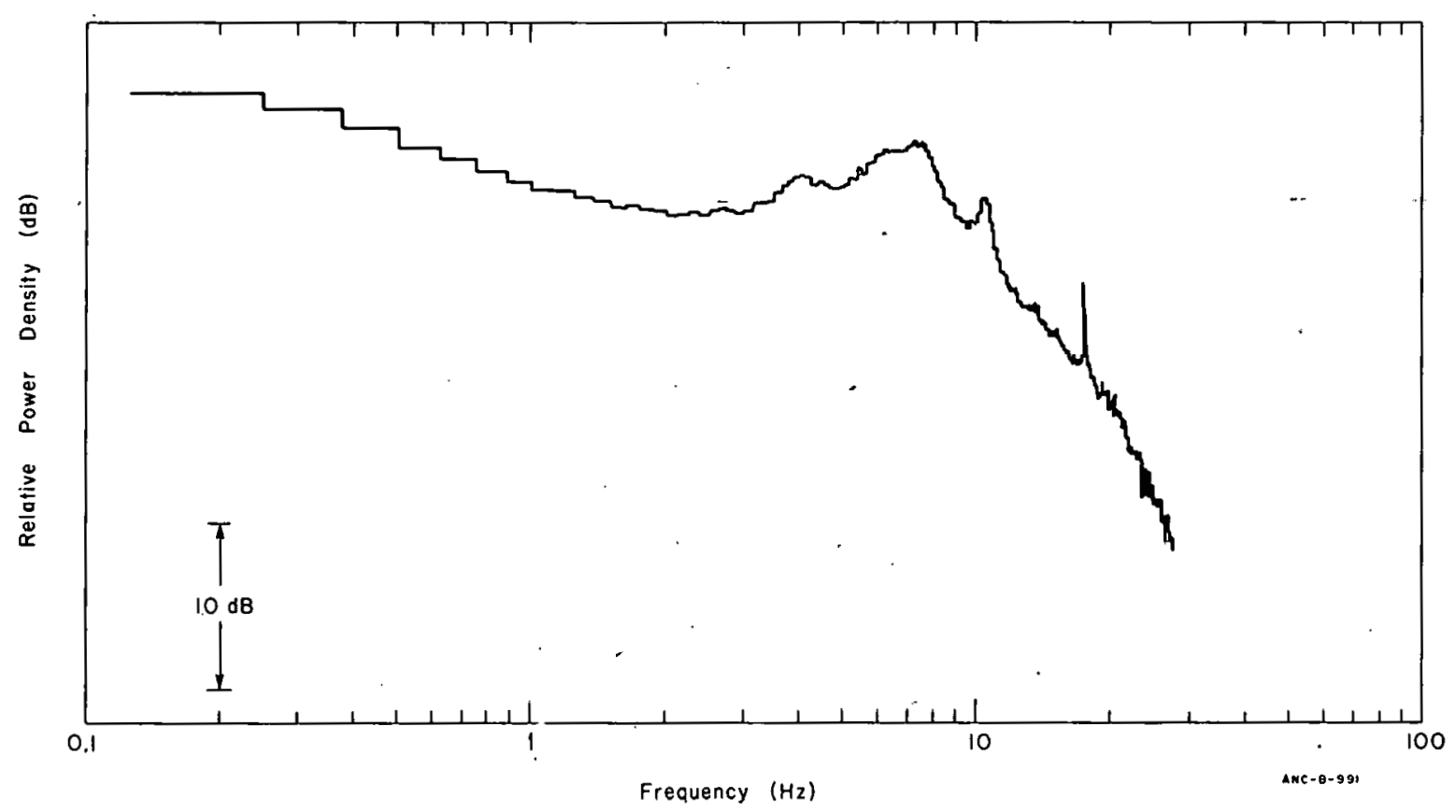

Fig. 17 ATR auto-correlated power-spectral density (corrected for recording gain) obtained at $80 \mathrm{MW}$ with a breeder fission chamber.

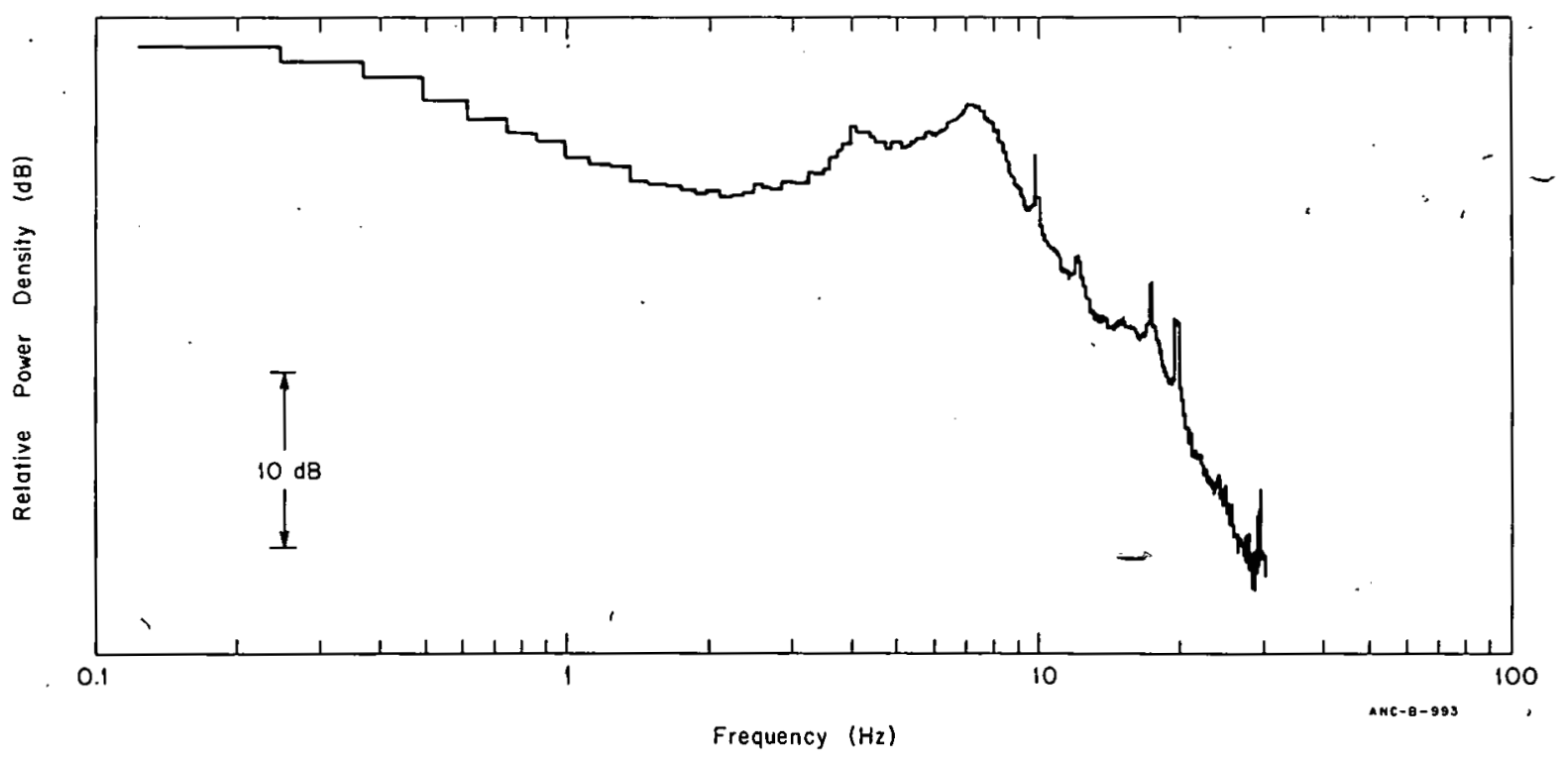

Fig. 18 ATR auto-correlated power-spectral density (corrected for recording gain) obtained at 125 MW with a breeder fission chamber. 


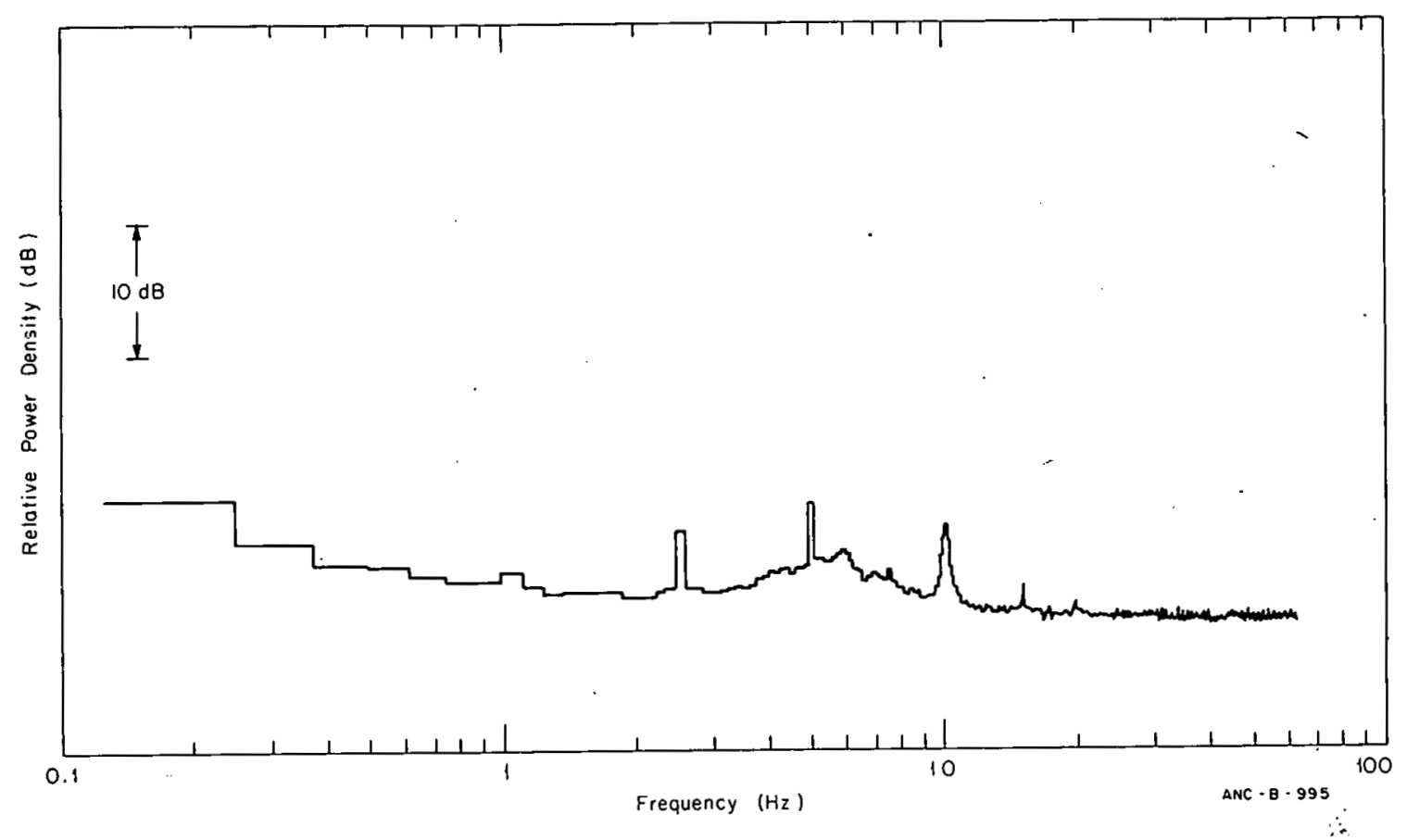

Fig. 19 ATR auto-correlated power-spectral density obtained at $2.5 \mathrm{MW}$ with a fission chamber.

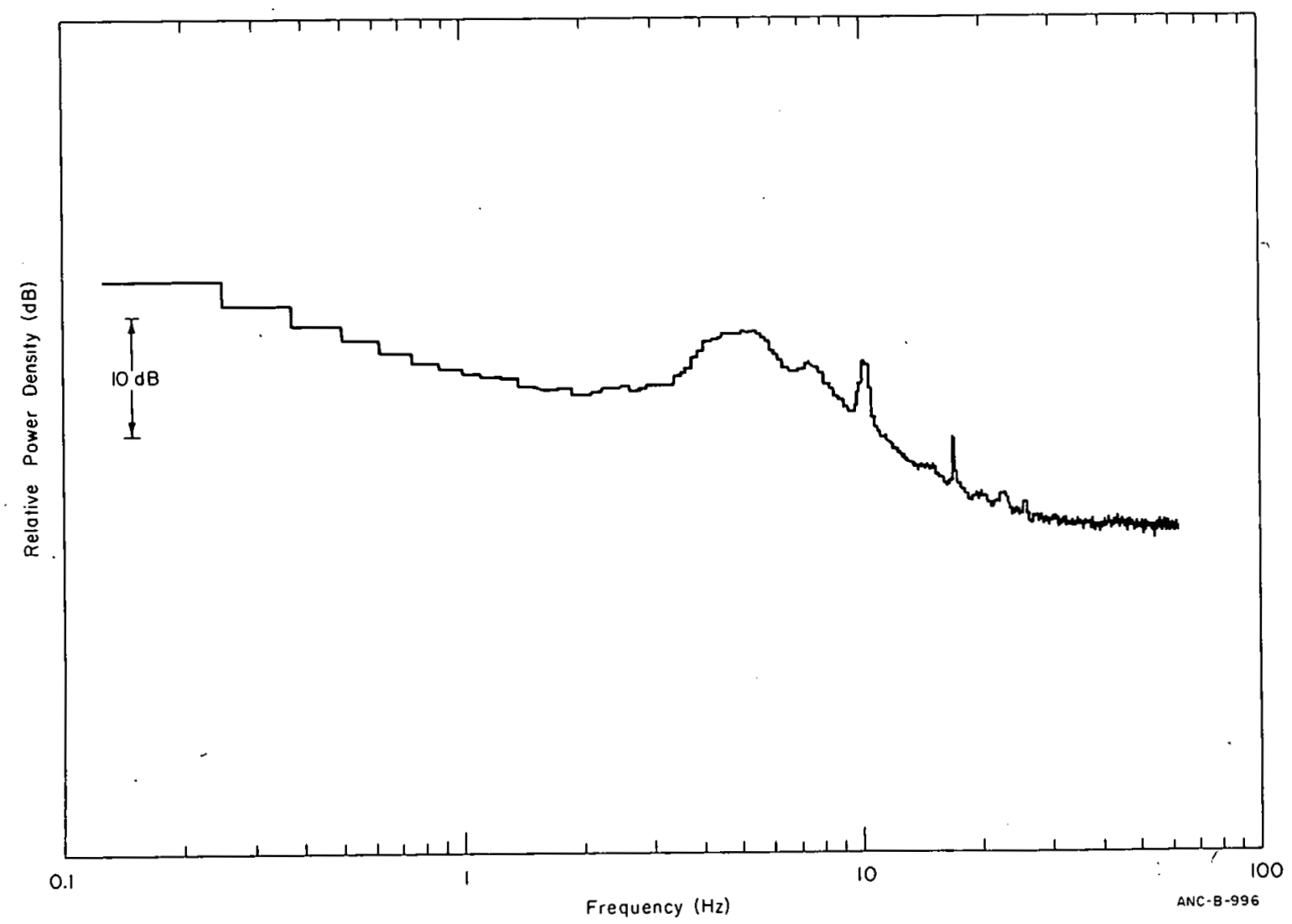

Fig. 20 ATR auto-correlated power-spectral density obtained at $50 \mathrm{MW}$ with a fission chamber. 


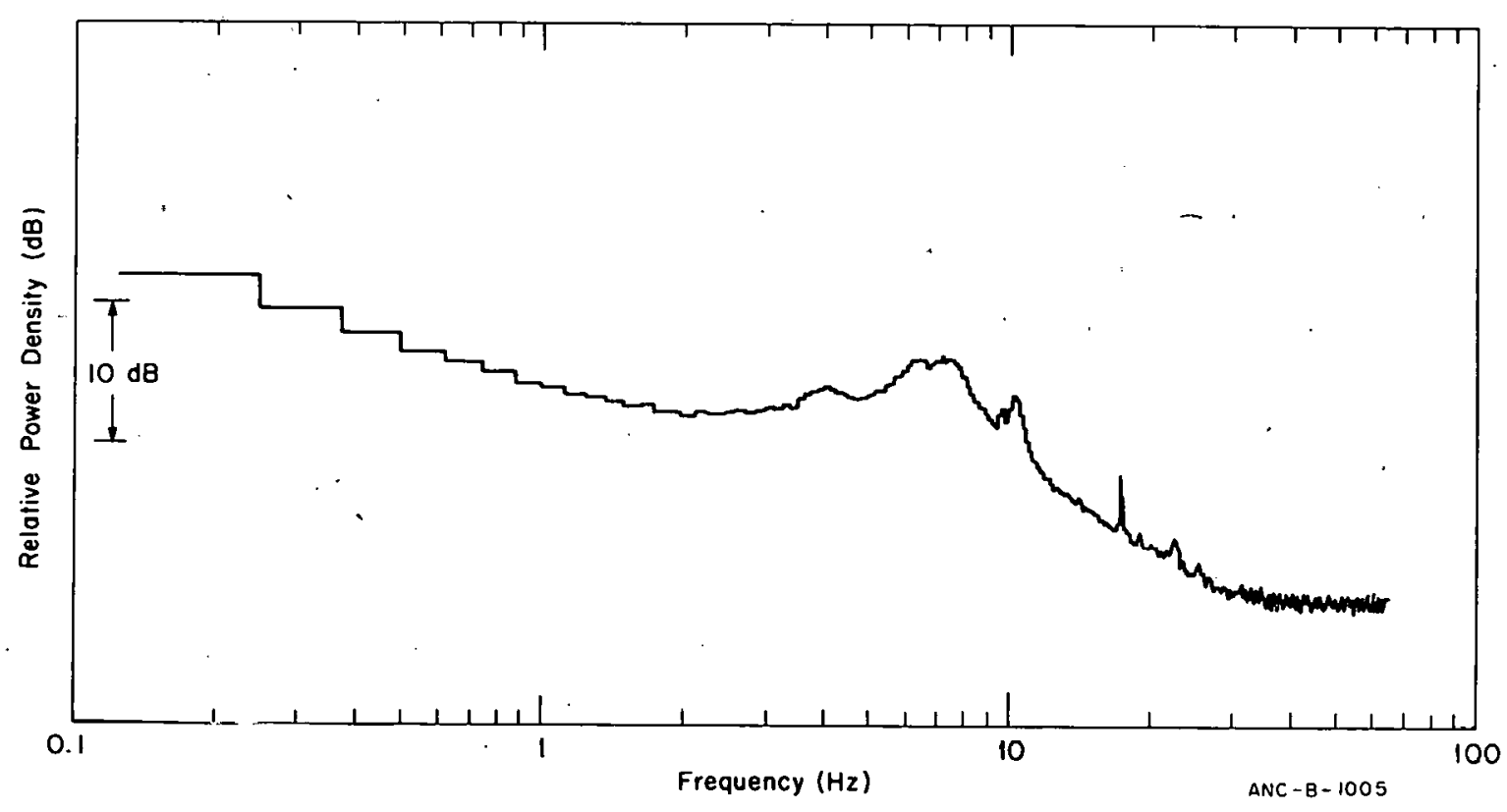

Fig. 21 ATR auto-correlated power-spectral density obtained at $80 \mathrm{MW}$ with a fission chamber.

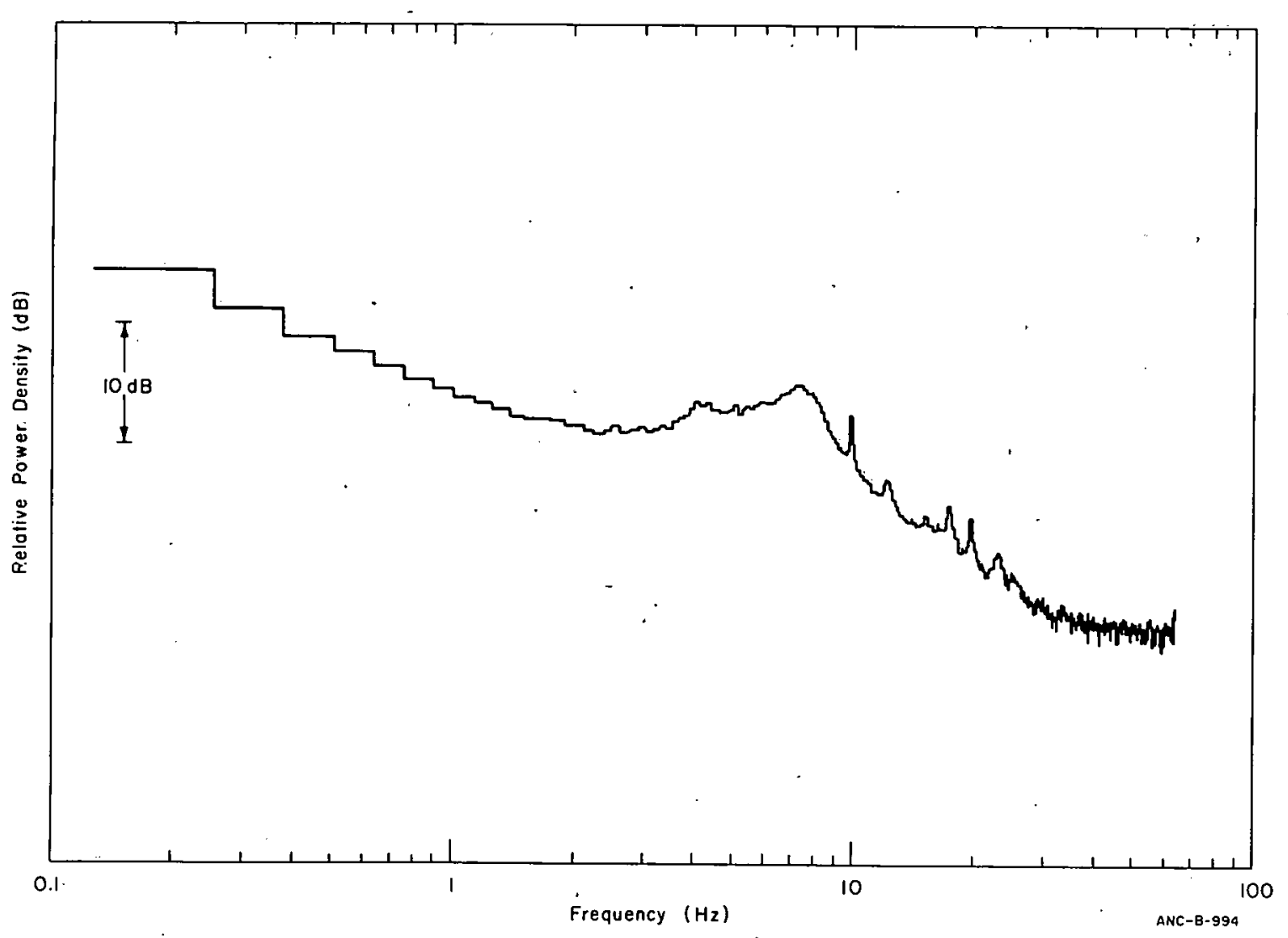

Fig. 22 ATR auto-correlated power-spectral density obtained at $125 \mathrm{MW}$ with a fission chamber. 


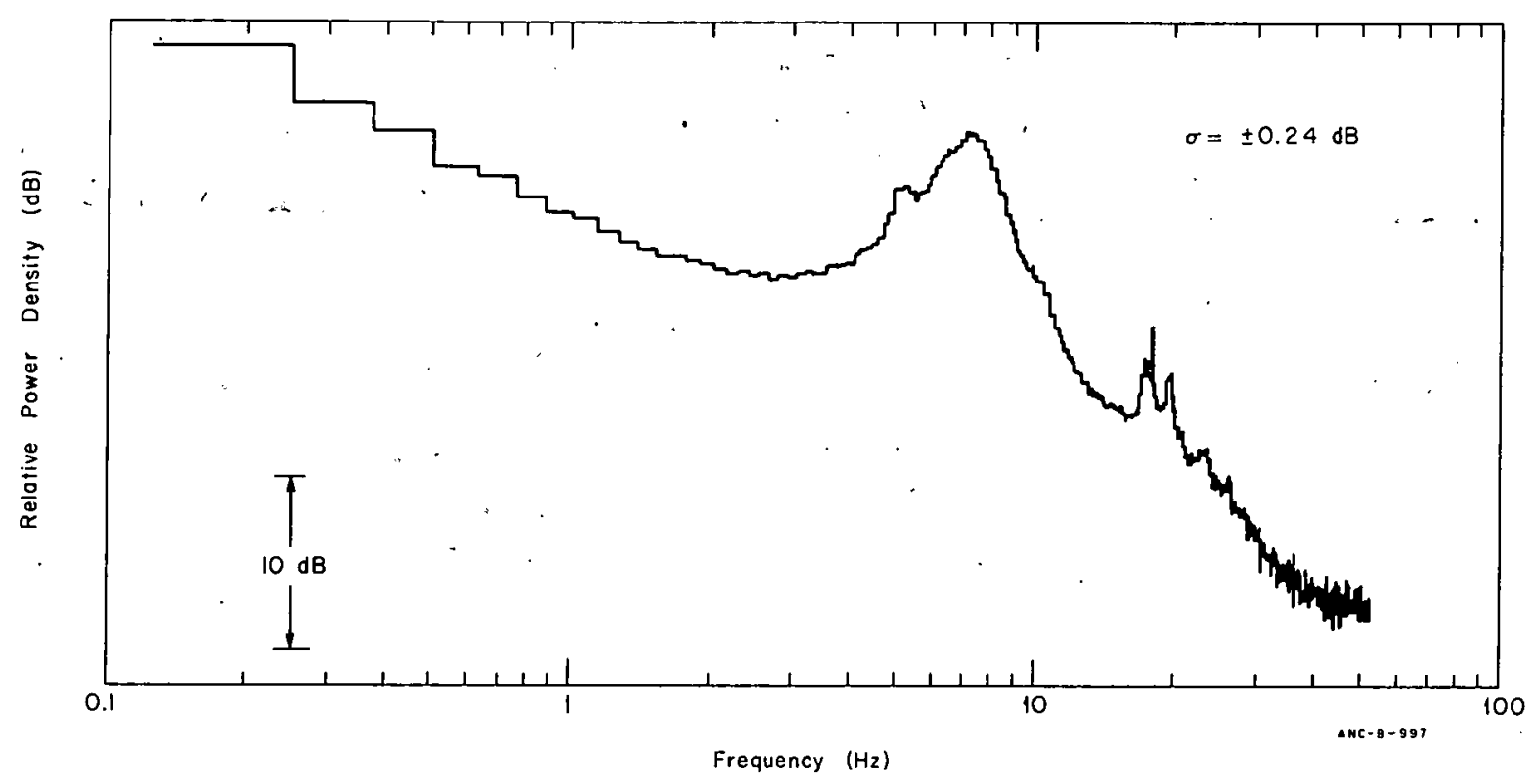

Fig. 23 ATR auto-correlated power-spectral density obtained at $150 \mathrm{MW}$ with a fission chamber.

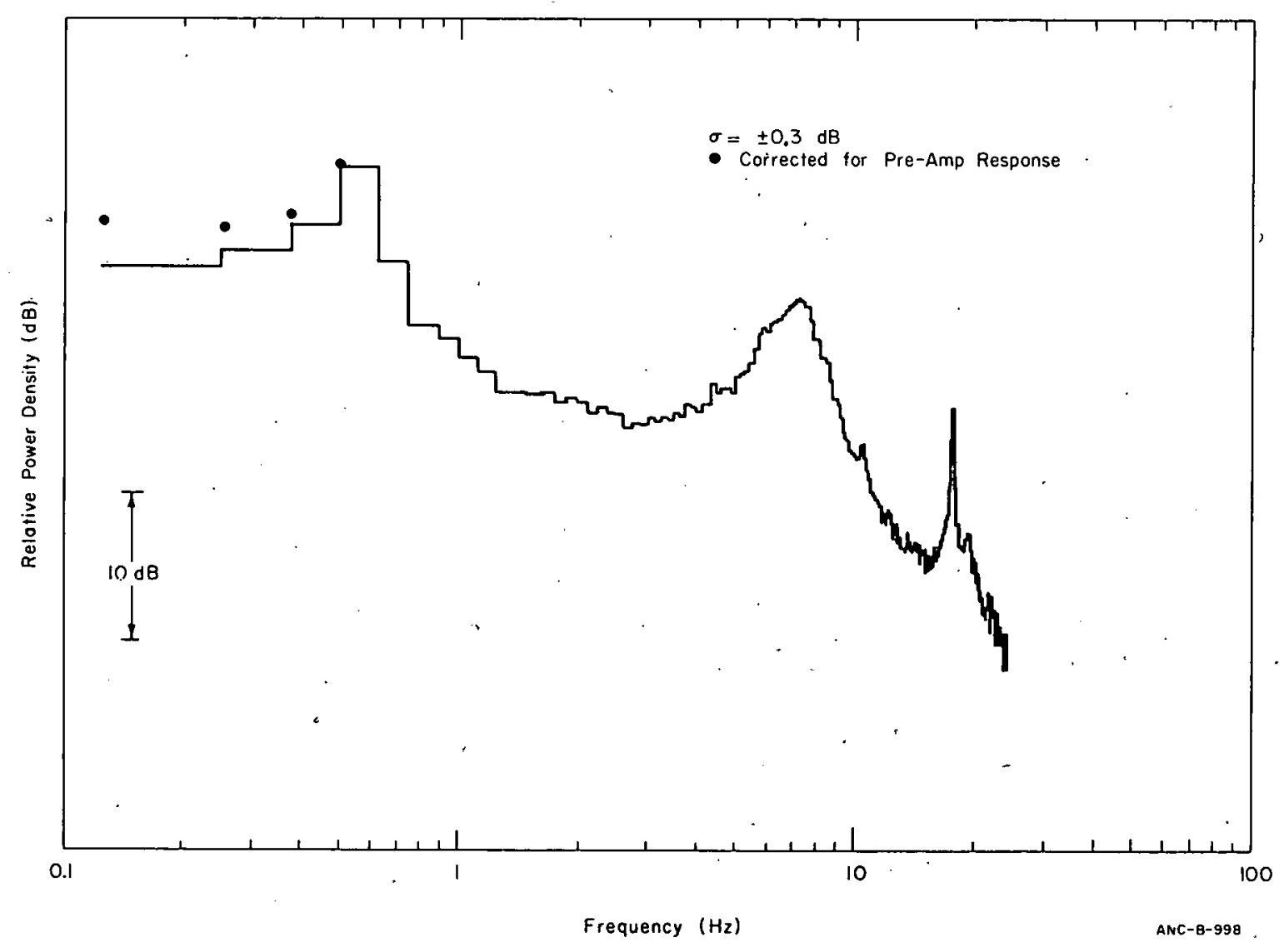

Fig. 24 ATR auto-correlated power-spectral density obtained at $188 \mathrm{MW}$ with a fission chamber. 


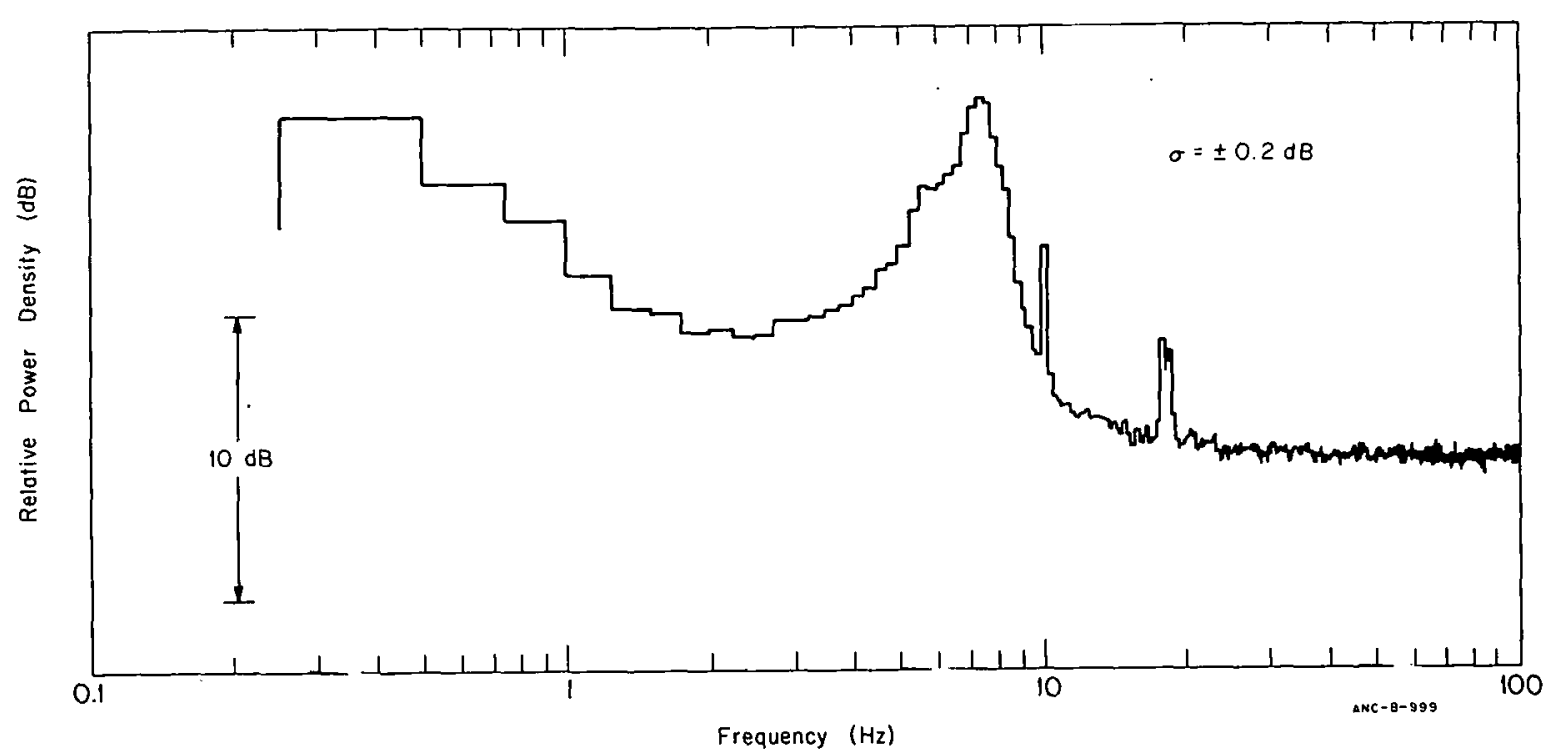

Fig. 25 A'I'R auto-correlated power-spertral density obtained at '250 MW with a fission chamber.

The most important facet of the data shown in Figures 15 through 25 is that the power spectral density at the resonant frequencies (regardless of origin) tends to decrease with increasing reactor power relative to the power spectral density at lower frequencies. This trend indicates that a greater constraint is being applied to individual core components probably because of increased temperature effects as the reactor power is increased. It is interesting to note that the character of vibration for the center and icornerin-pile tubes, at approximately 4 and $7 \mathrm{~Hz}$, respectively, changes as reactor power increases. This can be seen most clearly in Figures 15 through 18. Further, a comparison of the dala shown in Figures 23 and 25 shows that the character of vibration for the center and corner in-pile tubes is not affected by the power division of the reactor. To facilitate a comparison of the data reported here with the power spectral density of the reactor at zero power and with varying flow up to full flow, the previously reported data $[3]$ have been reanalyzed to obtain greater resolution and are shown in Figure 26.

The results obtained at 188 MW (Figure 24) show a previously undetected resonance at approximately $0.5 \mathrm{~Hz}$. The power density of this resonance was also evidenced by a wider signal envelope on the control system period recorders. After a thorough examination of the reactor core and system which did not locate the driving source of the resonance, the reactor power was increased gradually to determine whether the resonance effect would continue to increase. At approximately $200 \mathrm{MW}$ the effect disappeared and did not reappear for the remainder of the startup program (see Figure 25). A possible cause of the resonance may have been vibration of an in-core SPND used for startup instrumentation.

\section{ANALYSIS OF RESULTS}

The purpose of the neutron noise measurements throughout the ATR startup program was not to generate experimental data for detailed analysis; instead, the purpose was to provide a means of reactor surveillance. Nevertheless, qualitative conclusions may be drawn from the data which substantiate conclusions drawn from experiments in other reactors, and additionally, which allow a more detailed understanding of the ATR reactor system. 


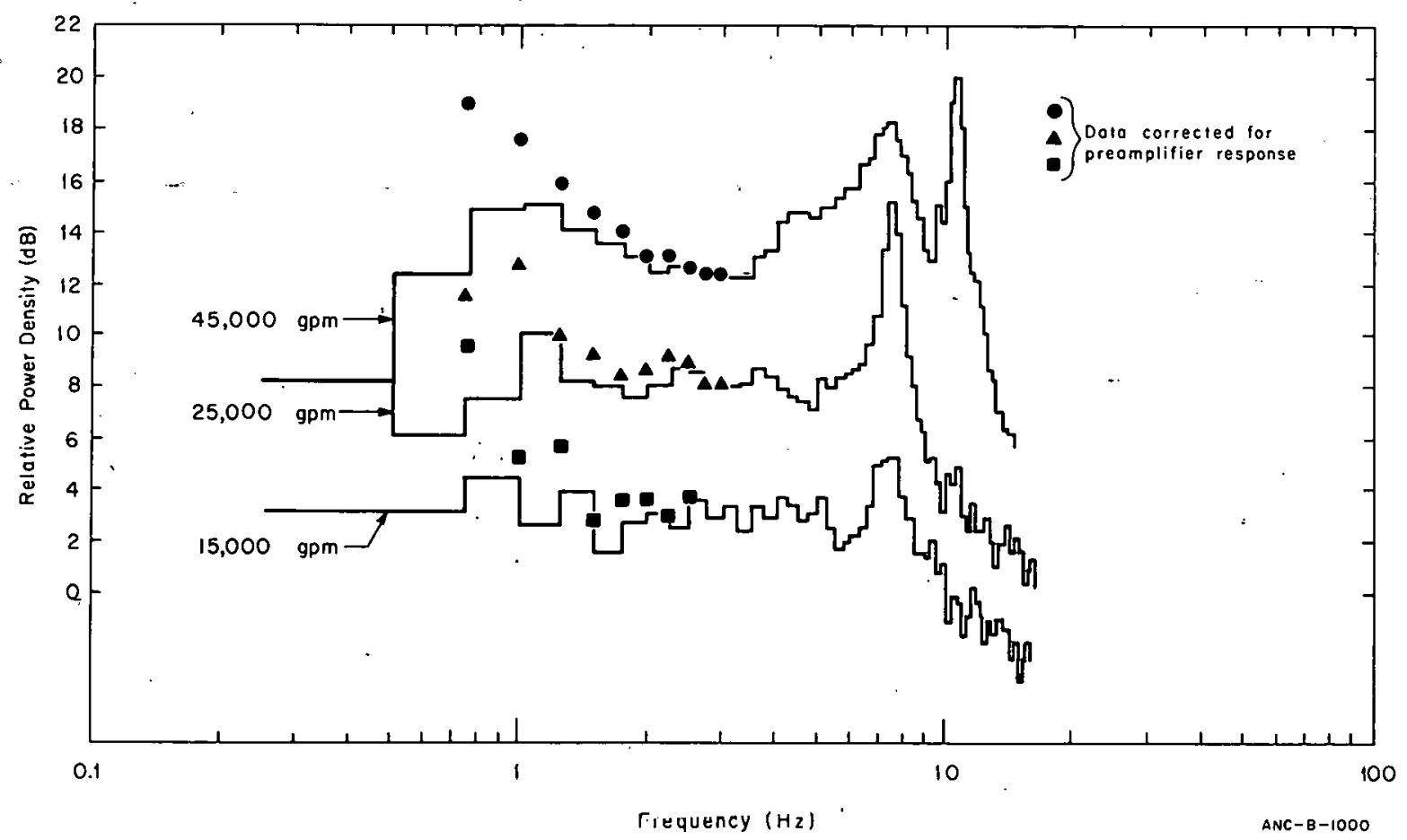

Fig. 26 Flow dependence of the ATR cross-correlated power-spectral density obtained at $500 \mathrm{~W}$ with a 3 He chamber.

The output power spectral density of a linear system may be related to the input power spectral density by the equation [9]

$$
\Phi_{\mathrm{o}}(\omega)=[\mathrm{G}(\omega)]^{2} \Phi_{\mathrm{I}}(\omega)
$$

where $\Phi_{0}(\omega)$ is the power spectral density of the system output, $\Phi_{I}(\omega)$ is the power spectral density of the system input, and $G(\omega)$ is the system transfer function. The system transfer function, $\mathrm{G}(\omega)$, used in this report is the power-reactivity transfer function. In nuclear reactors, vibration of core components and fluctuations in the multiplication process, system temperature, and system pressure are sources of input power spectral densities. The input power spectral density for fluctuations in the multiplication process commonly is assumed to be a constant, ie, independent of frequency [10]. The power-reactivity transfer function for the ATR was measured during the startup program and resembles the transfer function of a closely coupled reactor with a single negative-reactivity temperature coefficient (see Section IV).

If sources of input power spectral density to a reactor system are not correlated, the total output power spectral density of the reactor system as determined from the fluctuation portion of a neutron chamber signal is the sum of all output power spectral densities generated by uncorrelated sources [10]. Expressed mathematically the relationship is

$$
\Phi_{0}(\omega)=\Phi_{0}^{\mathrm{d}}(\omega)+\Phi_{0}^{\mathrm{m}}(\omega)+\Phi_{0}^{\mathrm{v}}(\omega)+\Phi_{0}^{\mathrm{f}}(\omega)+\Phi_{0}^{\mathrm{t}}(\omega)+\Phi_{0}^{\mathrm{p}}(\omega)+\ldots . \text { where } \Phi_{0}^{\mathrm{d}}(\omega) \text { is the }
$$

output power spectral density caused by the statistical nature of the neutron detection process in the ion chamber. This density has been shown to be constant; ie, independent of 
frequency, and proportional to the reactor power and efficiency of the chamber over the frequency interval of chamber sensitivity [10]. The quantity $\Phi_{0}^{\mathrm{m}}(\omega)$ is the output power spectral density caused by the fluctuating neutron multiplication process. This density has been shown to be proportional to reactor power and the square of chamber efficiency $[10]$. The quantities $\Phi_{\mathrm{o}}^{\mathrm{v}}(\omega), \Phi_{o}^{\mathrm{f}}(\omega), \Phi_{\mathrm{o}}^{\mathrm{t}}(\omega)$, and $\Phi_{\mathrm{o}}^{\mathrm{p}}(\omega)$ are output power spectral densilies causcd by vibration of core components and fluctuations in reactor flow, temperature, and pressure, respectively. It has been shown that these densities are proportional to the square of reactor power and the square of chamber efficiency[11].

A noise measurement was made in the ATR critical facility prior to the measurements in ATR to determine the relative efficiency of an ion chamber positioned in an ATR instrument thimble. The similarity of the kinctic response of A'TKC and ATR at low powcr and with no flow (the conditions of the reactor during the mcasurement) had been previously established [3]. The results of the measurement are shown in Figure 27. The efficiency of the chamber in this position was just large enough to allow distinguishing a slight decrease in the power spectral density as determined from a cross-correlation analysis as the reactor break frequency, $25.2 \mathrm{~Hz}$, was approached. The results of the measurement enabled a better understanding of the expected frequency dependence of the power spectral densities to be measured in ATR. More precisely, the output power spectral density of the reactor caused by fluctuations in the multiplication process would be distinguishable in the signal from a chamber located in an ATR instrument thimble if contributions to the total power spectral density from other sources were small.

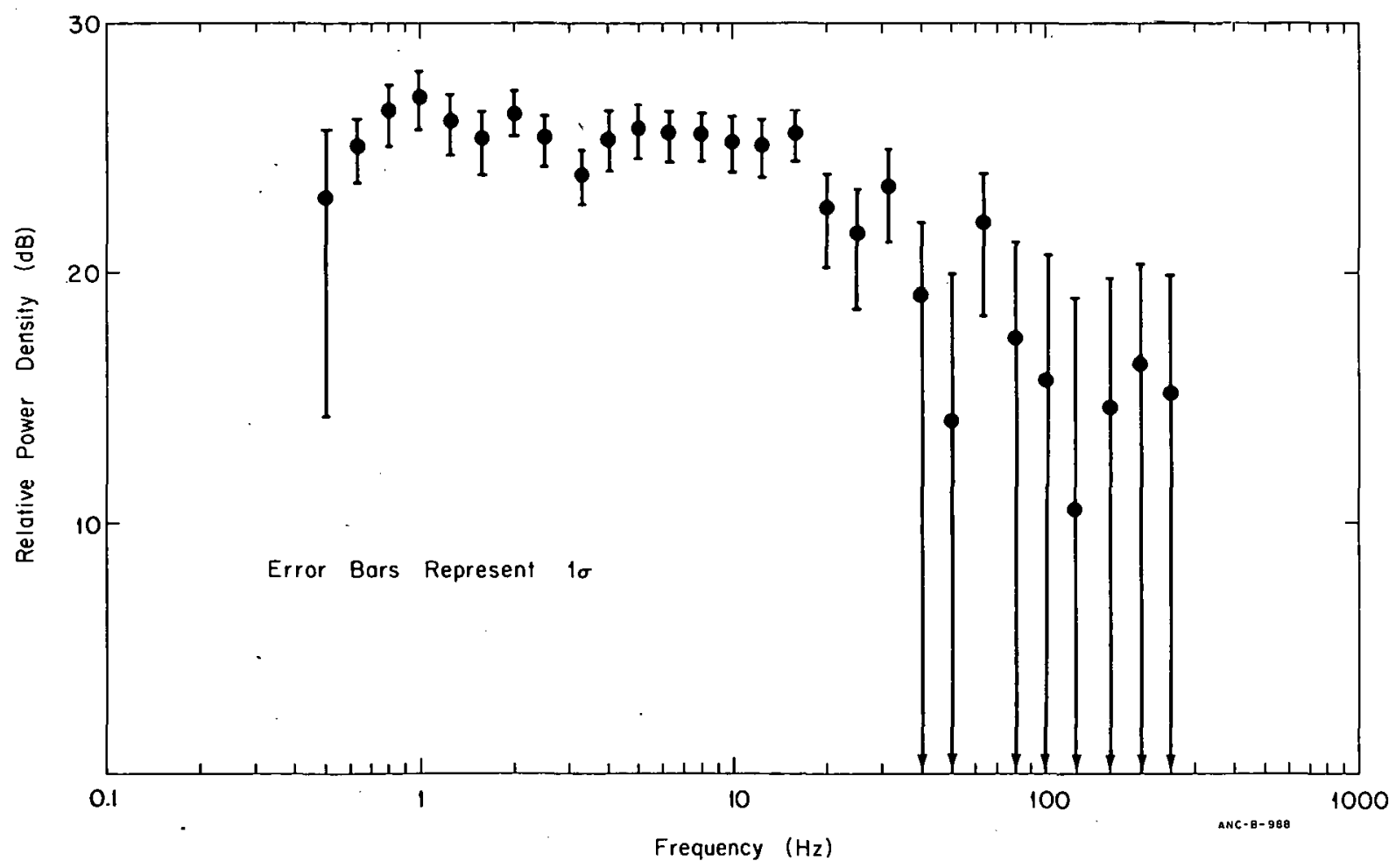

Fig. 27 ATRC cross-correlated power-spectral density obtained using an ion chamber in a dry tube outside of core at a power of about $650 \mathrm{~W}$. 
Individual output spectral densities comprising the total output spectral density of the, ATR as reactor power is increased are illustrated best in Figures 15 through 22 . The white noise component caused by the statistical nature of the detection process is clearly evident above $30 \mathrm{~Hz}$ in Figures 19 through 22 . This effect is not evident in Figures 15 through 18 because a cross-correlation method of analysis was used. The power spectral densities caused by vibration of the in-pile tubes are evident at approximately 4 and $7 \mathrm{~Hz}$, and power spectral densities presumably caused by vibration of unspecified core components occur at $11,13,15,18$, and $20 \mathrm{~Hz}$. The power spectral density at low frequencies is believed to be caused by vibration of many small core pieces with the composite low-frequency flow spectrum appearing as a continuum. The output power spectral density caused by fluctuations in the multiplication process is too small relative to the other output densities to be distinguishable. This was expected, particularly at higher reactor powers, because this component of the total density is proportional to reactor power in contrast to an approximate power-squared proportionality for contributions to the total density caused by vibration.

A quantitative intercomparison of the total output power spectral density at different reactor powers is only possible for the data shown in Figures 15 through 18 since different chamber efficiencies were used in obtaining the other data. Intercomparison of the output power spectral density at low frequencies caused by vibration of small core pieces and obtained at 2.5 ańd $50 \mathrm{MW}$ shows a dependence on reactor power raised to the exponent 1.98 with an estimated standard deviation of 0.01 . Intercomparison of similar data obtained at 50 and $80 \mathrm{MW}$ and intercomparison of data obtained at 80 and $125 \mathrm{MW}$ yield exponents for reactor power of less than two and greater than two, respectively. This inconsistency is believed to be the result of documenting incorrectly the electronic gain of the detection system used at $80 \mathrm{MW}$.

The logarithmic graphs of low-frequency output power spectral density shown in Figures 15 through 22 indicate that the driving source has a frequency dependence of 10 raised to an exponent proportional to inverse frequency. This frequency dependence of the source is believed to be different than that which has been observed in other testing reactors [12]. Again, it was not possible to determine the absolute frequency dependence of the driving source because some apparent preamplifier mismatch in the detection system gave rise to slightly different densities at low frequencies when the cross-or auto-correlation methods of analysis were used. 


\section{EXCESS REACTIVITY DURING CORE LIFE}

Curves of excess reactivity as a function of integrated power during Cores 2 and 3 indicate that (a) the fuel-boron mixture is acceptahle, (b) maximum core life is approximately $10,000 \mathrm{MWd}$, and (c) equilibrium xenon poisoning is about $\$ 5.4$. Reactivity comparison of Core 3 fuel elements at the end of Core 3 indicates that the loss of reactivity in a low-power lobe with standard fuel elements is essentially the same as the loss in a high-power lobe with $7 \mathrm{~F}$ fuel elements after about $6500 \mathrm{MWd}$.

\section{CORE 2 AND CORE 3 EXCESS REACTIVITY}

Excess reactivity as a function of power-time has been determined for ATR Cores 2 and 3 from (a) shim position data as a function of MWd in Core 2, Core 3, and Cycle 1B, and (b) reactivity measurements made in the ATRC mock-up of Core 2 . These data show the excess reactivity to be nearly constant for approximately $1800 \mathrm{MWd}$ aftcr initial xenon equilibrium had been reached and, thereafter, a slowly decreasing function of power-time.

The plots of excess reactivity as a function of MWd for Cores 2 and 3 are shown in Figures 28 and 29, respectively. In both figures Cycle $1 B$ data were used to determine the

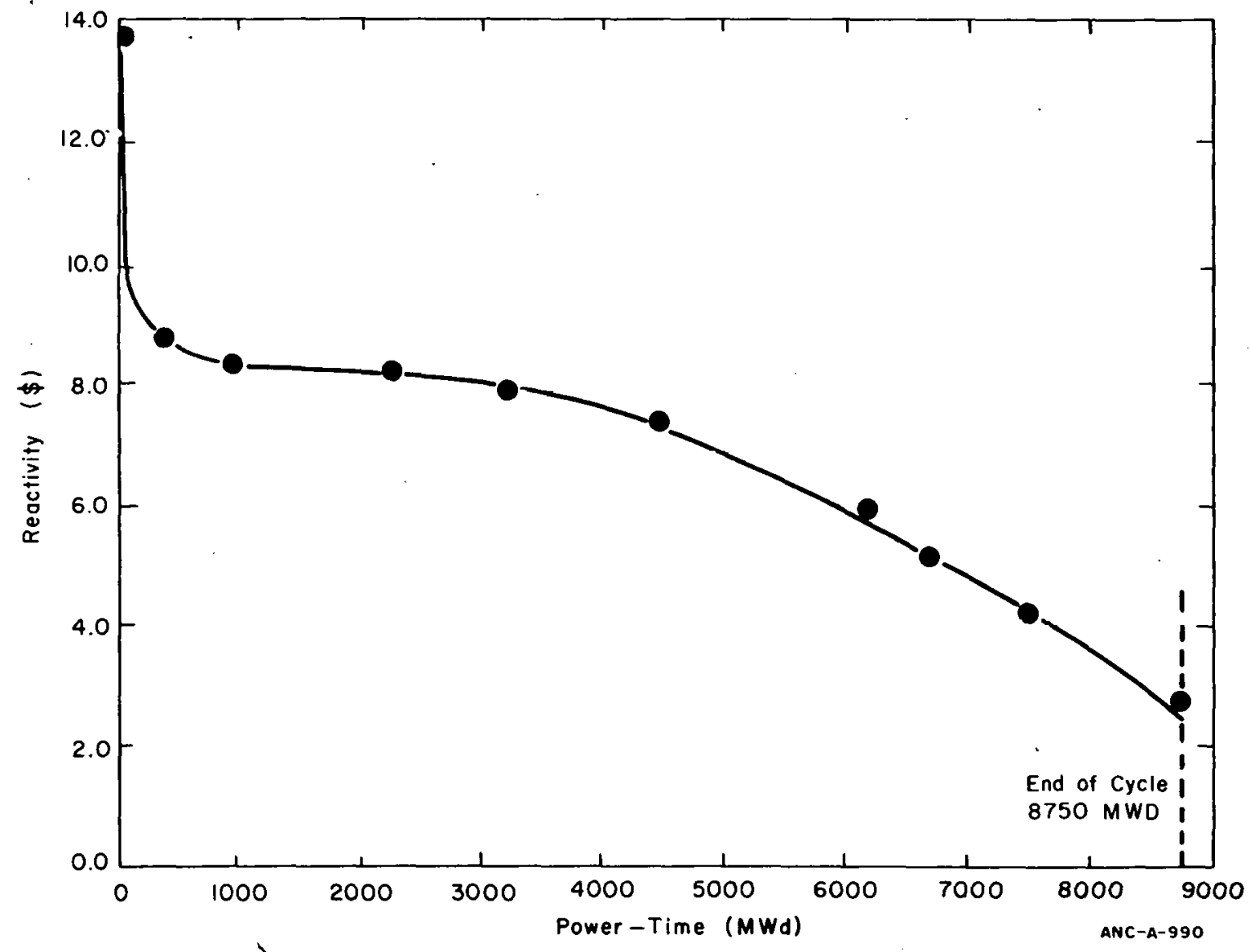

Fig. 28 Excess reactivity in Core 2 as a function of power-time. 


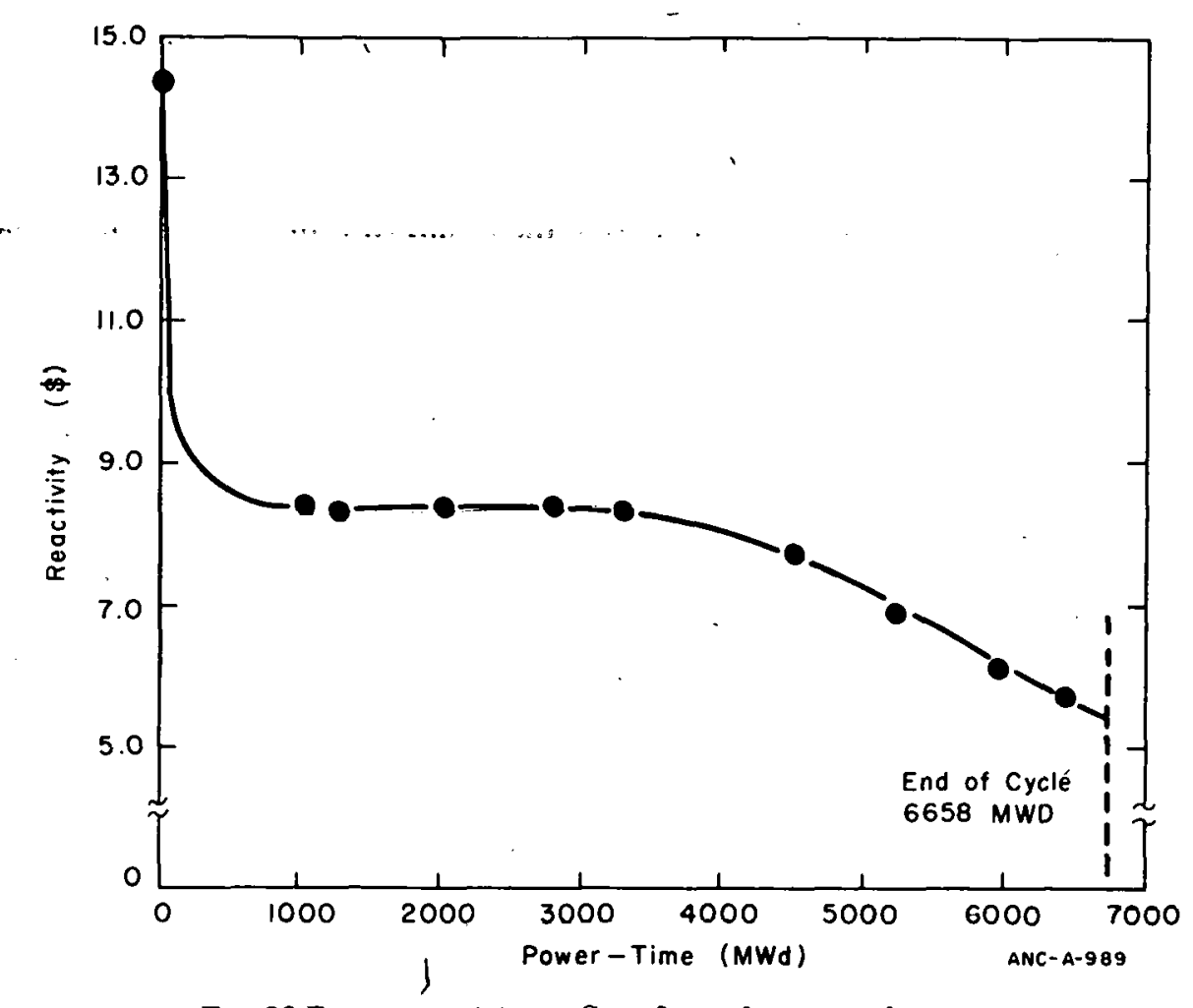

Fig. 29 Excess reactivity in Core 3 as a function of power-time.

shape of the curves for those times where shim positions for xenon equilibrium during Cores 2 and 3 were not available. The implied reactivity effect for initial xenon equilibrium for Cores 2 and 3 from these figures is $\$ 5.6$ and $\$ 6.1$, respectively. However, the excess reactivity for $0 \mathrm{MWd}$ was determined using shim positions at criticality obtained at essentially zero reactor power and with the reactor and experiment loops at operating temperatures. The power coefficient for ATR indicates a reactivity feedback of -0.15 for an increase in power of $1 \mathrm{MW}$ (see Section VII). Since the reactivity feedback for a $250-\mathrm{MW}$ increase in power is $\$ 0.4$, the two xenon equilibrium reactivity values corrected for this reactivity effect are $\$ 5.2$ and $\$ 5.7$. These values are in agreement with the accepted nominal reactivity value for xenon equilibrium poisoning of $\$ 5.4$.

The initial excess reactivities for Cores 2 and 3 are shown in Figures 28 and 29 to be $\$ 13.8$ and $\$ 14.5$, respectively. Core 3 was known to have more excess reactivity than Core 2 by approximately $\$ 0.6$ because of experiment differences and because of a lower center loop temperature in Core 2 relative to Core 3. This suggests an excess reactivity difference of $\$ 0.6$ between the two cores, whereas the excess reactivity data show a difference of $\$ 0.7$. These values are in good agreement and indicate that the excess reactivity values are reliable.

Reactivity measurements were made in the ATRC mock-up of Core 2 in order to determine more accurately the excess reactivity of Core 2 as a function of MWd and the initial available excess reactivity. The excess reactivity at various cycle times (MWd) during Core 2 was simulated by adding borated plastic strips uniformly to the water channels of the fuel elements in nine different loading steps. For each boron loading step the outer shim differential worths and the worth of each of the neck shims were determined. It was then 
possible to determine the difference in excess reactivity between each boron loading step. In addition, the outer shims and neck shims were manipulated at each boron loading step until they corresponded with the shim configuration of the ATR (at xenon equilibrium) at some time during the life of Core 2. This gave the relationship of boron step to MWd of Core 2 . The total excess reactivity of ATR Core 2 was found by summing the changes in excess reactivity between each boron loading step and the amount of reactivity left in the shims from the last boron loading step. Thus, knowing the initial excess reactivity and the change in excess reactivity between different times (MWd) in the cycle, a plot of excess reactivity as a function of power-time for Core 2 was determined.

The change in excess reactivity between two different times in Core 3 was determined by (a) noting the change in shim positions arıd (b) calculating the reactivity change for this shim movement by appropriately weighting the outer shim curves for the unbalanced power division. The worth of withdrawing neck shims in the unbalanced power division was determined by appropriately weighting the neck shim worths for a flat power distribution. By determining these incremental changes in excess reactivity, it was possible to determine the initial excess reactivity and to plot excess reactivity as a function of power-time for Core 3.

\section{FUEL ELEMENT REACTIVITY COMPARISONS AT THE END OF CORE 3}

During Core 3 operation the fuel burnup in a high-power (60 MW) lobe was 1.5 times the burnup in a low-power (10 MW) lobe. With this rather large discrepancy in burnup, it would appear that some fuel savings could be realized by recycling the fuel elements from the low-power lobes after the fuel in the high-power lobes was depleted. One of the simplest methods of recycling would be an interchange of fuel elements between the high- and low-power lobes near the end of core life. Although this type of recycling could not be accomplished in Core 3 due to fuel element performance considerations, the data necessary to evaluate such recycling could be useful in considering recycling in later cores. Consequently, the reactivity difference between fuel elements in the low- and high-power lobes was measured at the end of Core 3 operation.

Following the end-of-life flux monitor irradiation described in Section VIII of this report, the fuel elements in the NE lobe were moved to the SE lobe (final SE loading is a reflection of NE lobe loading about an E-W line), the fuel elements in the SE lobe were moved to the SW lobe (SE loading reflected about a N-S line), the fuel elements in the SW lobe were moved to the NW lobe (SW loading reflected about an E-W line), and the NW lobe loading moved to the NE lobe (NW loading reflected about a N-S line). The resultant loading consisted of 7F fuel elements [5] in the NE and SW lobes and standard fuel elements in the $\mathrm{NW}, \mathrm{SE}$, and center lobes. (Note that center lobe fuel elements were not relocated.) The shim positions for criticality were then established in the nominally 40-50-60 power division. Comparison of shim positions during the flux monitor irradiation and shim positions following this fuel element exchange indicated the reactivity difference between the high- and low-power lobe fuel elements. (Corrections were made for differences in the $\mathrm{Xe}-\mathrm{Sm}$ concentrations as a result of the time lapse between the two measurements.) A summary of the shim positions and the calculated Xe-Sm poisoning before and after the fuel element exchange is shown in Table III. 


\section{TABLE ITT.}

SUMMARY OF DATA FOR FUEL ELEMENT EXCHANGE IN CORE 3

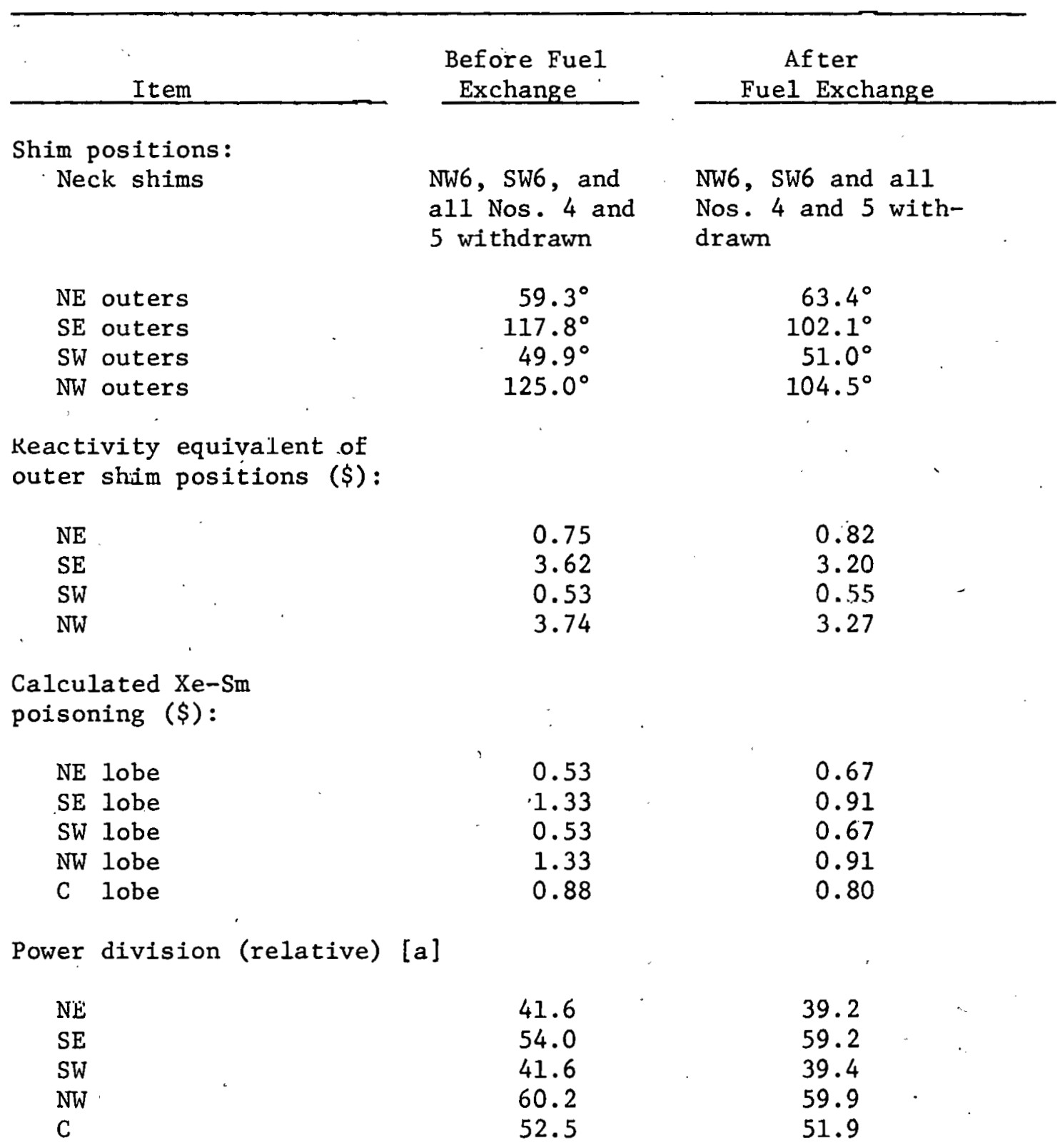

[a] The "before" power division is based on the irradiation data; the "after" power division is based on $16_{\mathrm{N}}$ lobe power monitor data. 
Exchanging fuel elements between the high- and low-power lobes would not have extended the core life of Core 3 since the fuel elements apparently have the same reactivity effect. (Core 3 operation was terminated due to the lack of available shim motion to maintain the high-power lobes at $60 \mathrm{MW}$.) This also means that the additional fuel in the $7 \mathrm{~F}$ elements (100 g more per element) resulted in a longer core life for Core 3 than could have been obtained with standard fuel elements. (Note that $7 \mathrm{~F}$ elements are required for operation at $60 \mathrm{MW}$ lobe power due to thermal stress considerations.) The estimated increase in operating time due to the $7 \mathrm{~F}$ fuel elements is nine days.

The high-power lobes contained eight $7 \mathrm{~F}$ fuel elements each $(8600 \mathrm{~g} 235 \mathrm{U})$, and the low-power lobes contained eight standard fuel elements cach $(7800 \mathrm{~g} 235 \mathrm{U})$. The estimated fuel content at the end of Core 3 is $6600 \mathrm{~g}$ for the eight $7 \mathrm{~F}$ elements and $6470 \mathrm{~g}$ for the eight standard elements. Although the initial distribution of fuel in the two types of elements is different, this measurement suggests that the fuel elements have a similar fuel distribution and content at the end of Core 3. (It is assumed that the difference in the final boron contents of the elements is negligible.)

The errors in the measurement result from uncertainties in the power divisions before and after the fuel element exchange, uncertainties in the shim worths, and uncertainties in the calculated Xe-Sm poisoning. The errors in these quantities are estimated to be $10 \%$ or less. The most significant error would probably be a $10 \%$ error in the power division. However, the difference in the reactivity effect for the burnup of the two types of elements is so small that the general conclusions reached are still valid. 


\section{POWER COEFFICIENT MEASUREMENTS}

The power coefficient of reactivity (ie, reactivity per MW change in power) in the ATR at full power represents a quantity frequently used in ATR safety analysis. A reasonably good measurement of this coefficient was obtained at the beginning as well as at the end of core life during Core 3.

The difference in excess reactivity between two different stable power levels, if coolant flow and reactor inlet temperature are held constant, is due to temperature differences throughout the reactor and the change in fission product inventory. The temperature differences arising from a power change are proportional to the power change, but their, magnitudes differ in the various parts of the core. These temperature differences cause a change in excess reactivity due to thermal expansion in the fuel, coolant, and structural materials. However, during a relatively fast power transient the reactivity feedback of the reactor is due primarily to the fast-acting temperature effects in the reactor and the changing fission product inventory. The fast-acting temperature effects would be those due to temperature changes in the fuel and in the reactor coolant and structure in the immediate vicinity of the fuel. The power coefficient as measured in the ATR is a measure of the reactivity feedback effect arising from only the fast-acting temperature effects in the reactor per megawatt change in reactor power.

The results of the power coefficient measurements at the beginning and end of core life in Core 3 indicate:

(1) The reactivity feedback from the fast-acting temperature effects in the reactor is $-0.15 \notin \pm 0.01 \notin$ per megawatt increase in reactor power

(2) The moderator reactivity feedback is negative

(3) The dependence of the moderator reactivity feedback on burnup (up to 6600 MWd) is within the uncertainty of the measurement.

The technique used to determine the power coefficient was to reduce power quickly using the servo system (ie, the "lower" switch on the MOR) and to allow the servo system to "track" the resultant reactivity transient. The position of the regulating rod and the output from a neutron level recorder were scanned approximately four times per second by the ATR data system and stored on magnetic tape. Plots of the regulating rod position and reactor power (determined from the neutron level recorder output) as a function of time from one of the power coefficient measurements are shown in Figure 30.

The reactivity transient after the power reduction was divided into two time periods: first, a nearly instantaneous reactivity effect resulting from the change in fuel and moderator temperatures and the initial excess of delayed neutron precursors; and second, a transient reactivity resulting from changes in fission product poison concentration, temperatures changing throughout the reactor, and the delayed neutron precursor 


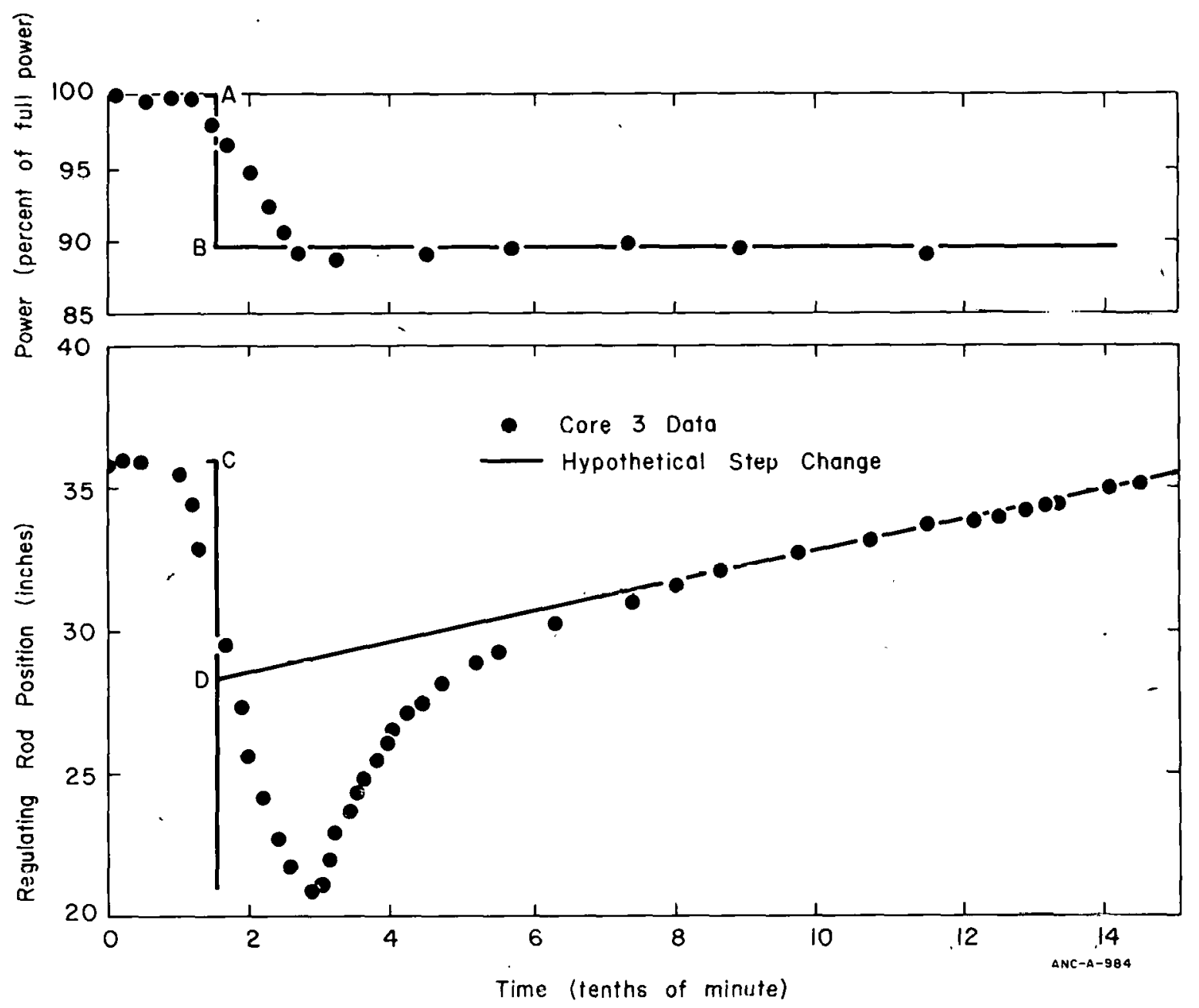

Fig. 30 Power and regulating rod position as a function of time for the power coefficient measurement.

population changing. The reactivity appropriate for the determination of the power coefficient is the initial or nearly instantaneous reactivity difference between the two power levels. Since the regulating rod did not react instantaneously to a reactivity change, the nearly instantaneous reactivity change in the reactor is not clearly defined in Figure 30, ie, it is smeared in with the reactivity transient following the power change.

The initial reactivity change is indicated by the hypothetical step- change curve drawn in Figure 30. This curve was established by extrapolating the approximately linear (with time) motion of the regulating rod following the change in power level back to the point in time at which half of the regulating rod motion had occurred in the actual experiment. The power level change in this case is indicated by points $A$ and $B$ in Figure 30, and the instantaneous change in regulating rod position due to the power level change is indicated by points $C$ and $D$. Using the reactivity calibration curve of the regulating rod, the reactivity equivalent of the change in regulating rod position was determined. These quantities were then used to obtain the power coefficient. 


\section{NEUTRON FLIUX DISTRIBUTIONS}

Detailed power distribution data obtained in ATR as a function of core life provide valuable information for the development of calculational models. The difficulty of obtaining such data necessitated compromise measurements of neutron flux near the fuel annulus. Data were obtained at the beginning and end of life for both Cores 2 and 3 to provide a comparison with calculations. The comparisons are not yet available, and the experimental data are reported here for future use by others.

\section{BEGINNING-AND END-OF-LIFE NEUTRON FLUX DISTRIBUTIONS}

Thermal and fast $(>1 \mathrm{MeV})$ neutron fluxes were measured in typical capsule irradiation positions and in the annulus of all flux traps except the west flux trap at the beginning and end of life in both Cores 2 and 3 . The core-midplane values obtained in these measurements are shown in Tables IV through VII. Approximate core locations for these data are shown in Figures 1 and 31. The conditions for each of the irradiations are summarized in Table VIII. Both end-of-life irradiations were delayed until at least 72 hours after scram from full power in order to allow the fission-product inventory to return to the approximate prescram reactivity value. The fission-product inventory was not changing rapidly after about 72 hours, and shim movement during the irradiation was minimized.

The data in Tables IV through VII have not been normalized to account for the differences in the power divisions for each measurement. The data are shown for the power level and power division for each irradiation. It was assumed prior to the irradiations that the total core power could be determined from activation data for gold wire in capsule experiment positions I-I and OS-20. (Base data for gold were obtained during Core 1 operation.) However, due to an apparent outer shim position effect on the neutron flux distribution in these positions, the data are not usable. Additionally, data obtained from the $16_{\mathrm{N}}$ lobe power monitors at these relatively low power levels are not consistent with data obtained during full-power operation. Consequently, an alternate method of determining the power divisions has been used.

The Core 2 beginning-of-life power division was assumed to be the same as that measured in the ATRC mock-up for Core 2. The absolute power was set by assuming that the average fast neutron flux in the $\mathrm{H}$-holes is directly proportional to the center lobe power. The fluence data obtained in the H-holes during Cores 2 and 3 operation were used to obtain the relationship between fast neutron flux in the H-holes and the center lobe power. Power generations and power divisions for the other three irradiations have been obtained by comparing the fast neutron flux obtained in each of the lobes with data obtained in the same positions during the Core 2 beginning-of-life irradiation. Lobe powers have been determined by requiring that the ratio of the average fast neutron flux in the safety rod positions of the NW, SW, and SE lobes and the corresponding lobe powers be the same as the ratio in the Core 2 beginning-of-life irradiation. Similarly, the average fast

neutron flux in the H-holes and the NE dummy flux trap filler was used to assign lobe powers in the center and NE lobes, respectively. 
TABLE IV

CORE MIDPLANE NEUTRON FLUX DATA OBTAINED AT THE BEGINNING OF CORE 2

\begin{tabular}{|c|c|c|c|c|}
\hline Position & $\begin{array}{c}\text { Holder } \\
\text { No. }\end{array}$ & $\begin{array}{c}\text { Fast } \\
\text { Neutron Flux } \\
\left(1012 \mathrm{n} / \mathrm{cm}^{2} \mathrm{sec}\right) \\
\end{array}$ & $\begin{array}{c}\text { Thermal } \\
\text { Neutron Flux } \\
\left(1012 \mathrm{n} / \mathrm{cm}^{2} \mathrm{sec}\right) \\
\end{array}$ & $\begin{array}{c}\text { Resonance [a] } \\
\text { Correction } \\
(\%)\end{array}$ \\
\hline$A-9$ & $A-5$ & 3.29 & 2.25 & 18 \\
\hline 10 & 6 & 3.16 & 2.04 & 18 \\
\hline 11 & 7 & 3.36 & 2.01 & 18 \\
\hline 12 & 8 & 3.28 & 2.01 & 18 \\
\hline$B-1$ & $\mathrm{R}-1$ & 1.46 & 3.37 & 10 \\
\hline 3 & 2 & 1.49 & 3.34 & 10 \\
\hline 4 & 3 & 1.51 & 3.13 & 10 \\
\hline 5 & 4 & 1.54 & 3.31 & 10 \\
\hline 6 & 5 & 1.53 & 3.52 & 10 \\
\hline 7 & 6 & 1.43 & 3.50 & 10 \\
\hline $\mathrm{H}-2$ & $\mathrm{H}-5$ & 2.59 & 2.61 & 16 \\
\hline 6 & 6 & 2.54 & 2.63 & 16 \\
\hline 10 & 7 & 2.58 & 2.57 & 16 \\
\hline 14 & 8 & 2.58 & 2.58 & 16 \\
\hline$I-11$ & $\mathrm{R}-7$ & 0.009 & 0.36 & 2 \\
\hline 13 & 8 & 0.018 & 0.44 & 2 \\
\hline$N W-1$ & SR-22 & 2.34 & 2.61 & 14 \\
\hline 2 & 23 & 2.42 & 2.69 & 14 \\
\hline 3 & 24 & 1.92 & 2.44 & 14 \\
\hline 4 & 21 & 2.00 & 2.28 & 14 \\
\hline$N-1$ & SR-34 & 1.71 & 3.47 & 12 \\
\hline 2 & missing & missing & missing & missing \\
\hline 3 & 27 & 2.59 & 3.22 & 14 \\
\hline 4 & 28 & 1.23 & 3.63 & 10 \\
\hline $\mathrm{NE}-1$ & $D-9$ & 2.10 & 3.03 & 11 \\
\hline 2 & 10 & 2.34 & 3.10 & 11 \\
\hline 3 & 11 & 2.44 & 3.52 & 11 \\
\hline 4 & 12 & 2.42 & 3.26 & 11 \\
\hline SW-1 & $S R-29$ & 2.44 & 2.62 & 14 \\
\hline . 2 & 30 & 2.20 & 2.40 & 14 \\
\hline 3 & 31 & 2.05 & 2.25 & 14 \\
\hline 4 & 32 & 2.46 & 2.48 & 14 \\
\hline$s-1$ & SR-26 & 2.34 & 3.08 & 14 \\
\hline 2 & 35 & 1.25 & 3.33 & 10 \\
\hline 3 & 36 & 1.88 & 3.12 & 12 \\
\hline 4 & 33 & 2.44 & 3.04 & 14 \\
\hline
\end{tabular}


TABLE IV' (Contd.)

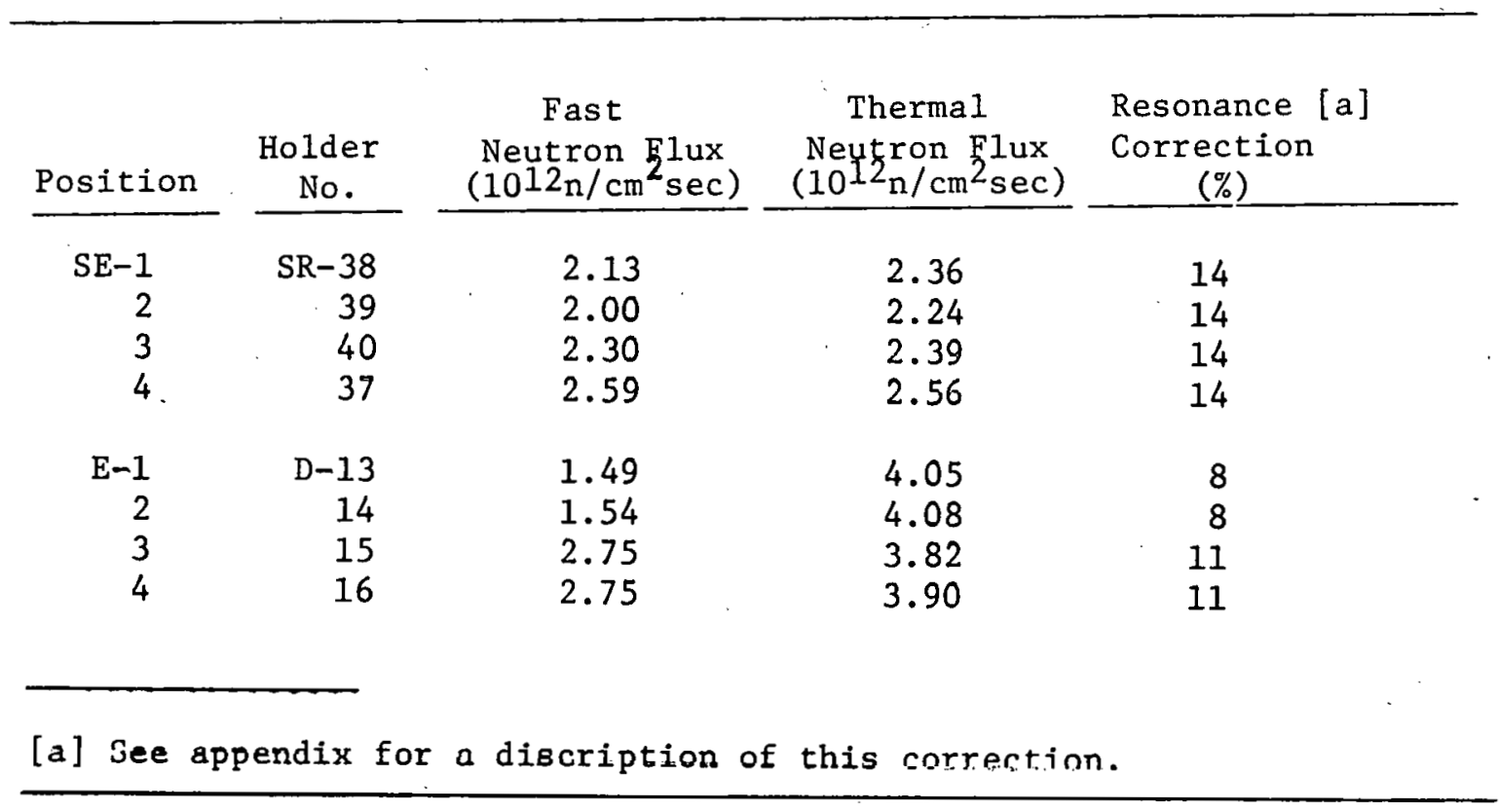




\section{TABLE $V$}

CORE MIDPLANE NEUTRON FLUX DATA OBTAINED AT THE END OF CORE 2

\begin{tabular}{|c|c|c|c|c|}
\hline Position & $\begin{array}{l}\text { Holder } \\
\text { No. }\end{array}$ & $\begin{array}{c}\text { Fast } \\
\text { Neutron Flux } \\
\left(1012 \mathrm{n} / \mathrm{cm}^{2} \mathrm{sec}\right) \\
\end{array}$ & $\begin{array}{l}\text { Thermal } \\
\text { Neutron Flux } \\
\left(1012 \mathrm{n} / \mathrm{cm}^{2} \mathrm{sec}\right)\end{array}$ & $\begin{array}{l}\text { Resonance } \\
\text { Correction } \\
(\%) \\
\end{array}$ \\
\hline $\begin{array}{r}A-9 \\
10 \\
11 \\
12\end{array}$ & $\begin{array}{r}A-13 \\
14 \\
15 \\
16\end{array}$ & $\begin{array}{l}3.29 \\
3.29 \\
3.26 \\
3.26\end{array}$ & $\begin{array}{l}3.72 \\
3.45 \\
3.37 \\
3.58\end{array}$ & $\begin{array}{l}15 \\
15 \\
15 \\
15\end{array}$ \\
\hline $\begin{array}{r}\text { B-1 } \\
3 \\
4 \\
5 \\
6 \\
7\end{array}$ & $\begin{array}{r}\text { R-19 } \\
20 \\
21 \\
22 \\
23 \\
24\end{array}$ & $\begin{array}{l}1.57 \\
1.59 \\
1.59 \\
2.42 \\
1.62 \\
1.65\end{array}$ & $\begin{array}{l}5.50 \\
5.31 \\
5.39 \\
5.17 \\
5.48 \\
5.53\end{array}$ & $\begin{array}{l}10 \\
10 \\
10 \\
10 \\
10 \\
10\end{array}$ \\
\hline $\begin{array}{r}\mathrm{H}-2 \\
6 \\
10 \\
14\end{array}$ & $\begin{array}{r}\mathrm{H}-13 \\
14 \\
15 \\
16\end{array}$ & $\begin{array}{l}2.38 \\
2.35 \\
2.42 \\
2.33\end{array}$ & $\begin{array}{l}2.97 \\
3.11 \\
2.98 \\
3.08\end{array}$ & $\begin{array}{l}16 \\
16 \\
16 \\
16\end{array}$ \\
\hline $\begin{array}{r}I-11 \\
13\end{array}$ & $\begin{array}{r}R-25 \\
26\end{array}$ & $\begin{array}{l}0.010 \\
0.022\end{array}$ & $\begin{array}{l}0.25 \\
0.45\end{array}$ & $\begin{array}{l}2 \\
2\end{array}$ \\
\hline $\begin{array}{r}\text { NW-1 } \\
2 \\
3 \\
4\end{array}$ & $\begin{array}{r}\text { SR-61 } \\
62 \\
63 \\
64\end{array}$ & $\begin{array}{l}2.52 \\
2.52 \\
2.35 \\
2.26\end{array}$ & $\begin{array}{l}3.57 \\
3.75 \\
3.53 \\
3.31\end{array}$ & $\begin{array}{l}13 \\
13 \\
13 \\
13\end{array}$ \\
\hline $\begin{array}{r}\mathrm{N}-1 \\
2 \\
3 \\
4\end{array}$ & $\begin{array}{r}S R-65 \\
66 \\
67 \\
68\end{array}$ & $\begin{array}{l}1.87 \\
2.54 \\
2.47 \\
1.22\end{array}$ & $\begin{array}{l}4.53 \\
4.24 \\
4.15 \\
4.71\end{array}$ & $\begin{array}{l}13 \\
13 \\
13 \\
13\end{array}$ \\
\hline $\begin{array}{r}\mathrm{NE}-1 \\
2 \\
3 \\
4\end{array}$ & $\begin{array}{r}\mathrm{D}-25 \\
26 \\
27 \\
28\end{array}$ & $\begin{array}{l}2.33 \\
2.61 \\
2.42 \\
2.49\end{array}$ & $\begin{array}{l}4.24 \\
4.42 \\
4.71 \\
4.35\end{array}$ & $\begin{array}{l}11 \\
11 \\
11 \\
11\end{array}$ \\
\hline $\begin{array}{r}\text { SW-1 } \\
2 \\
3 \\
4\end{array}$ & $\begin{array}{r}\text { SR-69 } \\
70 \\
71 \\
72\end{array}$ & $\begin{array}{l}2.42 \\
2.40 \\
2.28 \\
2.51\end{array}$ & $\begin{array}{l}3.46 \\
3.25 \\
3.16 \\
3.27\end{array}$ & $\begin{array}{l}13 \\
13 \\
13 \\
13\end{array}$ \\
\hline
\end{tabular}




\section{TABLE V (Conte)}

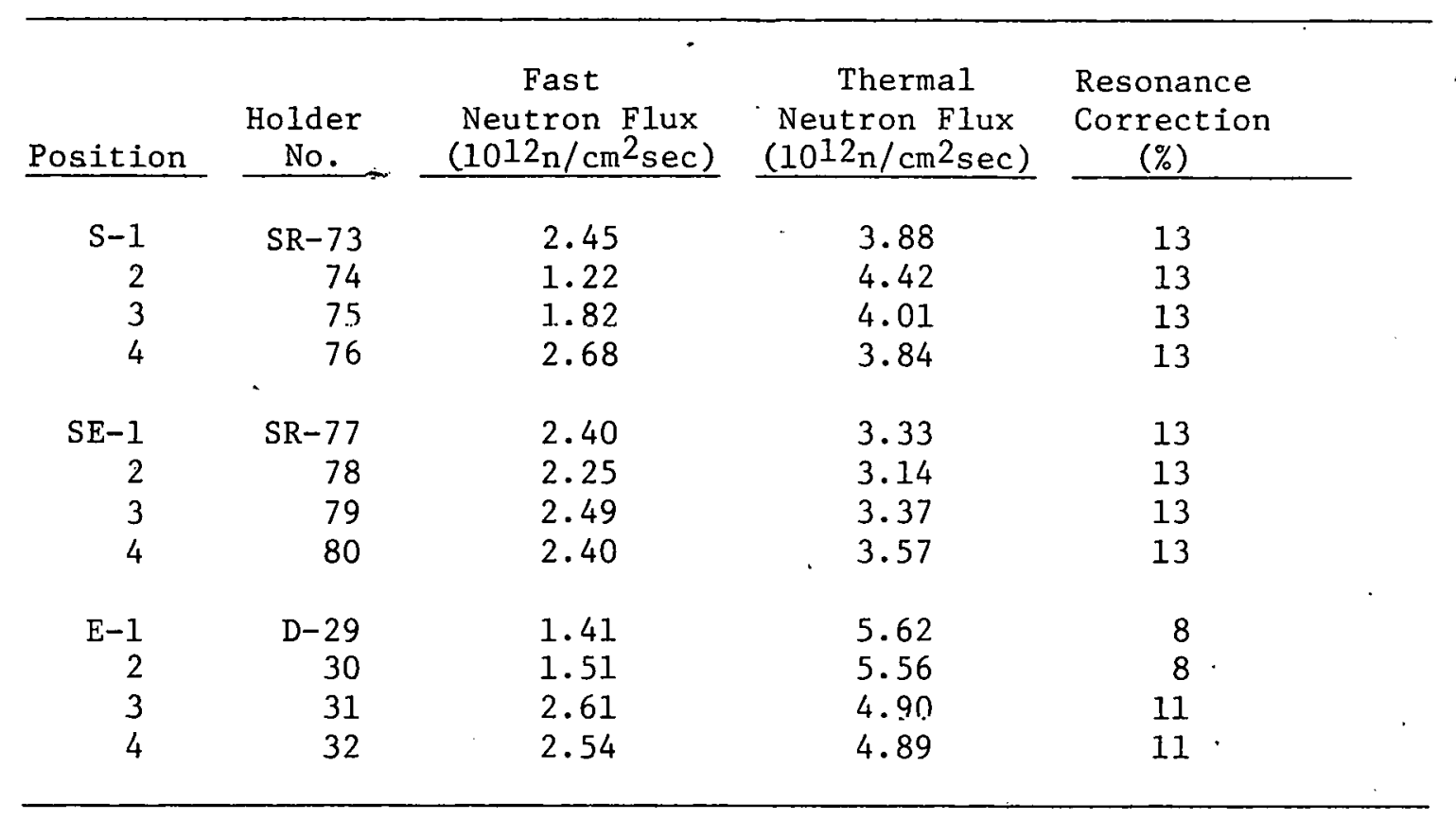




\section{TABLE VI}

CORE MIDPLANE NEUTRON FLUX DATA OBTAINED AT THE BEGINNING OF CORE 3

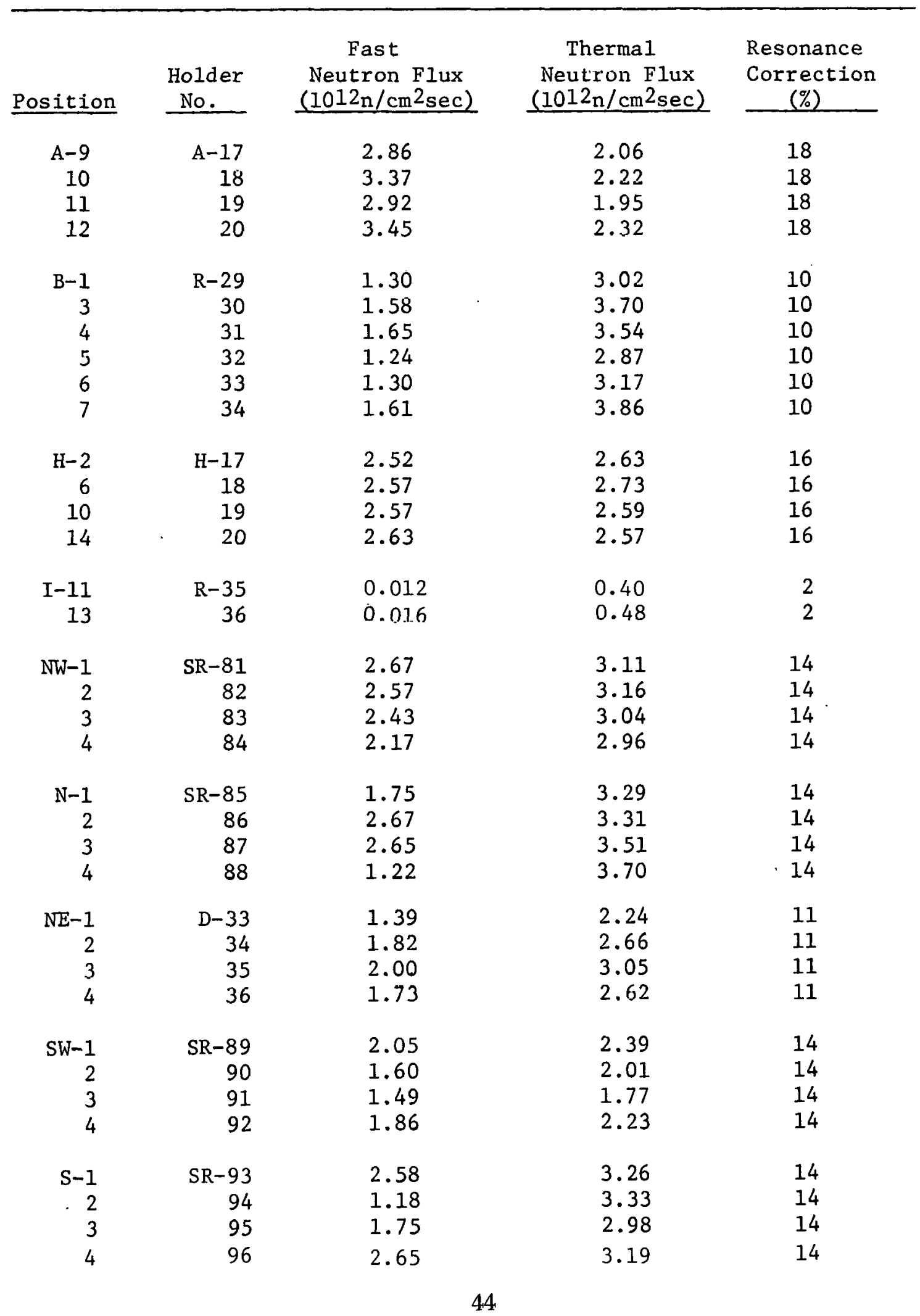


ṪABBLE VI. (Contd.)

\begin{tabular}{|c|c|c|c|c|}
\hline Position & $\begin{array}{l}\text { Holder } \\
\text { No. }\end{array}$ & $\begin{array}{c}\text { Fast } \\
\text { Neutron Flux } \\
\left(10^{12} \mathrm{n} / \mathrm{cm}^{2} \mathrm{sec}\right) \\
\end{array}$ & $\begin{array}{c}\text { Thermal } \\
\text { Neutron Flux } \\
\left(1012 \mathrm{n} / \mathrm{cm}^{2} \mathrm{sec}\right)\end{array}$ & $\begin{array}{c}\text { Resonance } \\
\text { Correction } \\
(\%) \\
\end{array}$ \\
\hline SE-1 & SR-97 & 2.52 & 3.15 & 14 \\
\hline 2 & 98 & 2.37 & 3.07 & 14 \\
\hline 3 & 99 & 2.23 & 2.82 & 14 \\
\hline 4 & 100 & 2.52 & 2.95 & 14 \\
\hline$E-1$ & $D-37$ & 1.81 & 4.17 & 8 \\
\hline 2 & 38 & 1.58 & 4.26 & 8 \\
\hline 3 & 39 & 2.82 & 3.97 & 11 \\
\hline 4 & 40 & 2.73 & 3.76 & 11 \\
\hline
\end{tabular}


CORE MIDPLANE NEUTRON FLUX DATA OBTAINED AT THE END OF CORE 3

\begin{tabular}{|c|c|c|c|c|}
\hline Position & $\begin{array}{c}\text { Holder } \\
\text { No. }\end{array}$ & $\begin{array}{c}\text { Fast } \\
\text { Neutron Flux } \\
\left(1012 \mathrm{n} / \mathrm{cm}^{2} \text { sec }\right) \\
\end{array}$ & $\begin{array}{c}\text { Thermal } \\
\text { Neutron Flux } \\
\left(1012 \mathrm{n} / \mathrm{cm}^{2} \mathrm{sec}\right) \\
\end{array}$ & $\begin{array}{c}\text { Resonance } \\
\text { Correction } \\
(\%) \\
\end{array}$ \\
\hline$A-9$ & $A-25$ & 2.33 & 2.03 & 15 \\
\hline 10 & 26 & 2.62 & 2.45 & 15 \\
\hline 11 & 27 & 2.39 & 2.41 & 15 \\
\hline 12 & 28 & 2.94 & 3.09 & 15 \\
\hline$B-1$ & $R-47$ & 1.09 & 3.10 & 10 \\
\hline 3 & 48 & 1.25 & 4.06 & 10 \\
\hline 4 & 49 & 1.28 & 3.99 & 10 \\
\hline 5 & 50 & 1.09 & 2.70 & 10 \\
\hline 6 & 51 & 1.09 & 3.18 & 10 \\
\hline 7 & 52 & 1.38 & 4.52 & 10 \\
\hline $\mathrm{H}-2$ & $\mathrm{H}-25$ & 1.97 & 2.34 & 16 \\
\hline 6 & 26 & 1.97 & 2.48 & 16 \\
\hline 10 & 27 & 1.93 & 2.28 & 16 \\
\hline 14 & 28 & 2.00 & 2.34 & 16 \\
\hline$I-11$ & $R-53$ & 0.006 & 0.25 & 2 \\
\hline 13 & 54 & 0.012 & 0.36 & 2 \\
\hline$N W-1$ & SR-122 & 2.12 & 3.30 & 13 \\
\hline 2 & 123 & 2.18 & 3.37 & 13 \\
\hline 3 & 124 & 2.19 & 3.17 & 13 \\
\hline 4 & 121 & 2.09 & 3.04 & 13 \\
\hline$N-1$ & SR-126 & 1.39 & 3.25 & 13 \\
\hline 2 & 127 & 2.09 & 3.12 & 13 \\
\hline 3 & 128 & 2.12 & 3.39 & 13 \\
\hline 4 & 125 & 1.01 & 3.76 & 13 \\
\hline $\mathrm{NE}-1$ & $\mathrm{p}-49$ & 1.33 & 2.29 & 11 \\
\hline 2 & 50 & 1.54 & 2.59 & 11 \\
\hline 3 & 51 & 1.61 & 2.79 & 11 \\
\hline 4 & 52 & 1.57 & 2.52 & 11 \\
\hline SW-1 & $S R-130$ & 1.70 & 2.42 & 13 \\
\hline 2 & 131 & 1.39 & 1.97 & 13 \\
\hline 3 & 132 & 1.24 & 1.74 & 13 \\
\hline 4 & 129 & 1.66 & 2.13 & 13 \\
\hline$s-1$ & SR-134 & 1.96 & 3.25 & 13 \\
\hline 2 & 135 & 0.951 & 3.33 & 13 \\
\hline 3 & 136 & 1.33 & 2.63 & 13 \\
\hline 4 & 133 & 2.08 & 2.90 & 13 \\
\hline
\end{tabular}




\begin{tabular}{|c|c|c|c|c|}
\hline Position & $\begin{array}{l}\text { Holder } \\
\text { No. }\end{array}$ & $\begin{array}{c}\text { Fast } \\
\text { Neutron Flux } \\
\left(1012 \mathrm{n} / \mathrm{cm}^{2} \mathrm{sec}\right) \\
\end{array}$ & $\begin{array}{c}\text { Thermal } \\
\text { Neutron F1ux } \\
\left(10^{12} \mathrm{n} / \mathrm{cm}^{2} \mathrm{sec}\right)\end{array}$ & $\begin{array}{l}\text { Resonance } \\
\text { Correction } \\
(\%) \\
\end{array}$ \\
\hline$S E-1$ & $S R-138$ & 1.91 & 2.99 & 13 \\
\hline 2 & 139 & 1.91 & 2.82 & 13 \\
\hline 3. & 140 & missing & 2.83 & 13 \\
\hline 4 & 137 & 2.00 & 2.96 & 13 \\
\hline$E-1$ & $D-53$ & 0.981 & 3.74 & 8 \\
\hline 2 & 54 & 1.18 & 4.07 & 8 \\
\hline 3 & 55 & 2.23 & 3.62 & 11 \\
\hline 4 & 56 & 1.90 & 3.45 & 11 \\
\hline
\end{tabular}

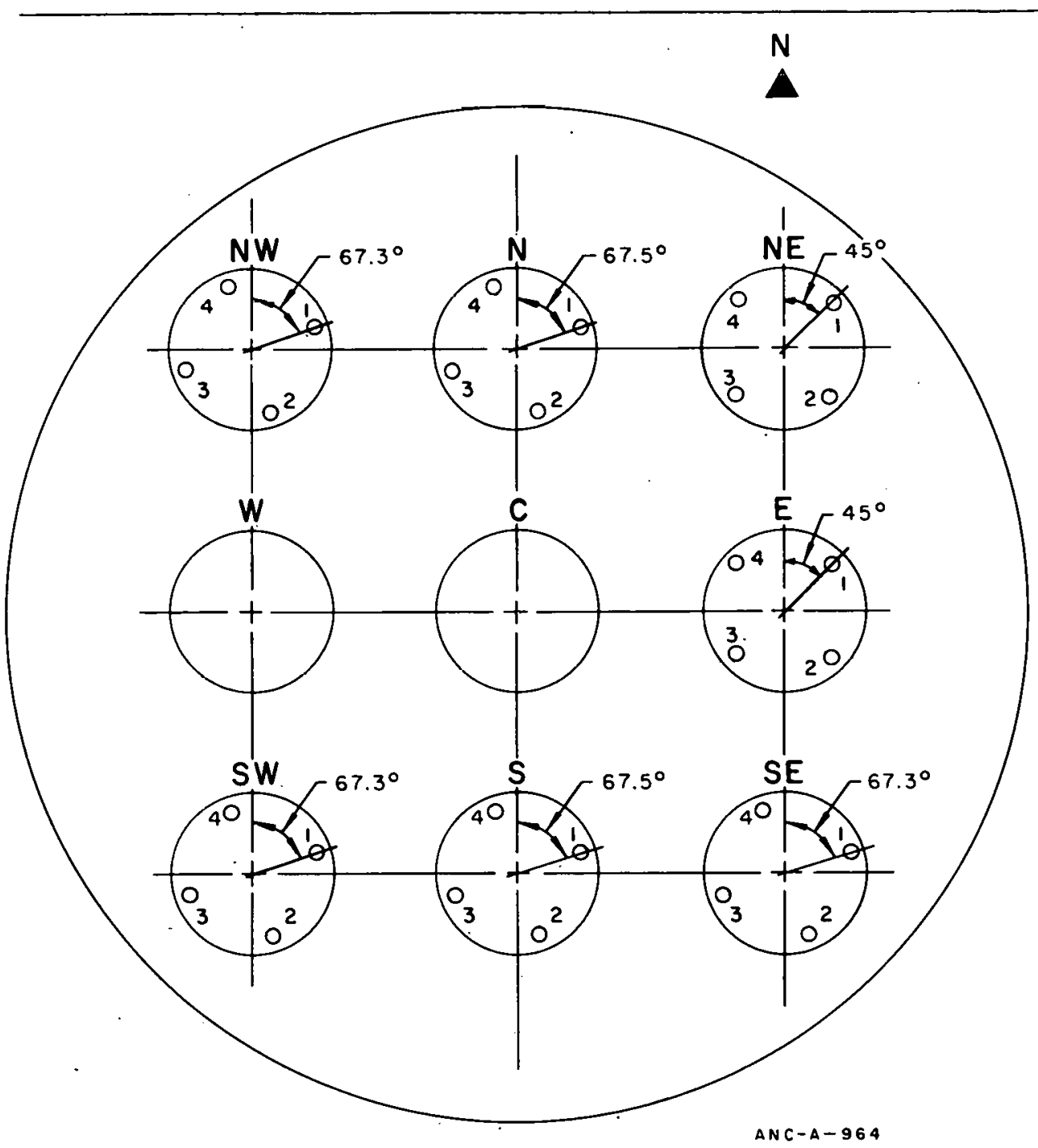

Fig. 31 ATR core diagram showing azimuthal location of monitors in the flux trap annuli. 
TABLE VIII

SUMMARY OF CONDITIONS DURING IRRADIATIONS

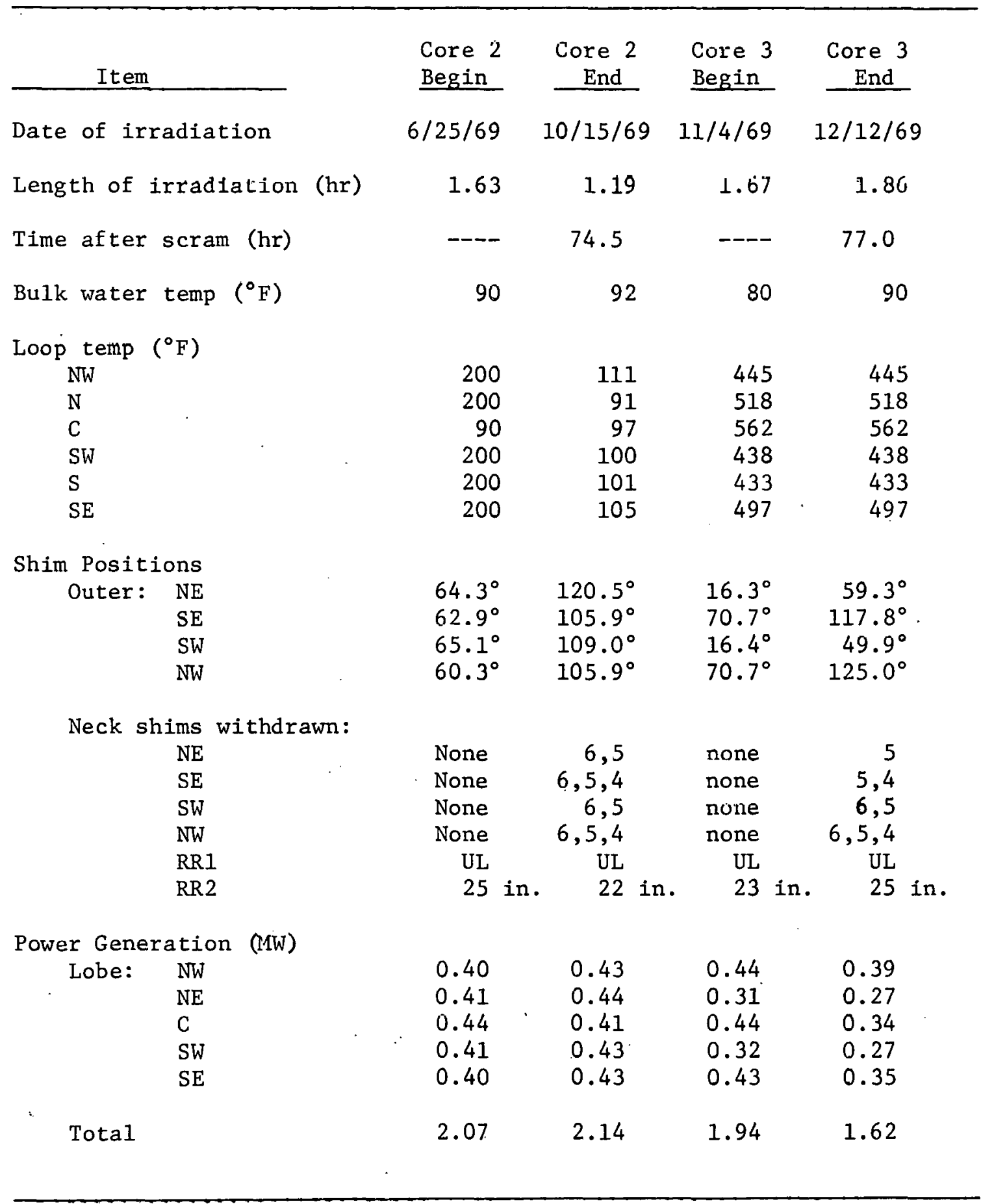


Nickel wires 0.020 inch in diameter were used to measure the fast neutron flux. Cobalt wires were used to measure thermal neutron flux (0.040-inch diameter in the first irradiation and 0.020 -inch diameter in the others). Resonance corrections based on cadmium ratio measurements were made to the cobalt activities. The corrections used are listed in Tables IV through VII. A brief description of the calculation of neutron flux from the activity of irradiated $\mathrm{Ni}$ and Co wires is contained in the Appendix.

The estimated relative error for one sigma in the data shown in Tables IV through VII is less than $1 \%$. The estimated error for one sigma in the power generation data in Table VIII is $6 \%$. This error is largely the result of the $5 \%$ error in data from the $16 \mathrm{~N}$ lobe power monitors used to adjust the power division during Cores 2 and 3 operation. Some loading errors were made in the safety rod positions due to the difficulty in identifying particular positions. These errors were interchanges of monitors and have been corrected in the. data.

\section{NEUTRON FLUENCE MEASUREMENTS}

Neutron fluence data obtained in Cores 2 and 3 provide neutron flux information at $250 \mathrm{MW}$ in the same positions where neutron fluxes were measured at the beginning and end of core life. The midplane values of thermal and fast $(>1 \mathrm{MeV})$ neutron flux obtained during Cores 2 and 3 operation are shown in Tables IX and X.

The data in Tables IX and $X$ were used to determine the power divisions for the beginning and end-of-life measurements described above. Although there is no data for direct comparison, the fluxes obtained in Cores 2 and 3 are reasonably consistent with earlier data obtained in ATR and ATRC. 
CORE MIDPLANE NEUTRON FLUX DATA AT $250 \mathrm{MW}$ OBTAINED FROM CORE 2 FLUENCE MEASUREMENTS

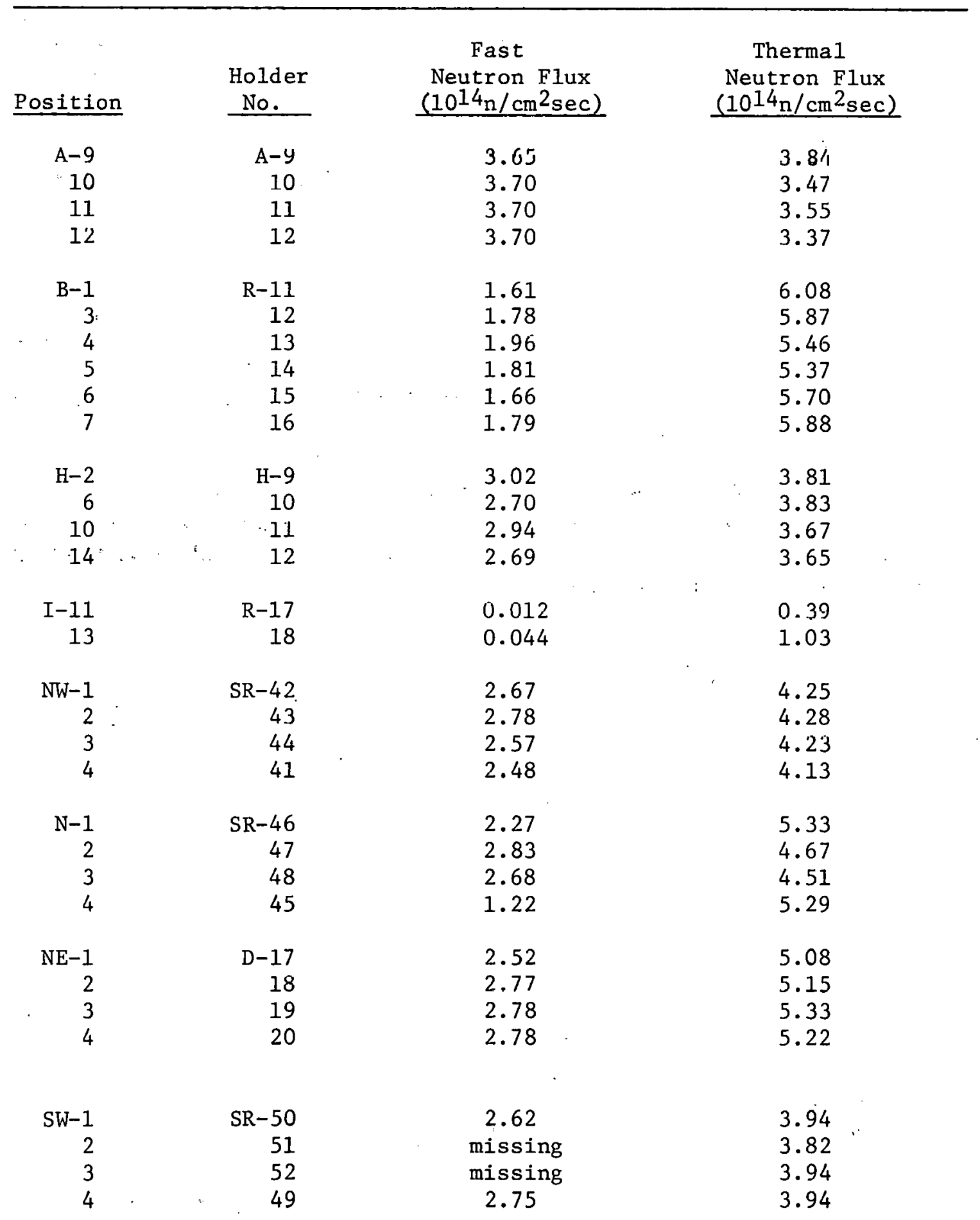


TABLE IX (Contd.)

\begin{tabular}{|c|c|c|c|c|}
\hline Position & $\begin{array}{l}\text { Holder } \\
\text { Nc. }\end{array}$ & $\begin{array}{c}\text { Fast. } \\
\text { Neutron Flux } \\
\left(1014 \mathrm{n} / \mathrm{cm}^{2} \mathrm{sec}\right)\end{array}$ & $\begin{array}{c}\text { Thermal } \\
\text { Neutron Flux } \\
\left(1014 \mathrm{n} / \mathrm{cm}^{2} \mathrm{sec}\right)\end{array}$ & \\
\hline$s-1$ & $S R-53$ & 2.71 & 4.69 & \\
\hline 2 & 54 & 1.38 & 4.17 & \\
\hline 3 & 55 & 2.09 & 4.84 & \\
\hline 4 & 56 & 2.93 & 4.40 & \\
\hline$S E-1$ & $S R-58$ & missing & 3.83 & \\
\hline 2 & 59 & 2.68 & 3.81 & \\
\hline 3 & 60 & 2.69 & 3.88 & \\
\hline 4 & 57 & 2.48 & 3.83 & \\
\hline$E-1$ & $D-21$ & 1.70 & 6.30 & \\
\hline 2 & 22 & 1.70 & 6.31 & \\
\hline 3 & 23 & 3.18 & 5.59 & \\
\hline 4 & 24 & 2.91 & 5.53 & \\
\hline
\end{tabular}


TABLE $X$

CORE MIDPLANE NEUTRON FLUX DATA AT $250 \mathrm{MW}$ OBTAINED FROM CORE 3 FLUENCE MEASUREMENTS

\begin{tabular}{|c|c|c|c|}
\hline Position & $\begin{array}{l}\text { Holder } \\
\text { No. } \\
\end{array}$ & 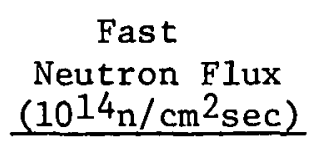 & $\begin{array}{c}\text { Thermal } \\
\text { Neutron Flux } \\
\left(10^{14} \mathrm{n} / \mathrm{cm}^{2} \mathrm{sec}\right)\end{array}$ \\
\hline $\begin{array}{r}A-9 \\
10 \\
11 \\
12\end{array}$ & $\begin{array}{r}A-21 \\
22 \\
23 \\
24\end{array}$ & $\begin{array}{l}3.67 \\
4.20 \\
3.70 \\
4.10\end{array}$ & $\begin{array}{l}3.23 \\
3.94 \\
3.18 \\
3.88\end{array}$ \\
\hline $\begin{array}{r}\text { B- } 1 \\
3 \\
4 \\
5 \\
6 \\
7\end{array}$ & $\begin{array}{r}R-39 \\
40 \\
41 \\
42 \\
43 \\
44\end{array}$ & $\begin{array}{l}1.70 \\
2.02 \\
2.10 \\
1.71 \\
1.75 \\
2.01\end{array}$ & $\begin{array}{l}5.03 \\
6.65 \\
6.39 \\
4.86 \\
5.09 \\
6.68\end{array}$ \\
\hline $\begin{array}{r}\mathrm{H}-2 \\
6 \\
10 \\
14\end{array}$ & $\begin{array}{r}\mathrm{H}-21 \\
22 \\
23 \\
24\end{array}$ & $\begin{array}{l}3.06 \\
2.97 \\
2.97 \\
3.00\end{array}$ & $\begin{array}{l}3.64 \\
3.77 \\
3.64 \\
3.80\end{array}$ \\
\hline $\begin{array}{r}I-11 \\
13\end{array}$ & $\begin{array}{r}R-45 \\
46\end{array}$ & $\begin{array}{l}0.011 \\
0.019\end{array}$ & $\begin{array}{l}0.41 \\
0.59\end{array}$ \\
\hline $\begin{array}{r}\text { NW-1 } \\
2 \\
3 \\
4\end{array}$ & $\begin{array}{r}\text { SR-102 } \\
103 \\
104 \\
101\end{array}$ & $\begin{array}{l}3.11 \\
3.11 \\
3.20 \\
3.02\end{array}$ & $\begin{array}{c}5.11 \\
5.05 \\
5.17 \\
\text { missing }\end{array}$ \\
\hline $\begin{array}{r}N-1 \\
2 \\
3 \\
4\end{array}$ & $\begin{array}{l}106 \\
107 \\
108 \\
105\end{array}$ & $\begin{array}{l}2.03 \\
3.14 \\
3.17 \\
1.48\end{array}$ & $\begin{array}{l}5.02 \\
5.04 \\
5.52 \\
5.94\end{array}$ \\
\hline $\begin{array}{r}\mathrm{NE}-1 \\
2 \\
3 \\
4\end{array}$ & $\begin{array}{r}D-41 \\
42 \\
43 \\
44\end{array}$ & $\begin{array}{l}2.13 \\
2.46 \\
2.57 \\
2.54\end{array}$ & $\begin{array}{l}3.98 \\
4.35 \\
4.64 \\
4.46\end{array}$ \\
\hline $\begin{array}{r}S W-1 \\
2 \\
3 \\
4\end{array}$ & $\begin{array}{r}S R-110 \\
111 \\
112 \\
109\end{array}$ & $\begin{array}{l}2.58 \\
2.22 \\
2.03 \\
2.56\end{array}$ & $\begin{array}{l}3.56 \\
3.35 \\
3.22 \\
3.50\end{array}$ \\
\hline
\end{tabular}


TABLE X (Contd.)

\begin{tabular}{|c|c|c|c|}
\hline Position & $\begin{array}{c}\text { Holder } \\
\text { No. }\end{array}$ & $\begin{array}{c}\text { Fast } \\
\text { Neutron Flux } \\
\left(10^{14} \mathrm{n} / \mathrm{cm}^{2} \mathrm{sec}\right) \\
\end{array}$ & $\begin{array}{c}\text { Thermal } \\
\text { Neutron Flux } \\
\left(10^{14} \mathrm{n} / \mathrm{cm}^{2} \mathrm{sec}\right)\end{array}$ \\
\hline $\begin{array}{r}S-1 \\
2\end{array}$ & $\begin{array}{r}\text { SR-114 } \\
115\end{array}$ & $\begin{array}{l}3.10 \\
1.48\end{array}$ & $\begin{array}{l}5.36 \\
5.70\end{array}$ \\
\hline $\begin{array}{l}3 \\
4\end{array}$ & $\begin{array}{l}116 \\
113\end{array}$ & $\begin{array}{l}1.97 \\
3.13\end{array}$ & $\begin{array}{l}4.61 \\
4.73\end{array}$ \\
\hline $\begin{array}{r}\mathrm{SE}-1 \\
2 \\
3 \\
4\end{array}$ & $\begin{array}{r}\text { SR-118 } \\
119 \\
120 \\
117\end{array}$ & $\begin{array}{l}2.96 \\
2.98 \\
3.16 \\
3.09\end{array}$ & $\begin{array}{l}4.95 \\
4.88 \\
4.78 \\
4.82\end{array}$ \\
\hline $\begin{array}{r}\mathrm{E}-1 \\
2 \\
3 \\
4\end{array}$ & $\begin{array}{r}D-45 \\
46 \\
47 \\
48\end{array}$ & $\begin{array}{l}1.62 \\
1.92 \\
3.53 \\
3.03\end{array}$ & $\begin{array}{l}6.30 \\
6.73 \\
5.78 \\
5.42\end{array}$ \\
\hline
\end{tabular}




\section{REFERENCES}

1. D. R. deBoisblanc and S. Cohen, Safety Analysis Report Advanced Test Reactor (Vol.1 and 2), IDO-17021 (April 1965).

2. E. E. Burdick and J. W. Henscheid, Advanced Test Reactor Critical Facility Safety Analysis Report, IDO-16950 (July 1964).

3. N. C. Kaufman et al, Reactor Physics Results from Low-Power Measurements in the Advanced Test Reactor, IN-1260 (February 1969).

4. J. W. Henscheid et al, ATR Startup, Zero-Power Experiments, and Comparison with ATR Critical Facility, IN-1136 (December 1967).

5. M. L. Griebenow et al, "ATR Graded Fuel 7F Designation", Nuclear Technology Branches Quarterly Report, April 1 - June 30, 1966, IDO-17202 (November 1966).

6. D. Randall and D. S. St. John, "Xenon Spatial Oscillations", Nucleonics, 16, 3 (March 1958) pp 82-86.

7. H. A. Bethe, Reactor Safety and Oscillator Tests, APDA-117 (October 1956).

8. AECL (Chalk River, Ontario) Progress Report Reactor Research Division October 1 to December 31, 1966, PR-RRD-48, pp 74-81.

9. Y. W. Lee, Statistical Theory of Communication, John Wiley and Sons, Inc. (1960).

10. C. E. Cohn, "A Simplified Theory of Pile Noise", Nucl. Sci. Eng., 7 (May 1960), p 472.

1. J. A. Thie, Reactor Noise, Rowman and Littlefield, Inc. (1963), p 210.

12. S. E. Stephenson, D. P. Roux, D. N. Fry, Neutron Fluctuation Spectra in the Oak Ridge Research Reactors, ORNL-TM-1401 (May 1966). 


\section{APPENDIX}

THERMAL AND FAST-NEUTRON FLUX MEASUREMENT 
THIS PAGE

WAS INTENTIONALLY

LEFT BLANK 


\section{APPENDIX \\ THERMAL AND FAST-NEUTRON FLUX MEASUREMENT}

\section{Definitions}

The thermal neutron flux[a] also called the $2200 \mathrm{~m} / \mathrm{sec}$ neutron flux, is defined as $2.2 \times 10^{5} \int 0.5 \mathrm{eV}_{\mathrm{n}}(\mathrm{E}) \mathrm{dE}$ where $\mathrm{n}$ is the neutron density and $0.5 \mathrm{eV}$ is taken as the cadmium "cut-off" energy. The fast-neutron flux is defined as $\int_{1 \mathrm{MeV}}^{\infty} \Phi(\mathrm{E}) \mathrm{dE}$ where $\Phi=\mathrm{nv}, \mathrm{v}$ is the neutron velocity, and it is assumed that the neutron spectrum above $1 \mathrm{MeV}$ neutron energy is the same as that for fission neutrons.

\section{Description of Method}

The method of measurement is a neutron-activation technique using the reactions ${ }^{59} \mathrm{Co}(\mathrm{n}, \lambda)^{60} \mathrm{Co}$ and ${ }^{58} \mathrm{Ni}(\mathrm{n}, \mathrm{p})^{58} \mathrm{Co}$ for measuring the thermal- and fast-neutronfluxes respectively. The basic equation for a single constant-power irradiation relating the neutron fluxes to the measured ${ }^{60} \mathrm{Co}$ and ${ }^{58} \mathrm{Co}$ activities is

$$
A=N_{0} \bar{\Phi} \bar{\sigma}\left(1-e^{-\lambda t} 1\right) e^{-\lambda t 2}
$$

where $\quad A=$ disintegration rate at the end of time period $t_{2}$,

$\mathrm{N}_{\mathrm{o}}=$ number of detector atoms,

$\bar{\Phi} .=$ neutron flux,

$\lambda=$ the decay constant of the reaction product,

$t_{1}=$ time duration of the irradiation,

$t_{2}=$ time interval from end of irradiation to count time, and

$\bar{\sigma}=$ appropriate activation cross section of the detector.

The cross section used for the $2200 \mathrm{~m} / \mathrm{sec}$ flux calculation is $37 \mathrm{~b}$ which is the neutron cross section of ${ }^{59} \mathrm{Co}$ at a neutron energy of $0.0250 \mathrm{eV}$, ie, the most probable velocity (2200 $\mathrm{m} / \mathrm{sec}$ ) of a Maxwellian neutron distribution at $20^{\circ} \mathrm{C}$. The calculation of the fast-neutron flux uses a cross-section of $95 \mathrm{mb} / .692=137 \mathrm{mb}$ for the $58 \mathrm{Ni}(\mathrm{n}, \mathrm{p})$ reaction where. $95 \mathrm{mb}$ is the average over a $235 \mathrm{U}$-fission neutron spectrum or

$$
\frac{\int_{0}^{\infty} \sigma(E) \Phi_{F}(E) d E}{\int_{0}^{\infty} \Phi_{F}(E) d E}
$$

[a] - The quantity nv would be called flux density in strict analogy with electrodynamics, but the shorter term flux has come to be generally used in reactor data. 
Recent evaluations of the differential cross sections for the ${ }^{58} \mathrm{Ni}(\mathrm{n}, \mathrm{p})$ reaction and the fission-neutron spectral measurements indicate that the integral cross section may be $105-110 \mathrm{mb}$ instead of $95 \mathrm{mb}$. However, present fast neutron flux data are processed using $95 \mathrm{mb}$ for thc ncutron cross section.

\section{Resonance-neutron Activation}

Since the ${ }^{60} \mathrm{Co}$ activities are generated by both thermal and resonance neutrons, the fraction due to resonance neutrons has to be determined; Cd-ratio measurements are used to obtain the needed data. The resonance contribution is subtracted from the total to obtain the contribution from the thermal neutrons. This correction is generally shown in the data as a percentage indicating a fractional multiplier (eg, a 25 percent resonance correction indicates that the flux obtained from Equation (1) has been multiplied by 0.75 ).

\section{Burnup of Nuclides}

A cobalt detector irradiated to a thermal-neutron fluence, $\Phi \mathrm{t}$, of about $5 \times 10^{20} \mathrm{n} / \mathrm{cm}^{2}$ (15 days at $4 \times 10^{14} \mathrm{n} / \mathrm{cm}^{2} / \mathrm{sec}$ as an example) will have experienced about a $2 \%$ burnup which requires a $1 \%$ correction (addition) to the thermal-neutron flux results.

Appropriate corrections have been made to the fast-neutron fluxes to account for the thermal-neutron burnup of the ${ }^{58} \mathrm{Co}$ isomers. Reference - IDO-16744 covers this subject in more detail. For example, the correction factor for $58 \mathrm{Co}$ burnup in a nickel detector irradiated in a thermal-neutron flux of $4.0 \times 10^{14} \mathrm{n} / \mathrm{cm}^{2} / \mathrm{sec}$ for 15 days is 1.97 where the $\mathrm{Ni}$ has no ${ }^{58} \mathrm{Co}$ content at the start of the irradiation.

\section{Multiple Irradiation Periods with Power Variation}

The operating history of the ATR shows that the reactor operated for periods of time at different power levels with periods of shutdown interspersed. The equation for calculating neutron flux with variation of reactor power and length of cycle neglecting the burnup of reaction nuclides is

$$
A=N_{0} \bar{\sigma}_{a} \bar{\Phi} \cdot \sum_{i=1}^{n} k_{i}\left[1-e^{-\lambda t_{i}}\right] \cdot e^{-\sum_{j=1}^{n} \lambda t_{j}}
$$

where

$$
\begin{aligned}
& n=\text { number of distinct power periods including zero power, } \\
& \bar{\Phi}=\text { neutron flux at a reference power } P \\
& \mathrm{P}_{1}, \mathrm{P}_{2}, \mathrm{P}_{3}, \ldots \mathrm{Pn}=\text { Power level during time intervals } \mathrm{t}_{1}, \mathrm{t}_{2}, \mathrm{t}_{3}, \ldots \mathrm{tn} \text {, and } \\
& \mathrm{K}_{1}, \mathrm{~K}_{2}, \mathrm{~K}_{3} \ldots \mathrm{Kn}=\frac{\mathrm{P}_{1}}{\mathrm{P}}, \frac{\mathrm{P}_{2}}{\mathrm{P}}, \frac{\mathrm{P}_{3}}{\mathrm{P}},-\frac{\mathrm{Pn}}{\mathrm{P}} .
\end{aligned}
$$




\section{Experimental and Calculation Procedures}

The detectors are irradiated as wires about 4 feet long placed in holders fabricated from 3/16 inch O.D. aluminum tubing. These holders may be inserted into more complicated spaces, depending upon the irradiation facility to be monitored. The nickel detector is 20 mil diameter wire fabricated from pure nickel. The cobalt detector is either $0.10 \%$ or $0.50 \%$ cobalt by weight in aluminum alloy drawn into 40 mil diameter wire.

The relative decay rates, $\mathrm{R}$, of ${ }^{60} \mathrm{Co}$ and ${ }^{58} \mathrm{Co}$ at intervals along the irradiated wires are measured using an automatic wire scanner. A 1/8-inch section is cut from each wire at the point having the highest activity, the absolute disintegration rate in the section is determined by gamma-ray counting on either a high-pressure ionization chamber or a pulse-height analyzer, the appropriate neutron flux is calculated for that irradiation position using Equation (1) or (3), and the flux factor, $\Phi / R$, is evaluated for each wire. Then, the product of any $R$ value measured on a given wire and the flux factor for that wire is the neutron flux at the corresponding irradiation position. 
